\title{
An Examination of Collegiate Athletes', Undergraduate Sport Science Majors', and Athlete Majors' Intent to Pursue Collegiate Coaching as a Career
}

Lauren Deckelbaum

Follow this and additional works at: https://researchrepository.wvu.edu/etd

\author{
Recommended Citation \\ Deckelbaum, Lauren, "An Examination of Collegiate Athletes', Undergraduate Sport Science Majors', and \\ Athlete Majors' Intent to Pursue Collegiate Coaching as a Career" (2016). Graduate Theses, Dissertations, \\ and Problem Reports. 5459. \\ https://researchrepository.wvu.edu/etd/5459
}

This Dissertation is protected by copyright and/or related rights. It has been brought to you by the The Research Repository @ WVU with permission from the rights-holder(s). You are free to use this Dissertation in any way that is permitted by the copyright and related rights legislation that applies to your use. For other uses you must obtain permission from the rights-holder(s) directly, unless additional rights are indicated by a Creative Commons license in the record and/ or on the work itself. This Dissertation has been accepted for inclusion in WVU Graduate Theses, Dissertations, and Problem Reports collection by an authorized administrator of The Research Repository @ WVU.

For more information, please contact researchrepository@mail.wvu.edu. 
An Examination of Collegiate Athletes', Undergraduate Sport Science Majors', and Athlete Majors' Intent to Pursue Collegiate Coaching as a Career

\title{
Lauren Deckelbaum
}

Dissertation submitted

to the College of Physical Activity and Sport Sciences

at West Virginia University

in partial fulfillment of the requirements for the degree of

Doctorate of Education in

Coaching and Teaching Studies with a Concentration in Women's Studies and Sport

Kristen Dieffenbach, Ph.D., Chair

Valerie Wayda, Ph.D.

Jennifer Orlikoff, Ph.D.

M. Ryan Flett, Ph.D.

Ann Oberhauser, Ph.D.

Department of Coaching and Teaching Studies

\author{
Morgantown, West Virginia \\ 2016
}

Keywords: social cognitive career theory, collegiate coaching, coaching intentions, collegiate athletes, sport science majors, and athlete majors

Copyright 2016 Lauren Deckelbaum 


\begin{abstract}
An Examination of Collegiate Athletes', Undergraduate Sport Science Majors', and Athlete Majors' Intent to Pursue Collegiate Coaching as a Career
\end{abstract} Lauren Deckelbaum, M.S.

Social cognitive career theory (SCCT) has been used to examine how various predictive variables impact an individual's career choice (Lent, Brow, \& Hackett, 1994). SCCT has been applied within coaching education research to examine collegiate athletes interest and intent in collegiate coaching as a profession (Cunningham \& Singer, 2010; Moran-Miller \& Flores, 2011). This study expanded upon this research by examining non-revenue producing varsity collegiate athletes' (CA), sport science majors that are non-varsity collegiate athletes' (SSM), and varsity collegiate athletes in sport science majors' (AM) intent to pursue full-time collegiate coaching as a career. The results of the study found that AMs' reported a statistically significantly higher level of intent and desire to coach at all four collegiate levels compared to SSMs' and CAs'; with CAs' reporting the lowest level of intent and desire to coach at all four collegiate levels. SSMs' level of collegiate coaching self-efficacy and perceived supports had a statistically significant effect on SSMs level of intent to pursue collegiate coaching as a full-time career. CAs' level of perceived supports also had a statistically significant effect on CAs' level of intent to pursue collegiate coaching as a full-time career. Coaching education programs and sport organizations can use the information from this study to create resources (i.e., network building, internships, mentorship, and coaching education) and structure coaching education curriculums to incorporate methods to increase an individual's level of coaching self-efficacy and supports. Thus, individuals could increase their level of intent to pursue full-time collegiate coaching as a career and help reduce attrition rates of collegiate coaches. 


\section{Dedications}

The journey of completing my dissertation has been one of the most grueling and trying endeavors thus far in my life. Completing this massive project would not have been possible without compassion and understanding of the various support systems in my life. I would first like to thank my parents Michael and Ginny Deckelbaum for their support and encouragement over the numerous years. Always having your love and support has meant the world to me and I will forever be thankful for you always believing in me. I would also like to thank my partner Jaclyn Mazza for consistently being my rock through this process. With your support, I pushed through even when I didn't want to or think I could. Additionally, I would like to thank my friends and family for being patient and understanding during this time; as I was not able to spend as much time with you as I wanted. I especially wanted to say thank-you to Dr. Lisa Simpson and Dr. Lindsay Hammond for always being there for me and providing me with advice along the way. Finally, I would like to thank my fur kids Zoe, Wizard, and Owen for always listening and loving me no matter my state of mind. Though my time at West Virginia University has come to end, I will take what I have learned and continue to grow as an educator. Thank-you to all who have supported and helped me through this process. 


\section{Acknowledgements}

I want to take this time to acknowledge some important individuals who have helped contribute to the execution and completion of my dissertation. I would first like to acknowledge and thank my chair, Dr. Kristen Dieffenbach. You have been with me throughout my Master's, doctoral coursework, and now my dissertation. I know this has been a long and difficult road, but thank you for sticking with me and helping me get through this journey. To Dr. Valerie Wayda, thank you for taking the time out of your already super hectic schedule to be on my committee and providing vital feedback on my dissertation. To Dr. Anne Oberhauser, thank you for your willingness to stay on my committee even after relocating to Iowa State University. I appreciate the time and feedback you have given towards my dissertation. Dr. Jennifer Orlikoff, thank you taking part in my dissertation and serving as my supervisor and mentor in Women's and Gender Studies. Dr. Ryan Flett, thank you for providing essential feedback regarding my survey construction and data analysis. Again, thank you to all my committee members for your time and feedback; this project would not have been possible without your advice and feedback. Finally, I would like to thank all the instructors, coaches, athletes, and students who took the time to take part in my study. Without all of you, completing my dissertation would not have been possible. 
Preliminary Materials.

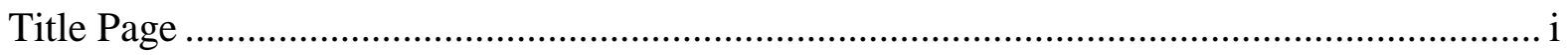

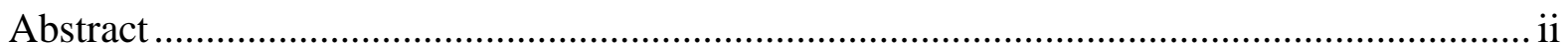

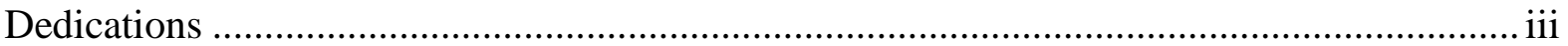

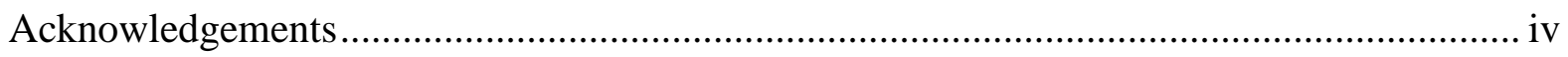

Lists of Tables ........................................................................................................ vii

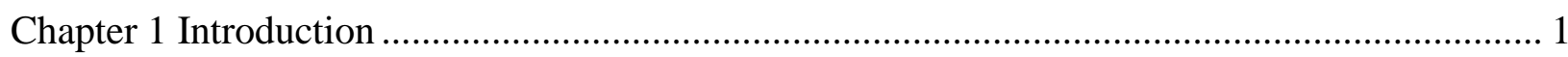

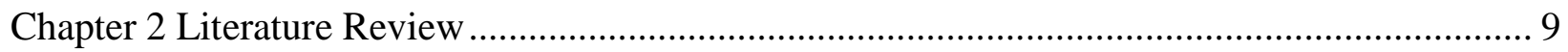

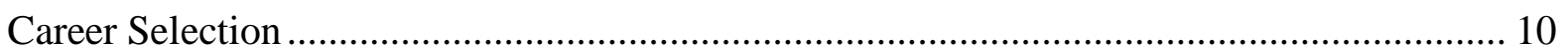

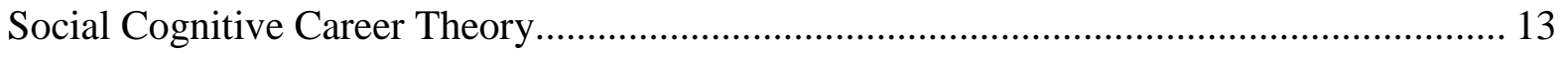

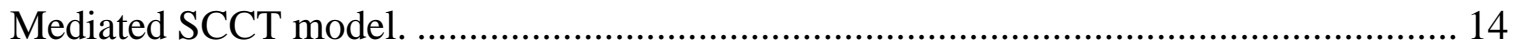

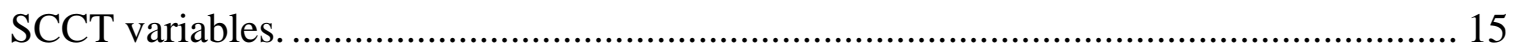

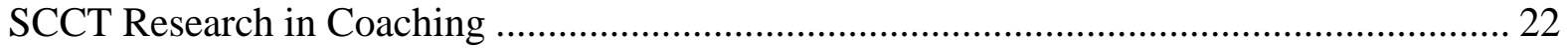

SCCT Variables within the Coaching Literature .......................................................... 24

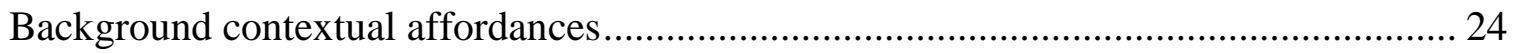

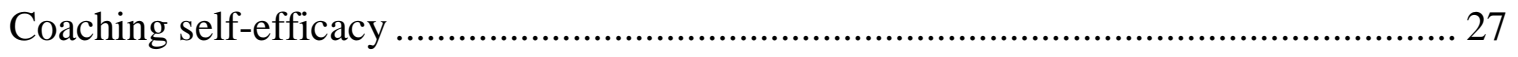

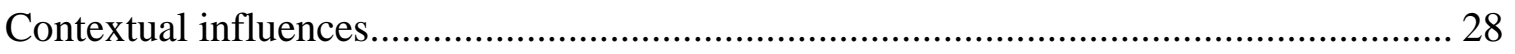

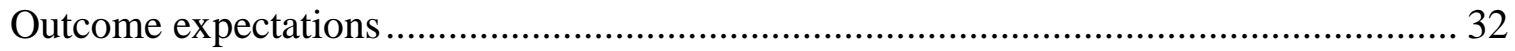

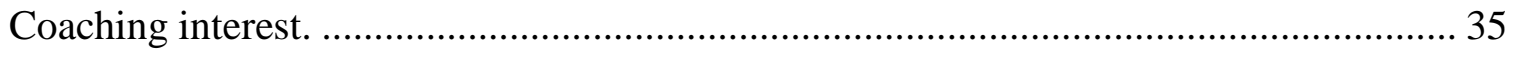

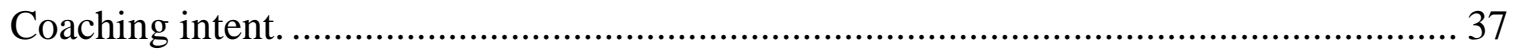

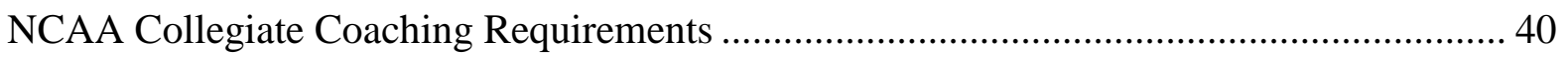

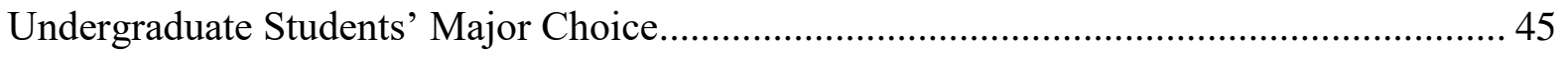

Non-collegiate athletes' major choice. ….......................................................... 46 


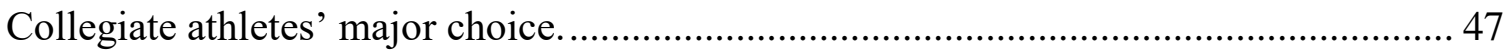

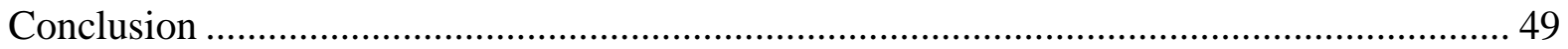

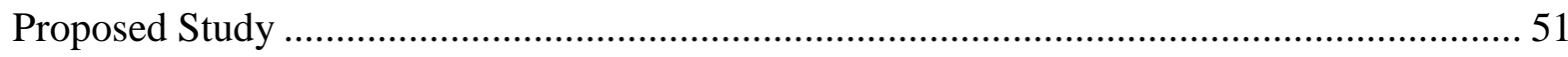

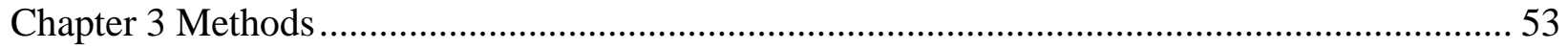

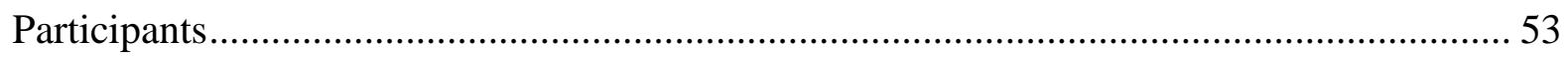

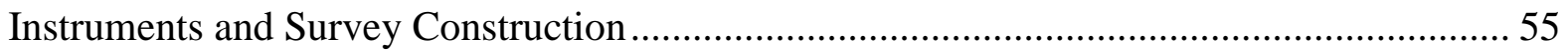

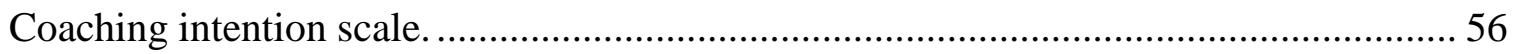

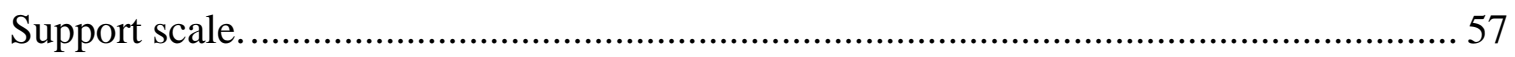

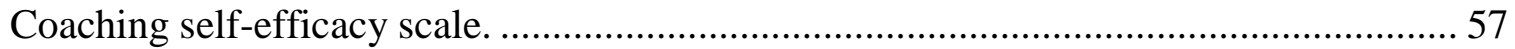

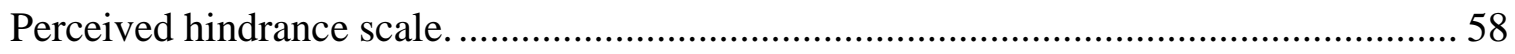

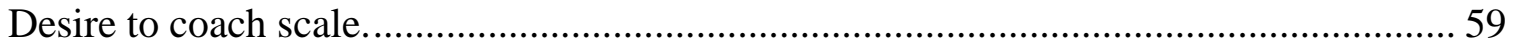

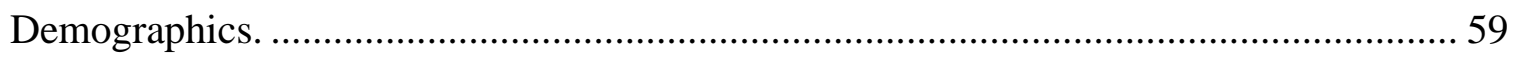

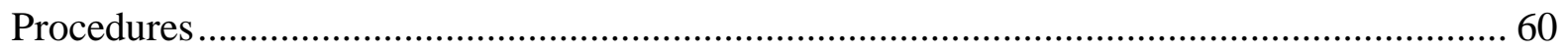

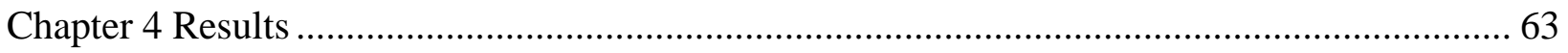

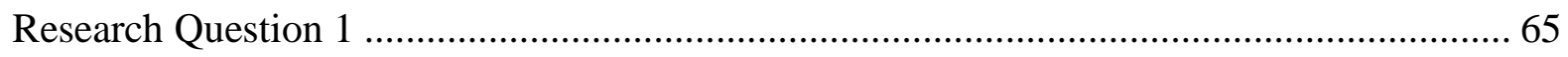

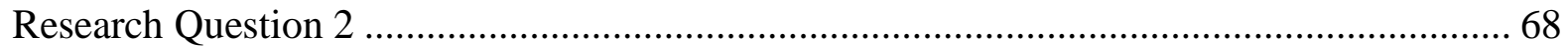

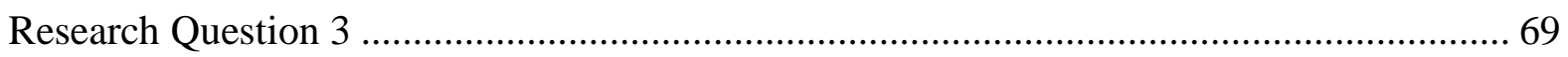

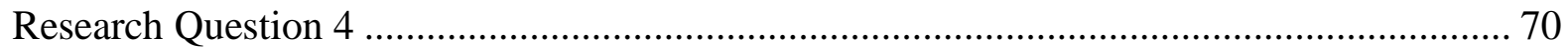

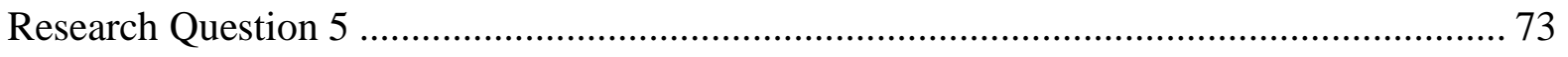

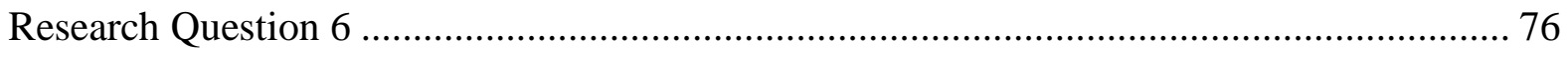

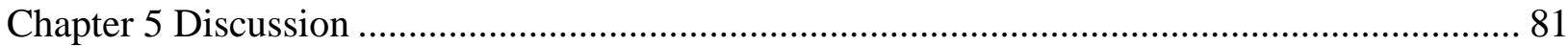

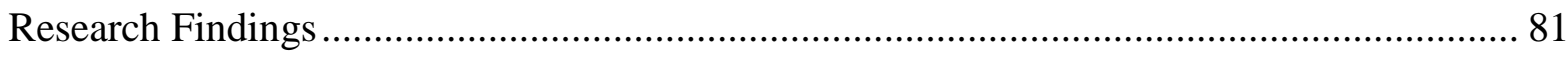

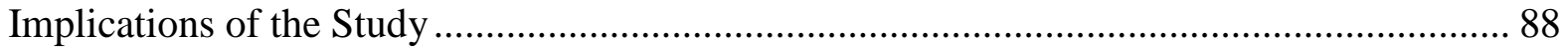




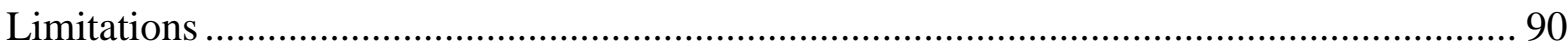

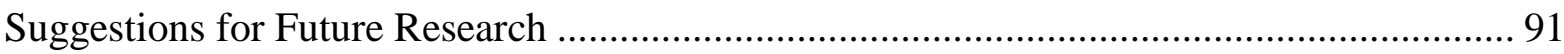

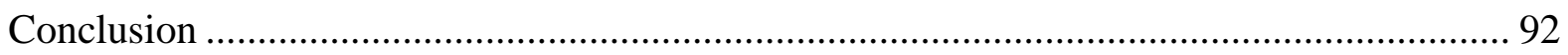

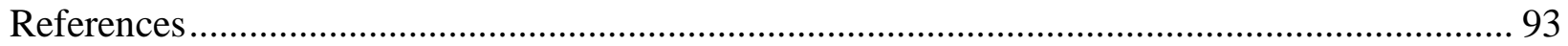

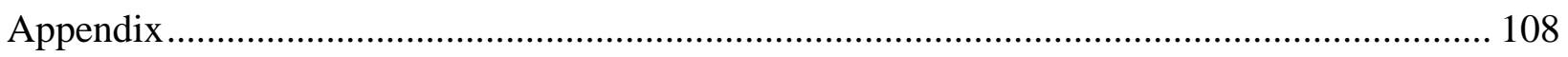

Figure 1. Social Cognitive Career Theory Mediated Model............................................... 108

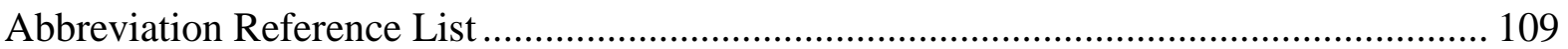

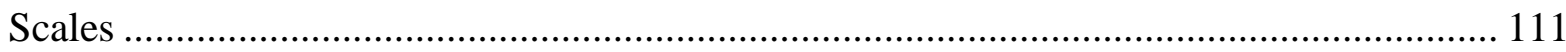

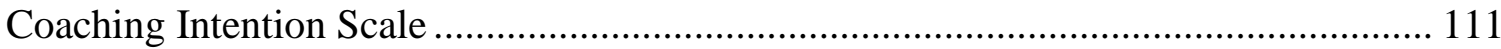

Coaching Support Scale ....................................................................................... 112

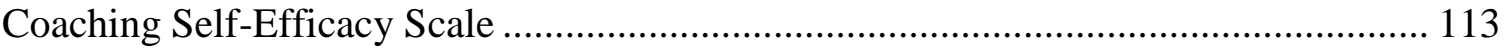

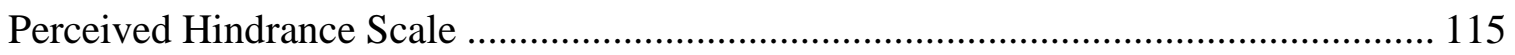

Desire to Coach Scale ………………………………............................................... 117

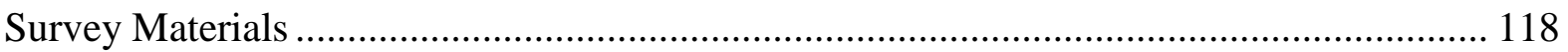

Demographic Questions....................................................................................... 118

Department Chair Cover Letter .................................................................................. 119

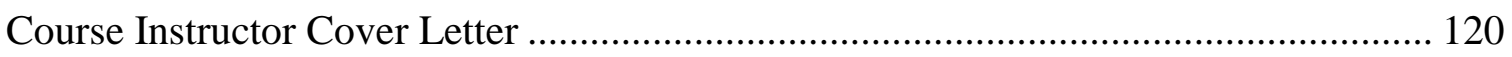

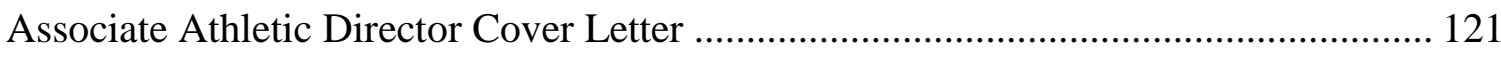

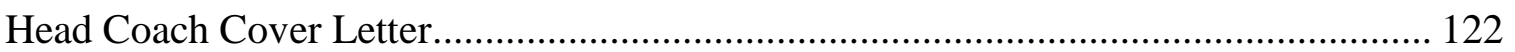

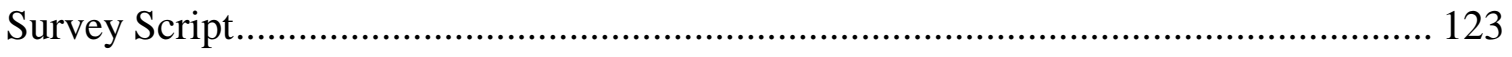

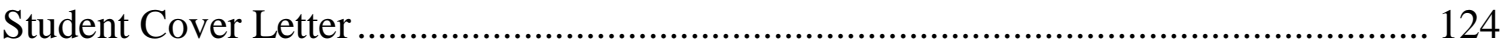

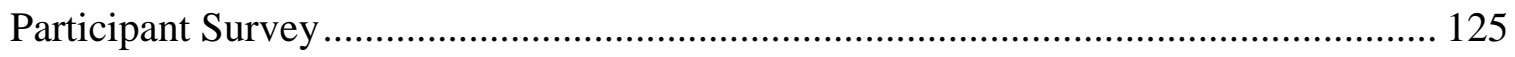

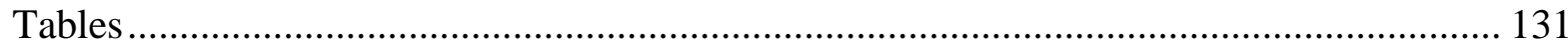




\section{Lists of Tables}

Table 1 Demographic Information for SSM, CA, and AM Groups ...................................... 131

Table 2 Sport Science Majors Breakdown for SSM and AM Groups ................................... 132

Table 3 Varsity Sports Participation Representation for CA and AM Groups ........................ 133

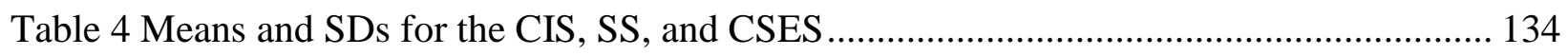

Table 5 Means and SDs for the each sub-scale of the PHS ............................................. 135

Table 6 Means and SDs for each collegiate level on the DCS ......................................... 136

Table 7 Kruskal-Wallis Non-Parametric Results for the CIS and CSES.............................. 137

Table 8 Kruskal-Wallis Non-Parametric Results for the DCS ............................................ 138

Table 9 One-Way Analysis of Variance Results for the SS ............................................ 139

Table 10 One-Way Analysis of Variance Results for the PHS .......................................... 140

Table 11 One-Way Analysis of Variance Results for Class Rank for PHS 1 \& 2 ................. 141

Table 12 Means, SDs, and Intercorrelations for SSMs' Intent and Predictive Variables.......... 142

Table 13 Means, SDs, and Intercorrelations for CAs' Intent and Predictive Variables ............ 143

Table 14 Means, SDs, and Intercorrelations for AMs' Intent and Predictive Variables ........... 144

Table 15 Regression Results for SSMs' Intent and Predictive Variables............................... 145

Table 16 Regression Results for CAs' Intent and Predictive Variables ................................. 146

Table 17 Regression Results for AMs' Intent and Predictive Variables ............................... 147

Table 18 Content Analysis for Intent to become a Collegiate Coach................................... 148

Table 19 Content Analysis for no Intent to become a Collegiate Coach................................ 149

Table 20 Content Analysis for Major Choice .............................................................. 150 


\section{Chapter 1}

\section{Introduction}

One of the most important choices an individual will make is which career they will choose to pursue. Within the field of NCAA collegiate coaching, research has mainly focused on examining collegiate athletes (CAs) interest and intent to become a collegiate coach (e.g., Bernhard, 2010; Cunningham \& Singer, 2010; Kamphoff \& Gill, 2008; Moran-Miller \& Flores, 2011). However, there is no research that suggests CAs are more likely pursue full-time NCAA collegiate coaching as a career compared to college students who are not athletes. This study seeked to explore the differences among CAs from non-revenue producing sports, individuals pursuing a sport science majors (SSM), and individuals who are a CA and pursuing a SSM (athlete major/AM) intent to pursue full-time NCAA collegiate coaching as a career.

Most research on individuals' career choice has focused on high school and college-aged students; as career selection typically takes place during late adolescents and early adulthood (e.g., Cunningham, Bruening, Sartore, Sagas, \& Fink, 2005; Daniels, Stewart, Stupnisky, Perry, \& LoVerso, 2011; Mensch \& Mitchell, 2008). The term career refers to an individuals’ continuous pursuit in an occupation (Sears, 1982). Career research has suggested that there are numerous factors that can influence an undergraduate college students' career choice (e.g., Cunningham et al., 2005; Daniels et al., 2011; Mensch \& Mitchell, 2008). Researchers have examined how demographic variables such as gender, ethnicity, socioeconomic status, class rank, and age can influence an individual's career choice (e.g., Chen \& Hu, 1997; Chung, 2002; Hutchinson \& Buschner, 1996). In addition, researchers have also examined predictive variables such as exposure to the career field, perceptions of the profession, role model influence, supports for entering the profession, barriers within the profession, interest, intent, and self-efficacy 
related to the profession (e.g., Cunningham et al., 2005; Daniels et al., 2011; Lent et al., 2002; Mensch \& Mitchell, 2008).

In order to understand better how and why an individual would choose a certain career, researchers have developed numerous career theories. Some prominent career theories include trait and factor theory of occupational choice (Parson, 1909), theory of planned happenstance (Krumboltz, Mitchell, \& Jones, 1976), Holland's theory (Holland, 1997), Super's theory (Super, 1980), and social cognitive career theory (Lent, Brown, \& Hackett, 1994). Social cognitive career theory (SCCT) was selected as the foundation for this study because SCCT examines how "people (a) develop basic academic and career interests, (b) make and revise their educational and vocational plans, and (c) achieve performances of varying quality in their chosen academic and career pursuits" (Lent et al., 2003, p. 458). Within SCCT there are 10 variables that contribute to an individual's pursuit towards a career; those variables are: (a) personal inputs, (b) background contextual affordances, (c) learning experiences, (d) self-efficacy, (e) outcome expectations, (f) proximal contextual influences, (g) interests, (h) intent, (i) choice actions, and (j) performance domains and attainments (Lent, Brown, \& Hackett, 1994).

SCCT has mainly been used to examine undergraduate students' level of interest and intent to pursue a career in science, technology, engineering, and math fields (e.g., Lent et al., 2001 \& 2003; Lent, Lopez, Shue, \& Lopez, 2011). The application of SCCT within U.S. collegiate coaching field is limited and has only examined CAs (Cunningham \& Singer, 2010; Moran-Miller \& Flores, 2011). However, there is ample amount of coaching research on the variables that comprise SCCT (e.g., Bernhard, 2010; Everhart \& Chelladurai, 2004; Kamphoff, 2010; Kamphoff \& Gill, 2008; LaVoi \& Dutove, 2012). 
The coaching research on the variables that comprise SCCT has focused primarily on the experiences of collegiate coaches and CAs perceptions of the coaching as a profession (e.g., Kamphoff \& Gill, 2008; LaVoi \& Dutove, 2012; Moran-Miller \& Flores, 2011). Gender and ethnicity are the two major demographic variables that have been examined within the U.S. coaching literature when comparing the differences in experiences and perceptions of collegiate coaching as a profession (e.g., Bernhard, 2010; Cunningham, Sagas, \& Ashley, 2003; Kamphoff, Armentrout, \& Driska, 2010). Within SCCT, demographic variables such as gender, ethnicity, sexual orientation, and disability are examined as personal inputs. For this particular study, being a CA, SSM, or AM will be examined`as a personal input.

According to SCCT, an individual's personal inputs and background contextual affordances (role model exposure, task opportunities, supports, and cultural and gender role socialization), impact an individual's learning experiences (Lent et al., 1994). In the context of this study, learning experiences refer to the relations that an individual has related to coaching. SCCT suggest that an individual's learning experiences (coaching, playing, and academic experience) will vary due to their personal inputs (CA, SSM, or AM) and background contextual affordances (Lent et al., 1994).

Research suggests that role model influence (background contextual affordance) plays a factor in an individual's level of self-efficacy (vicarious experience) and intent to pursue a career (Lent et al., 1994; Lent, Brown, \& Hackett, 2000; Paa \& McWhirter, 2000). Not only does career role model exposure play a part in an individual's learning experience with coaching, but so does task opportunity (background contextual affordance). In addition, coaching research has suggested that years of coaching experience (e.g., Feltz, Chase, Moritz, \& Sullivan, 1999; Feltz, Helper, Roman, \& Paiement, 2009; Helper, Feltz, Roman, \& Paiement, 2007; Kavussanu, 
Boardley, Jutkiewicz, Vincent, \& Ring, 2008), extensive playing experience (Feltz et al., 1999; Helper et al., 2007), social supports (Feltz et al., 1999), role models (Moran-Miller \& Flores, 2011), and the number of coaching hours an individual predicts they will have to work (Everhart \& Chelladuria, 1998; Moran-Miller \& Flores, 2011) can influence an individual's level of coaching self-efficacy.

Coaching self-efficacy has been defined as "the extent to which coaches believe they have the capacity to affect the learning and performance of their athletes" (Feltz et al., 1999, p. 153). Research has suggested that coaching self-efficacy is predictive of both male and female assistant coaches to become head coaches (Cunningham et al., 2003) and an individual's level of intent to coach at various competitive levels (Everhart \& Chelladurai, 1998). Coaching selfefficacy has been examined to help predict an individual's level of interest, intent, and desire to enter or leave the coaching profession (Cunningham et al., 2003; Kent \& Sullivan, 2003; MoranMiller \& Flores, 2011).

SCCT suggests that an individual's level of self-efficacy is influenced by their personal inputs, background contextual affordances, learning experiences, and also proximal contextual influences (Lent et al., 1994, 2000, \& 2003). Proximal contextual influences are the immediate supports and barriers an individual may experience when deciding to pursue a career (Lent et al., $1994 \& 2000)$. Some examples of proximal contextual influences within NCAA collegiate coaching are discriminatory hiring practices, lack of networking contacts, and limited learning experiences (e.g., Cunningham \& Singer, 2010; Kampoff, 2010; LaVoi \& Dutove, 2012; Walker \& Bopp, 2011).

Coaching research has suggested that an individual's personal inputs can impact the type of barriers an individual can perceive or experience (e.g., Kamphoff et al., 2010; LaVoi \& 
Dutove, 2012; Walker \& Bopp, 2011). For example, female and ethnic minority collegiate coaches have reported experiencing a lack of networking contacts and discriminatory hiring practices as barriers to entering collegiate coaching (Cunningham, Bruening, \& Straub, 2006; Kane \& Stangl, 1991; Lovett \& Lowery, 1994; Walker \& Bopp, 2011). Collegiate female coaches have also reported that sexism (Abney \& Richey, 1991; Bracken, 2009; Kamphoff et al., 2010; LaVoi \& Dutove, 2012), homophobia (Kamphoff, 2010; LaVoi \& Dutove, 2012), and work and family conflict (Bracken, 2009; Bruening \& Dixon, 2008; Dixon \& Bruening, 2007; LaVoi \& Dutove, 2012; Kamphoff, 2010) are barriers that collegiate female coaches encounter. Both female and minority collegiate coaches have reported that lack of pay presents itself as a barrier (Abney \& Richey, 1991; Cooper, Hunt, \& Camille, 2007; LaVoi \& Dutove, 2012).

An individual could face numerous barriers when trying to enter collegiate coaching. However, having a solid support system and resources could help an individual manage or overcome barriers (e.g., Blom et al., 2011; Cunningham \& Singer, 2010; LaVoi \& Dutove, 2012; Kamphoff et al., 2010). Collegiate coaches have reported that having support from friends, family, peers, other coaches, media, administration, or significant other can help with managing the barriers (Blom et al, 2011; Bruening \& Dixon, 2008; LaVoi \& Dutove, 2012; Weiss, Barber, Sisley, \& Ebbeck, 1991). In addition to having a support system, resources such as coaching experience, training, education, contacts, and networks are needed to obtain a coaching position (Cunningham \& Singer, 2010). Conversely, if a coach does not perceive to have enough supports to enter collegiate coaching, then the barriers can be harder to manage and may lead to a coach leaving the profession early (Abney \& Richey, 1991; Blom et al., 2011; Cunningham \& Singer, 2010; LaVoi \& Dutove, 2012; Kamphoff et al., 2010). Identifying and recruiting individuals who intend to become a collegiate coach into coaching education programs, is one 
way to help increase an individual's level of perceived supports for entry into collegiate coaching.

The criteria for becoming a NCAA collegiate coach could impact an individual's perceptions of one's supports and barriers when entering collegiate coaching and influence one's intent to pursue NCAA collegiate coaching as a full-time career. In order to be hired as a collegiate coach in the U.S., the job requirements are dependent upon what each institution sets as the criteria (Siegl \& Newhof, 1992; T. Howes, personal communication, September 7, 2014). Most NCAA institutions require a bachelor's degree, and many prefer a master's degree; however, it does not matter in which field the degree is attained (NCAA "The Market", n.d; Siegel \& Newhof, 1992). In addition, few institutions require their head coach to have a coaching certificate (Siegl \& Newhof, 1992); and collegiate coaching listings did not list having a coaching degree or coaching certificate as a requirement or preference (NCAA "The Market", n.d). On the other hand, most institutions and collegiate coaching job listings do require collegiate coaching experience and or collegiate playing experience (NCAA "The Market”, n.d; Siegel \& Newhof, 1992).

Coaching research has mainly focused on CAs when examining individuals' intent to pursue NCAA coaching as a full-time career (Everhart \& Chelladurai, 1998; Kamphoff \& Gill, 2008; Sagas, Cunninghma, \& Pastore, 2006). The research suggests that male CAs reported a higher level of desire to become a full-time coach at the high school level, at Division I or professional level compared to female CAs (Everhart \& Chelladurai, 1998; Kamphoff \& Gill, 2008). Research has also suggested that female CAs reported a higher level of desire to coach full-time at the youth sport/community/recreational level compared to male CAs (Kamphoff \& 
Gill, 2008). In addition, it has been suggested that female collegiate coaches reported having a lower level of intent on becoming a head coach compared to males (Sagas et al., 2006a).

SCCT research on individual's intent to pursue NCAA collegiate coaching as a career has focused solely on CAs (Cunningham \& Singer, 2010; Moran-Miller \& Flores, 2011). However, there is no research to suggest that CAs are more likely to pursue collegiate coaching as a career compared to SSMs or AMs. In order to fill this gap within the literature, this study will seek to explore the differences between CAs', SSMs', and AMs' level of perceived supports for entering collegiate coaching, perceived barriers to entry into collegiate coaching, perceived collegiate coaching self-efficacy, intent to pursue full-time collegiate coaching as a career, and their desire to coach at various collegiate coaching levels.

By examining personal inputs other than gender and ethnicity and factoring in background contextual affordances such as coaching and playing experience, researchers can better understand the impact personal inputs and background contextual affordances can have on an individual's intent to pursue NCAA collegiate coaching as a full-time career. Examining these three sample groups will hopefully shed light on researchers' assumption that CAs are more likely to become collegiate coaches than other sample populations. In addition, if there is a significant number of CAs or AMs who want to become collegiate coaches, but are not pursuing coaching education as a major, steps can be taken to recruit these individuals to coaching education programs for formal training.

Based on the U.S. coaching research that has used SCCT and the coaching research on the variables that comprise SCCT, this study explored the following research questions: (1) were there differences among the three groups' level of intent in pursuing a career as a full-time collegiate coach, (2) were there differences among the three groups' level of perceived supports 
for entering collegiate coaching, (3) were there differences among the three groups' level of collegiate coaching self-efficacy, (4) were there differences among the three groups' level of perceived barriers to entering collegiate coaching, (5) were there differences among the three groups' desire to coach full-time at 2-year colleges, Division III, Division II, and Division I, and (6) of the evaluated independent variables (collegiate coaching self-efficacy, supports, and barriers), which predicted CAs', SSMs', and AMs' level of intent to pursue full-time collegiate coaching as a career. 


\section{Chapter 2}

\section{Literature Review}

Research surrounding an individual's intent to pursue collegiate coaching as a career has focused mainly on collegiate athletes (CA) and the effects of demographic variables such as gender and ethnicity when choosing coaching as a profession (e.g., Bernhard, 2010;

Cunningham, 2003; Cunningham \& Singer, 2010; Everhart \& Chelladurai, 1998; Kamphoff \& Gill, 2008; Moran-Miller \& Flores, 2011). However, there is no research that suggests CAs are more likely to pursue collegiate coaching as a career than other sample populations. There are two older coaching studies that examined individuals coaching intentions other than CAs (Pease \& Drabelle, 1988; Sage, 1989). In addition, the career path to becoming a collegiate coach is not clearly defined, since most institutions do not require a degree or certificiation in coaching nor does the degree need to be in a sport related field (NCAA "The Market", n.d.; Siegel \& Newhof, 1992).

In order to better understand what influences an individual's intent to choose NCAA collegiate coaching as a full-time career, social cognitive career theory (SCCT) was used as the guiding framework. The application of SCCT within the U.S. coaching profession is still at the beginning stages and is limited to three studies (Cunningham, Doherty, \& Greg, 2007; Cunningham \& Singer, 2010; Moran-Miller \& Flores, 2011). However, there is substantial coaching research on the variables that comprise SCCT (e.g., Cunningham \& Singer, 2010; Kamphoff, 2010; LaVoi \& Dutove, 2012; Moran-Miller \& Flores, 2011).

The research surrounding college students' career selection is discussed mainly within the broad context of career theories. In addition, a detailed explanation of SCCT and the research that that has examined SCCT and its variables within NCAA collegiate coaching is discussed. The literature review is organized into the following eight sections: (a) career 
selection, (b) SCCT, (c) SCCT research within coaching, (d) SCCT variables within collegiate coaching research, (e) NCAA collegiate coaching requirements, (f) undergraduate students' major choice, (g) conclusion, and (h) an overview of the proposed study.

\section{Career Selection}

One of the most important choices an individual will make is which career they will choose to pursue. The term career refers to an individuals' continuous pursuit in an occupation (Sears, 1982). A career is defined as the steps in which an individual has taken to progress forward within the same field. A step that often occurs when pursuing a career is selecting and completing an academic degree that aligns with the individual's selected career field. The majority of research on individual's career choice has focused mainly on high school and college-aged students as career selection typically takes place during this age range (e.g., Cunningham, Bruening, Sartore, Sagas, \& Fink, 2005; Daniels, Stewart, Stupnisky, Perry, \& LoVerso, 2011; Mensch \& Mitchell, 2008).

Choosing a career can be a difficult decision and research has suggested that there are numerous factors that can influence an undergraduate college student's career choice (e.g., Chung, 2002; Cunningham et al., 2005; Daniels et al., 2011; Mensch \& Mitchell, 2008). Some of the demographic factors that researchers have examined are age, number of years at a university, gender, and ethnicity (e.g., Chen \& Hu, 1997; Chung, 2002; Hutchinson \& Buschner, 1996). Demographic information has been examined to understand better how these variables impact an individual's career choice and to compare the differences between two or more groups. Overall, gender and ethnicity are most frequently studied demographic variables. Research has suggested that the perceived supports and barriers when entering a career field can 
vary due to an individual's gender and ethnicity (e.g., Cunningham \& Singer, 2010; Cooper, Hunt, \& O’Bryant, 2007; Moran-Miller \& Flores, 2011).

Researchers have studied various predictive variables impact on an individual's career choice. Some examples of predictive variables that have been examined are: perceived control, career guidance, exposure to the career field, perceived ability within the career, perceptions of the profession, role model influence, outcome expectations, supports, barriers, interest, intent, self-efficacy, and career decision-making self-efficacy (e.g., Chen \& Hu, 1997; Cunningham et al., 2005; Daniels et al., 2011; Lent et al., 2002; Mensch \& Mitchell, 2008; Taylor \& Betz, 1983). Examining predictive variables help researchers to understand what impacts an individual's likelihood to pursue a career.

Demographic and predictive variables have been examined among different groups to analyze their effects on an individual's career choice (e.g., Chen \& Hu, 1997; Mensch \& Mitchell, 2008; Singaravelu, White, \& Bringaze, 2005; Zeldin, Britner, \& Pajares, 2008). By better understanding the differences between groups, researchers can suggest strategies to recruit various demographic populations, ways to decrease barriers within a field, and to better prepare individuals for entering a certain profession. Furthermore, researchers have developed career theories to better understand and contextualize how various demographic and predictive variables can influence an individual's career choice (e.g., Cunningham et al., 2005;

Cunningham \& Singer, 2010; House, 2004; Krumboltz, Foley, \& Cotter, 2013; Lent et al., 2002; Monson, 2012).

\section{Career theories.}

Career theories can be used as a guideline for career counselors, to examine career development over a lifespan, to better understand how and why an individual chooses a career, a way to increase recruitment, and a means to identify and reduce barriers within a career. 
Prevalent career theories include trait and factor theory of occupational choice (Parson, 1909), theory of planned happenstance (Krumboltz, Mitchell, \& Jones, 1976), Holland's theory (Holland, 1997), Super's theory (Super, 1980), and SCCT (Lent, Brown, \& Hackett, 1994). Some examples of career theories used by career counselors are trait and factor theory, the theory of planned happenstance, and Holland's theory. Trait and factor theory examine an individual's personal abilities, interests, and aptitudes when selecting an occupation based on the job market (Parson, 1909). The theory of planned happenstance is similar to trait and factor theory, but also factors in the changes in the job market when helping individuals select an occupation (Krumboltz, 1976). Within the theory of planned happenstance, career counselors prepare individuals with the skills necessary to adjust to the changing job market, and adapt to unexpected events. Holland's theory focuses on equipping individuals with the skills they need to be successful, but it also guides the individual to select a career based upon their personality (Holland, 1997). After assessing an individual's personality and selecting an occupation that aligns with one's personality, the career counselor then equips the individual with the skills associated with that particular occupation.

Holland's theory, trait and factor theory, and the theory of planned happenstance focus on assessing and training individuals for entering the job market. However, Super's theory focuses on career development as it occurs throughout an individual's lifespan (Super, 1980). Super's theory examines the various stages that an individual goes through from birth to death, and how an individual's perception of self-concept changes during these stages. In addition to factoring in the individual's chronological and vocational age, Super's theory also examines environmental (labor market and employment practices), situational (historical and socioeconomic), and personal factors (psychological and biological). 
Similar to Super's theory, SCCT also takes into account various factors that influence an individual's career choice. The foundation for SCCT is social cognitive theory (Lent et al., 1994). Social cognitive theory (SCT) examines how an individual's personal, environmental, and behavioral factors help to understand and explain human behavior (Bandura, 1986). Lent and colleagues applied SCT to career theory in order to better understand how and why an individual would pursue a certain career field (Lent et al., 1994).

The three factors that construct SCT (personal, environmental, and behavioral) support the primary predictive variables of SCCT (Lent et al., 1994). Within SCCT personal factors are examined through the variables of learning experiences and outcome expectations.

Environmental factors are examined through the variables of background contextual affordances, personal inputs, and contextual influences (supports and barriers). Lastly, behavioral factors are examined through the variables of learning experiences and self-efficacy.

\section{Social Cognitive Career Theory}

According to Lent and colleagues, SCCT specifically examines how "people (a) develop basic academic and career interests, (b) make and revise their educational and vocational plans, and (c) achieve performances of varying quality in their chosen academic and career pursuits" (2003, p. 458). Within SCCT, there are 10 variables that can impact an individual's decision to pursue a career (Lent et al., 1994). The 10 variables of SCCT are personal inputs, background contextual affordances, self-efficacy, learning experiences, outcome expectations, interests, proximal contextual influences, choice goals (intent), choice actions, and performance domains and attainments.

The 10 variables that construct SCCT have been situated in a model to demonstrate how each variable impacts other variables and influence an individual's career choice process. 
According to SCCT, an individual's personal inputs and background contextual affordances impact each other bi-directionally and also impact an individual's learning experiences (Lent et al., 1994). Personal inputs also impact an individual's contextual influences. Contextual influences impact an individual's intent and choice actions. An individual's learning experiences impact one's level of perceived self-efficacy and outcome expectations towards a particular career. Outcome expectations also impact an individual's interest, intent, and choice actions. Additionally, an individual's self-efficacy impacts one's outcome expectations, interest, intent, choice actions, and performance domains and attainments. Performance domains and attainments then impact an individual's learning experiences.

\section{Mediated SCCT model.}

The original SCCT model suggests that an individual's perceived contextual affordances toward a career directly influence an individual's level of interest and intent towards a career (Lent et al., 1994). However, an early study completed on students enrolled in an introductory psychology course suggested that an individual's level of self-efficacy and outcome expectations towards math and science was predictive of an individual's level of interest and intent (Lent et al., 2001). Additionally, contextual affordances demonstrated a weak relation to an individual's level of interest and intent. However, contextual affordances revealed an indirect impact on an individual's level of interest and intent via self-efficacy. As a result of this study (Lent et al., 2001), the validity of the original model of SCCT came into question.

In order to validate that contextual affordances impact an individual's level of interest via self-efficacy, a follow-up study compared the original model of SCCT to a new mediated model that linked contextual affordances to self-efficacy, interest, and intent (Lent et al., 2003). The results of this study suggested that contextual affordances have a stronger link to interest and 
intent via self-efficacy. As a consequence, the mediated model for SCCT was validated and has become the standard for SCCT research (Lent et al., 2003). The mediated model will be used as the reference for the remainder of the study (Appendix A).

\section{SCCT variables.}

The constructs and purpose of each variable within SCCT play a role in the understanding of why an individual would decide to pursue a certain career. A detailed explanation of each variable and its role within SCCT give insight on how SCCT examines an individual's likelihood of pursuing a certain career. The variables discussed include personal inputs, background contextual affordances, learning experiences, self-efficacy, contextual influences (supports and barriers), outcome expectations, interest, intent, choice actions, and performance domains and attainments.

\section{Personal inputs.}

One of the main variables that is studied within SCCT is personal inputs. Personal inputs are characteristics that an individual possesses (Lent et al., 1994). Some examples of personal inputs are gender, ethnicity, disability, health status, or predispositions. According to Lent and colleagues, predispositions refer to an individual who is prone to anxiety, stress, or anger.

Individuals who may have one or more of these predispositions may experience or perceive more barriers than an individual who does not have these predispositions.

Personal inputs are typically demographic variables that researchers examine to compare the differences in various predictive variables for career choice between groups (e.g., Chen \& Hu, 1997; Mensch \& Mitchell, 2008; Singaravelu et al., 2005; Zeldin et al., 2008). Two of the most common personal inputs that are examined within the literature are gender and ethnicity. However, personal inputs can include more than just gender and ethnicity. SCCT suggests that 
an individual's personal inputs have a direct influence on an individual's learning experiences and contextual influences (Lent et al., 2003). In addition, an individual's personal inputs can impact and be impacted by an individual's background contextual affordances.

\section{Background contextual affordances and learning experiences.}

Background contextual affordances can include opportunities for task exposure, role model exposure, emotional/parental support, financial support, educational background, and cultural and gender role socialization (Lent et al., 1994; Lent, Brown, \& Hackett, 2000). Background contextual affordances can impact an individual's learning experience and can vary depending on an individual's personal inputs such as gender, ethnicity, and sexual orientation. According to SCCT, the experiences an individual has in relation to a career are considered to be their learning experiences.

SCCT suggests that cultural and gender role socialization can contribute to an individual's likelihood of pursuing a career (Lent et al., 1994). Cultural and gender role socialization are the social norms that society has constructed society's views as an acceptable career for an individual based on their gender and/or ethnicity (Blom et al., 2011; Walker \& Sartore-Baldwin, 2013). Choosing a profession that does not align with what society views as an acceptable career based on the individual's gender and ethnicity can impact the individual's learning experiences associated with a particular career.

Learning experiences are also influenced by an individual's financial support and emotional support (background contextual affordances; Lent et al., 1994 \& 2000). Emotional support can come from family, friends, peers, teammates, teachers, or coaches. When an individual has emotional support in their life, the individual is more likely to have a more positive learning experience, increased self-efficacy and be more likely to pursue a career in that 
particular career field. Furthermore, research has suggested that role model exposure can influence an individual's career decision and self-efficacy. Increased task opportunity has also been suggested to increase an individual's level of performance and self-efficacy (Lent et al., 1994). Furthermore, SCCT suggests that an individual's learning experiences influence an individual's perceived outcome expectations and self-efficacy towards a career.

\section{Self-efficacy.}

According to SCCT, an individual's level of self-efficacy is influenced by their learning experiences and contextual influences (Lent et al., 2003). Bandura describes self-efficacy as “people's judgments of their capabilities to organize and execute courses of action required to attain designated types of performances" (1986, p. 391). An individual's level of self-efficacy can affect whether or not an individual pursues a course of action and how long the individual will continue to pursue the course of action if barriers are encountered (Bandura, 1977, 1982). There are four components that construct an individual's self-efficacy: performance accomplishment, vicarious experiences, verbal persuasion, and physiological state (Bandura, 1977, 1986, 1997).

One of the four components of self-efficacy is performance accomplishment (Bandura, 1977, 1986, 2003). When an individual has an opportunity to practice their performance and experiences limited success and encounters barriers that they are not able to overcome, then one will be more likely have a lower level of self-efficacy. However, if the individual experiences success, especially when overcoming a barrier, then one is more likely to have a higher level of self-efficacy.

The second component of self-efficacy is vicarious experience (Bandura, 1977, 1986, 2003). Vicarious experience is if an individual observes someone similar to oneself (gender, 
ethnicity, age, etc.) being successful at the performance, then one will be more likely to believe one can also be successful (Everhart \& Chelladurai, 1998; Wood \& Bandura, 1989). The individual can then visualize oneself being successful during the performance and believes one is also capable of being successful. When an individual is given the choice to observe a model, the individual will typically choose to watch a performer who resembles oneself (Bandura, 1997). Research has suggested that career role model influence plays a factor in an individual's selfefficacy and intent to pursue a career (Lent et al., 1994, 2000; Paa \& McWhirter, 2000).

The third factor contributing to an individual's level of self-efficacy is verbal persuasion (Bandura, 1977, 1986; Wood \& Bandura, 1989). Verbal persuasion is when an individual receives positive comments and feedback regarding one's interest in a career, it may increase their self-efficacy of being successful in that career. However, if the individual receives negative comments and feedback regarding one's interest in a career; it may lower one's self-efficacy towards that career (Bandura, 2003). An individual's level of self-efficacy can be influenced positively or negatively by verbal persuasion.

The fourth factor that contributes to an individual's level of self-efficacy is one's physiological state (Bandura, 1977, 1986, 2003). An individual, who has a high physical and mental state, is more likely to have a higher level of self-efficacy compared to an individual who has a low physical and mental state (Wood \& Bandura, 1989). In addition to an individual's physical and mental state, an individual's evaluation of one's physical and mental state impacts one's level of self-efficacy (Bandura, 2003). An individual, who is not able to manage one's physical and mental state, will most likely have a lower level of self-efficacy. SCCT suggests that an individual's level of self-efficacy influences an individual's level of interest in a career, 
outcome expectation, intent, choice actions, and performance domains and attainments (Lent et al., 2003).

\section{Contextual influences (support and barriers).}

According to the mediated model of SCCT, contextual influences (supports and barriers) impact an individual's level of self-efficacy, intent, and choice actions (Lent et al., 2003). SCCT suggests that the only factor that impacts one's perceived contextual influences towards a career are personal inputs. Swanson and Woitke define barriers as "events or conditions, either within the individual or in his or her environment, that make career progress difficult" (1997, p. 434). Some examples of barriers associated with career choice could be discriminatory hiring practices, lack of networking contacts, structural barriers, and lack of learning experiences (Lent et al., 1994, 2000). The career barriers inventory suggested that college students are aware of the presence of barriers associated with a career (Swanson \& Woitke, 1997).

SCCT suggests that if an individual perceives numerous barriers associated with a profession, the individual is less likely to choose that profession (Lent et al., 2000). In addition, if an individual chooses a profession that has numerous perceived barriers, the individual is more likely have a lower level of self-efficacy. Conversely, if an individual has supports in regards to career choice, such as networking contacts, social and financial support, then the individual is more likely to pursue that career (Lent et al., 2002). SCCT suggests that one's perceived contextual influences can impact an individual's self-efficacy, intent, and choice actions (Lent et al., 2003).

\section{Outcome expectations.}

According to SCCT, an individual's personal inputs, background contextual affordances, learning experiences, and self-efficacy can influence an individual's perception of outcome 
expectations associated with a career (Lent et al., 1994, 2000, 2003). Outcome expectations are the perceived possible outcomes (proximal and distal) that the individual will encounter in a profession. Some examples of outcome expectations could be money, social support from peers, and self-satisfaction (Lent et al., 2000). Outcome expectations are influenced by an individual's self-efficacy and learning experiences.

Research suggests that individuals who have a high level of self-efficacy and have positive outcome expectations towards a career are more likely to pursue that profession compared to an individual who has a low level of self-efficacy and limited positive outcome expectations (Bandura, 1986; Lent, Brown, \& Larkin, 1986; Moran-Miller \& Flores, 2011). SCCT suggests that an individual's perception of one's outcome expectations of a career influence one's interests, intent, and choice actions associated with a career (Lent et al., 1994, 2000, 2003).

\section{Interest.}

Within SCCT, perceived outcome expectations and self-efficacy influence an individual's interest in a career (e.g., Diegelman \& Subich, 2001; Lent et al., 1994, 2000; Multon, Brown, \& Lent, 1991). Interests refer to an individual's likes, dislikes, and indifferences to an activity (Lent \& Brown, 2006); this is also sometimes referred to as vocational interest (Lent \& Brown, 2006; Lent et al., 1994, 2000). An individual's level of interest can impact their level of intent to pursue a career.

\section{Intent (choice goals).}

According to SCCT, an individual's choice goals are the goals that an individual sets for oneself in relation to a profession (Lent \& Brown, 2006). SCCT research suggests that an individual's level of intent to pursue a career is influenced by one's level of self-efficacy, 
outcome expectations, contextual influences, and level of interest (Diegelman \& Subich, 2001; Lent et al, 2000, 2003, 2011; Moran-Miller \& Flores, 2011; Pease \& Drabelle, 1988). Within SCCT, there are two different types of choice goals: choice-content goals and performance goals. Choice-content goals refer to the type of activity an individual wants to pursue. An example of a choice content goal would be an individual's intent to pursue an academic field or major. Performance goals are determined by how successful or unsuccessful an individual believes oneself will be in a profession. This literature review focuses on choice-content goals, and refers to choice-content goals as an individual's level of intent. SCCT suggests that an individual's level of intent influences an individual's choice actions (Lent et al., 1994).

\section{Choice actions.}

According to SCCT, choice actions are the steps in which an individual takes toward a career (Lent et al., 2003). Choice actions are influenced by an individual's levels of selfefficacy, outcome expectations, interests, contextual influences, and intent. Examples of choice actions could be looking into career options in a related field, job shadowing, talking to an advisor or someone in the field, applying or enrolling in a program to be trained for a career (Rogers \& Creed, 2011). Choice actions are linked to the final variable of SCCT which is performance domains and attainments. An individual's level of performance and attainment within a career directly impacts an individual's learning experiences associated with a career (Lent et al., 1994).

SCCT is being used by researchers to understand better how and why an individual chooses a career, a way to increase career recruitment, and to identify and reduce barriers within a career (e.g., Lent et al., 2001, 2003, 2011). SCCT is mostly used by researchers to understand what factors influence an individual's (predominantly college students' in introductory courses) 
intent to pursue a career. In order to better understand how and why an individual would be interested in pursuing NCAA collegiate coaching as a full-time career, researchers have begun to apply SCCT to the coaching profession (Cunningham \& Singer, 2010; Moran-Miller \& Flores, 2011). The coaching research has focused solely on examining CAs and comparing the differences between gender and ethnicities.

\section{SCCT Research in Coaching}

The application of SCCT to examine individuals' intent to pursue NCAA collegiate coaching as a career is limited to two studies and has only studied CAs (Cunningham \& Singer, 2010; Moran-Miller \& Flores, 2011). In addition to these two studies, there was one additional study that used SCCT to examine the differences between male and female assistant coaches in a Canadian University league and their intent to become a head coach (Cunningham et al., 2007). The findings of Canadian study suggested that men had a higher level of coaching self-efficacy, perceived more positive outcome expectations, and had more interest, and intent to become a head coach compared to female assistant coaches.

Cunningham and Singer's study examined CAs and suggested that there was no significant difference in the area of coaching self-efficacy between ethnic minorities and Caucasians (Cunningham \& Singer, 2010). However, the findings did suggest that there was a significant difference between ethnic minorities and Caucasians CAs' level of intent to become a full-time collegiate coach, perceived outcome expectations, and perceived barriers. Ethnic minority CAs reported a higher level of intent to become a collegiate coach and perceived greater outcome expectations compared to Caucasian CAs. However, racial minority CAs reported they would encounter more barriers than Caucasians CAs. Follow-up interviews with some of the African American CAs suggested that the participants knew they would encounter 
barriers no matter what profession they entered, so they rather deal with the barriers within collegiate coaching than another profession.

In a more recent study completed on female CAs' interest towards collegiate coaching, the study suggested that coaching self-efficacy was impacted by role model influence and the amount of predicted working hours (Moran-Miller \& Flores, 2011). Coaching self-efficacy was then linked to female CAs' perceived outcome expectations of collegiate coaching as a profession. Some of the listed outcome expectations were: personal growth and development, respect from others, overcoming odds, helping others, and prestige among peers. Outcome expectations, coaching self-efficacy, and contextual factors (working hours, perceived discrimination, and female coaching role models) were suggested to impact female CAs' level of interest towards collegiate coaching as a career. The results of this study suggested that the variables of SCCT were predictive of female CAs' level of interest towards collegiate coaching as a full-time career.

These studies demonstrate the applicability of SCCT to examine CAs' intent to pursue collegiate coaching as a profession; however, there is a lack of depth when examining other demographics variables (besides gender and ethnicity) and sample populations. On the other hand, there is a substantial amount of coaching research (primarily collegiate coaching) on the predictive variables that comprise SCCT (e.g., Cunningham \& Singer, 2010; Kamphoff, 2010; LaVoi \& Dutove, 2012; Moran-Miller \& Flores, 2011). The research on the predictive variables comprise SCCT within the context of coaching provides insight on how the variables of SCCT could contribute to individuals' perception of collegiate coaching and their decision to pursue collegiate coaching as a full-time career. 


\section{SCCT Variables within the Coaching Literature}

The coaching research on the variables that comprise SCCT has focused mainly on comparing the differences between gender and ethnicity (e.g., Cunningham et al., 2007; Cunningham, Sagas, \& Ashley, 2003; Bernhard, 2010). Within this study, group membership (CA, SSM, and AM) was examined as a personal input. The impact that personal inputs have on the predictive variables of SCCT was addressed when discussing the research on the variables of SCCT. According to SCCT, personal inputs influence an individual's contextual influences, learning experiences, and background contextual affordances (Lent et al., 1994).

\section{Background contextual affordances within sport and coaching.}

Within SCCT, background contextual affordances can include opportunities for task exposure, role model exposure, emotional/parental support, financial support, educational background, and cultural and gender role socialization (Lent et al., 1994; Lent et al., 2000). Within the context of coaching, task opportunities refer to an individual's experience with coaching. Research suggests that years of coaching experience (e.g., Feltz, Chase, Moritz, \& Sullivan, 1999; Feltz, Helper, Roman, \& Paiement, 2009; Helper, Feltz, Roman, \& Paiement, 2007; Kavussanu, Boardley, Jutkiewicz, Vincent, \& Ring, 2008) and extensive playing experience (Feltz et al., 1999; Helper et al., 2007) can influence a coach's level of coaching selfefficacy.

Coaches can impact an individual's learning experiences with sport and can serve as a career role model to an athlete. Research suggests that if a female athlete has had a successful female coach she is more likely to want to become a coach, than if she never had a woman coach (Everhart \& Chelladurai, 1998; LaVoi \& Dutove, 2012; Moran-Miller \& Flores, 2011). Yet, women account for $43.4 \%$ of all head coaching positions of all NCAA collegiate women's sports 
teams (Acosta \& Carpenter, 2014). Additionally, within the NCAA 1 out of 4.5 of all head coaching positions of all collegiate men's and women's team and 2-3.5\% of all head coaching positions of men's collegiate sports teams are coached by a woman. Not only are there a lack of female collegiate head coaches to serve as career models in collegiate coaching, but there is also a lack of ethnic minority collegiate coaches (Lapchick, 2010).

In 2008-09, the Racial and Gender Report Card stated that male Caucasians accounted for $89.3 \%$ of all head coaching positions in Division I men's sports, $89.2 \%$ of all Division II, and 92.3\% of all Division III (Lapchick, 2010). In women's sports teams, Caucasians accounted for $87.7 \%$ of all Division I head coaching positions, $89.5 \%$ of all Division II, and $91.9 \%$ of all Division III. African-Americans male collegiate head coaches were the next highest ethnic representatives at $6.6 \%$ at the Division I level, $4.8 \%$ at Division II, and $3.7 \%$ in Division III. African-American females accounted for a slightly higher percentage of collegiate head coaches, with $7.2 \%$ at Division I, $4.8 \%$ at Division II, and 3.9\% in Division III. Caucasian and AfricanAmerican collegiate coaches account for approximately $94 \%$ of all the head coaching positions for both men and women at all three NCAA divisions.

Caucasians also account for the majority of assistant collegiate coaching positions for both men and women's teams at all three NCAA divisions (Lapchick, 2010). The lack of female and ethnic minority collegiate coaches that can serve as a career role model is one of the potential reasons why more females and ethnic minorities do not apply for collegiate coaching positions. Furthermore, the lack of exposure of female and ethnic minority coaches could influence individual's perceptions of pursuing collegiate coaching as a career.

Cultural and gender role socialization are also suggested to contribute to the lack of diversity of female and ethnic minority collegiate coaches (e.g., Blom et al., 2011; Borland \& 
Bruening, 2010; Kamphoff, 2010; Walker \& Sartore-Baldwin, 2013). Cultural and gender role socialization are socially constructed and contribute to what society views as an acceptable occupation for a certain gender and/or ethnicity (Blom et al., 2011; Walker \& Sartore-Baldwin, 2013). Coaching (especially at the collegiate and professional level) is considered to be a masculine profession, and research suggests that men are perceived to be a better coach than a female; this is partially due to the attributes of masculinity aligning with the characteristics of an effective coach (Blom et al., 2011; Kamphoff, 2010; Walker \& Sartore-Baldwin, 2013).

If a female coach displays too many masculine characteristics, she may be perceived as a lesbian (Walker \& Bopp, 2011). Research has suggested that there are some heterosexual female coaches who feel the need to overcompensate their heterosexuality in order to not be perceived as being a lesbian. Furthermore, many lesbian collegiate coaches remain in the closet and keep their personal life as private as possible to stay under the radar (Kamphoff, 2010; Krane \& Barber, 2005). The presence of homophobia within collegiate coaching is one of the reasons why some female coaches decided to leave the coaching profession (Kamphoff, 2010; LaVoi \& Dutove, 2012).

According to SCCT, an individual's personal inputs (gender, ethnicity, and sexual orientation) and background contextual affordances (emotional and financial support, cultural and gender role socialization, and task opportunities) can influence an individual's learning experiences (Lent et al., 1994). Learning experiences are an individual's past experiences associated with a profession. An individual's participation or non-participation in collegiate athletics could influence their learning experiences with sport and coaching as a profession. According to SCCT, learning experiences influence an individual's perceived outcome expectations and self-efficacy towards a career (Lent et al., 1994). 


\section{Coaching self-efficacy.}

Coaching self-efficacy has been used as a variable to help predict an individual's level of interest, intent, and desire to enter collegiate coaching as a profession and also why an individual would leave the coaching profession early (e.g., Cunningham et al., 2003; Everhart \& Chelladurai, 1998; Kent \& Sullivan, 2003; Moran-Miller \& Flores, 2011). Coaching selfefficacy is defined by Feltz and colleagues as "the extent to which coaches believe they have the capacity to affect the learning and performance of their athletes" (Feltz et al., 1991, p. 153). Research suggests that coaching self-efficacy is predictive of both male and female assistant coaches' intent to become head coaches (Cunningham et al., 2003), female CAs' level of interest towards collegiate coaching (Moran-Miller \& Flores, 2011), and CAs' intent to coach full-time at various competitive levels (Everhart \& Chelladurai, 1998).

Research has suggested that some of the factors that influence an individual's level of coaching self-efficacy are: years of coaching experience (e.g., Feltz et al., 1999, 2009; Helper et al., 2007; Kavussanu et al., 2008), extensive playing experience (Feltz et al., 1999; Helper et al., 2007), social supports (Feltz et al., 1999), role models (Moran-Miller \& Flores, 2011), and the number of hours the individual predicts they will have to work (Everhart \& Chelladuria, 1998; Moran-Miller \& Flores, 2011).

The factors that impact an individual's level of coaching self-efficacy (coaching experience, playing experience, social supports, role models, and number of work hours) align with the variables (learning experience, supports, and barriers) that SCCT suggests impacts an individual's level of self-efficacy (Lent et al., 2003). CAs' level of coaching self-efficacy may be higher than a non-CA due to their playing experience and exposure to the profession. Furthermore, AMs level of coaching self-efficacy may be higher than CAs and SSMs due to their 
exposure to collegiate coaching as CA and their knowledge gained in a SSM. Coaching research has suggested that coaching self-efficacy can influence an individual's outcome expectations, interest, and intent to pursue coaching as a career (Cunningham et al., 2003; Everhart \& Chelladuria, 1998; Moran-Miller \& Flores, 2011).

\section{Contextual influences (supports and barriers) within collegiate coaching.}

According to SCCT, personal inputs are the only variable that impacts an individual's contextual influences (Lent et al., 1994). Within collegiate coaching, the main personal inputs that have been examined when discussing contextual influences are gender and ethnicity (e.g., Cunningham \& Singer, 2010; Kamphoff, Armentrout, \& Driska, 2010; LaVoi \& Dutove, 2012; Walker \& Bopp, 2011). In addition, CAs have also been asked their perceptions of contextual influences within collegiate coaching (e.g., Cooper et al., 2007; Cunningham \& Singer, 2010; Moran-Miller \& Flores, 2011).

U.S. collegiate coaching research has documented various potential barriers within the profession such as: discriminating hiring practices, lack of networking contacts, balancing work and family life, lack of pay, lack of support, time commitment, sexism, racism, and homophobia (e.g., Cunningham \& Singer, 2010; Kampoff, 2010; LaVoi \& Dutove, 2012; Walker \& Bopp, 2011). An individual's perceptions of these barriers could impact their decision to pursue collegiate coaching as a career. Furthermore, CAs and AMs may have different perceptions of the collegiate coaching as a profession compared to SSMs due to their collegiate playing experience.

Coaching research has suggested that females and ethnic minorities tend to have a lack of networking contacts, and this can contribute to the difficulty of attaining a collegiate coaching position (Cunningham, Bruening, \& Straub, 2006; Kane \& Stangl, 1991; Lovett \& Lowery, 
1994; Walker \& Bopp, 2011). Acquiring a collegiate coaching position can have a lot to do with your past accomplishments as an athletic participant (CA) and also whom you know that can get you the job; this is sometimes referred to as the "old boys' network" (Allen \& Shaw, 2009;

LaVoi \& Dutove, 2012). It is suggested that female and ethnic minority coaches do not have the extensive amount of networking connections as Caucasian and male coaches (Cunningham et al., 2006; Kane \& Stangl, 1991; Lovett \& Lowery, 1994; Walker \& Bopp, 2011). In addition, it is suggested that ethnic minority coaches experience hiring discrimination based on their ethnicity (Cunningham et al., 2006). CAs and AMs may have a larger network of contacts compared to SSMs due to their collegiate playing experience.

Another barrier that may contribute to an individual's decision to pursue collegiate coaching as a full-time career is if the individual has or wants to have a family; specifically children. The concern of balancing both work and family life can be difficult for coaches due to the time commitment (Bracken, 2009; Everhart \& Chelladurai, 1998; Kampoff, 2010; LaVoi \& Dutove, 2012; Wilson, 2007) and the amount of traveling that collegiate coaching requires (LaVoi \& Dutove, 2012; Wilson, 2007). Female collegiate coaches have reported the balance between work and family as a barrier (Bracken, 2009; Bruening \& Dixon, 2008; Dixon \& Bruening, 2007; Kamphoff, 2010; LaVoi \& Dutove, 2012). Additioanlly, female coaches have also reported that they do not have enough time to be an effective coach and be as involved as they would like in their child/children's life. Part of this conflict is due to the patriarchal roles that society has created for male and female coaches (background contextual affordances). Females are thought to have to be the main caregivers, or they are not they are not a suitable mother (Dixon \& Bruening, 2007; Kampoff, 2010). However, it is socially acceptable for a male to be an effective full-time collegiate coach, father, and husband. Due to gender discrimination 
and sexism within collegiate coaching, men are seen to be qualified applicants to coach both men's and women's sports; however, women are only seen as valid applicants to coach women's sports (Walker \& Bopp, 2011; Walker \& Sartore-Baldwin, 2013). This view is reflective in the discriminatory hiring practices within U.S. collegiate coaching.

Coaching research has suggested that one of the factors as to why there is a lack of female and ethnic minority collegiate coaches is due to the lack of female and ethnic minority athletic directors (Acosta \& Carpenter, 2014; Cunningham \& Sagas, 2005; Kilty, 2006; Sagas et al., 2006b; Stangl \& Kane, 1991; Whisenant et al., 2002). Research suggests that an individual is more likely to hire someone who is similar to them; this behavior is called homologous reproduction (Kanter, 1977). Coaching research has suggested that athletic directors (AD) tend to hire someone who is similar to them (Acosta \& Carpenter, 2014; Cunningham \& Sagas, 2005; Kilty, 2006; Sagas, Cunningham, \& Teed, 2006; Stangl \& Kane, 1991; Whisenant, Pedersen, \& Obenour, 2002). Not only does the AD's gender play a role, but so does one's ethnicity. For example, if the $\mathrm{AD}$ is a Caucasian male, not only is he more likely to hire a male, but also a Caucasian male. Homologous reproduction is not only present when an AD hires a head coach, but also when a head coach selects their assistant coach. Research has also suggested that the gender and ethnicity of the head coach also plays a role in the gender and ethnicity of the assistant coach that is hired (LaVoi \& Dutove, 2012; Sagas, Cunningham, \& Pastore, 2006).

Another example of gender bias and discrimination in collegiate coaching is the pay difference between male and female coaches (Bracken \& Irick, 2012; Dunn, 2013). Salary within a career is typically associated with an individual's perceived outcome expectations of a career; however, low salary within collegiate coaching has been suggested to be perceived as a barrier (Abney \& Richey, 1991; Cooper et al., 2007; LaVoi \& Dutove, 2012). Head coaches of 
collegiate Division I men's teams make $58.6 \%$ of the total salaries of both men's and women's teams and assistant coaches of men's Division I sports teams make $66.8 \%$ of the total salaries of both men's and women's teams (Bracken \& Irick, 2012). Another example is in research institutions, where male head basketball coaches make $\$ 250,000$ and female head basketball coaches make $\$ 175,000$ (Dunn, 2013).

An individual's perceptions of the barriers when trying to enter collegiate coaching could deter an individual from pursuing the profession; however, support from friends, peers, family, partner and or children can help increase an individual's choice to pursue a career in collegiate coaching and remain within the profession (Abney \& Richey, 1991; Blom et al., 2011; Cunningham \& Singer, 2010; Kamphoff et al., 2010; LaVoi \& Dutove, 2012). Conversely, having a lack of support can contribute to an individual not pursuing a profession or wanting to leave the profession early in their career. Having an emotional support system can help an individual navigate and manage barriers within collegiate coaching (Blom et al., 2011; Bruening \& Dixon, 2008; LaVoi \& Dutove, 2012; Weiss, Barber, Sisley, \& Ebbeck, 1991). When an individual feels they are able to handle possible career hindrances, it is often referred to as coping self-efficacy (Lent et al., 2000). An individual's level of coping self-efficacy can affect what barriers the individual may perceive as a deterrence within a career.

Coaching research has suggested that CAs perception of contextual influences impact their level of coaching self-efficacy and intent towards coaching as a full-time career (Cunningham \& Singer, 2010; Moran-Miller \& Flores, 2011). CAs, AMs, and SSMs may perceive different contextual influences when entering collegiate coaching due to their exposure collegiate coaching and or knowledge gained in their SSM. According to SCCT, contextual 
influences can influence an individual's self-efficacy, intent, and choice actions (Lent et al., 2003).

\section{Outcome expectations within collegiate coaching.}

According to SCCT, an individual's outcome expectations are influenced by one's learning experiences and self-efficacy (Lent et al., 1994). Within collegiate coaching, some of the main outcome expectations that have been researched are salary, social support from peers, and self-satisfaction (e.g., Bracken \& Irick, 2012; Cunningham \& Singer, 2010; Dunn, 2013; Kamphoff \& Gill, 2008). An individual's outcome expectations may vary due to one's personal inputs. However, the majority of the research on outcome expectations within collegiate coaching have focused on CAs' perceptions of outcome expectations, along with gender and ethnicity (e.g., Cunningham \& Singer, 2010; Kamphoff et al., 2010; Kamphoff \& Gill, 2008).

In 2012, the NCAA made available their Gender-Equity report which listed the median salary of head and assistant coaches of men's and women's teams in 2010 (Bracken \& Irick, 2012). The report only indicates the pay difference between men's and women's teams and not the difference between male and female coach's median salaries. The biggest pay gap between head coaches of men's and women's teams was at the Division I level. Head coaches of men's teams make $58.6 \%$ of the total salaries of both men and women's teams and assistant coaches of men's Division I sports teams make $66.8 \%$ of the total salaries of both men's and women's teams. At the Division II level, men make 53\% of the total salaries for head coaches of men's and women's teams. Division II has the closest percentage for head coaches making the same median salary of men's and women's teams. However, the Division II level has the biggest pay difference for assistant coaches. Assistant coaches of men's teams make $71.4 \%$ of the total median salaries of men's and women's team. Head coaches of Division III men's team make 
$55.4 \%$, and assistant coaches of men's teams make $71.2 \%$ of the total median salaries for men's and women's teams. At every level and position (assistant and head), males teams make more than female teams.

In 2013, the Chronicle of Higher Education published an article listing the median salary for male and female coaches at research institutions (Dunn, 2013). Men who are the head of an athletic program, on average make $\$ 152,823$ compared to a woman who is head of an athletic program makes $\$ 102,261$. The biggest pay gap between male and female coaches were in the hyper-masculine team sports. Male ice hockey coaches make $\$ 210,000$, and female ice hockey coaches make less than half of men at $\$ 97,282$. The next highest gender pay difference was in basketball. In basketball, male head coaches make \$250,000, and female head basketball coaches make $\$ 175,000$. There were two sports listed in which female coaches made more than male coaches, and the sports were gymnastics and volleyball (Dunn, 2013). In volleyball, female coaches make $\$ 81,490$, and male coaches make $\$ 76,875$. In gymnastics, female coaches make $\$ 85,189$, and male coaches make $\$ 81,273$. The difference in median salaries based on gender was closer in some of the coed sports such as golf, rowing, and soccer.

Lack of pay is suggested to be a barrier in collegiate coaching for female and ethnic minority coaches (Abney \& Richey, 1991; Cooper et al., 2007; LaVoi \& Dutove, 2012). It is also suggested that inadequate salaries make it difficult for female coaches to support their household (Abney \& Richey, 1991) and contribute to the burnout of both male and female coaches (Felder \& Wishnietsky, 1990). Due to the lack of pay that female coaching salaries are known to have, this could be a potential reason for a lack of support for females pursuing collegiate coaching as a full-time career. 
When choosing a career, support and approval from friends, peers, family, partner or children can help increase an individual's level of interest in a career (Lent et al., 1994, 2000). Athletes and coaches have suggested that having support is a major factor in collegiate coaching (Blom et al, 2011; Cunningham \& Singer, 2010; Inglis, Danylchuk, \& Pastore, 2000; Kamphoff et al., 2010; LaVoi \& Dutove, 2012). Some of the potential reasons for an individual wanting to choose coaching as an occupation could be to stay involved in sport, enjoy the coaching role, to help and develop young people, be a good coach and role model, and because they love the sport (Inglis et al., 2000; Kamphoff \& Gill, 2008; Sage, 1989; Weiss \& Stevens, 1993).

If an individual does not receive support or approval for pursuing collegiate coaching as a career, it could be perceived as an additional barrier (Abney \& Richey, 1991; Inglis et al., 2000; LaVoi \& Dutove, 2012). Some additional reasons why there might be lack of support for pursuing collegiate coaching as a career could be the potential barriers (work/family conflict, homophobia, gender discrimination, sexism, lack of support administrative, discriminating hiring practices, lack of pay, and lack of respect) that an individual could face when trying to enter the collegiate coaching as a profession (Abney \& Richey, 1991; Cooper et al., 2007; Dixon \& Bruening, 2007; LaVoi \& Dutove, 2012; Norman, 2012; Weiss \& Stevens, 1993).

The numerous barriers that an individual could face when entering collegiate coaching could be deterring; however, coaches (high school and collegiate) have reported that coaching can be very satisfying and rewarding career (Lumpkin \& Anshel, 2012; Weiss \& Stevens, 1993; Whisenant \& Smucker, 2009). Coaching can also provide an individual with the opportunity for personal growth, overcoming obstacles (barriers), gaining respect and recognition from others, and advancement to higher positions (Moran-Miller \& Flores, 2011). 
An individual's outcome expectations of a career can vary due to an individual's personal inputs, learning experiences, and self-efficacy (Lent et al., 1994, 2000 \& 2003). Perceived outcome expectations of collegiate coaching as a profession may also differ depending upon group membership (CA, AM, and SSM). SCCT suggests that an individual's perception of one's outcome expectations of a career can influence one's interests, intent, and choice actions associated with a career (Lent et al., 1994, 2000, 2003).

\section{Coaching interest.}

The research on individual's level of interest towards collegiate coaching has varied within the literature. One of the main reasons for the variation is due to researchers using a broad range of scales to measure an individual's level of interest towards collegiate coaching as a career. The lack of consistency of coaching interest scales makes drawing conclusions and comparisons difficult. The following are examples of how one's level of interest towards collegiate coaching has been examined within the U.S. coaching literature.

One study on female CAs' level of intent towards coaching at various levels, reported the results as their level of interest towards collegiate coaching (Moran-Miller \& Flores, 2011). Another study combined collegiate football athletes' interest and intent towards collegiate coaching as one variable (Bernhard, 2010). There was an additional study that did not list which scale was used to measure female undergraduate students' level of interest towards collegiate coaching (Cooper et al., 2007), while another study did not examine one's interest towards collegiate coaching (Cunningham \& Singer, 2010). In addition to the various coaching interests scale, additional studies used vocational interest (Cunningham et al., 2007) or occupational/coaching valence scales (Everhart \& Chelladurai, 1998, 2004) as their measure for an individual's level of interest towards collegiate coaching. 
Cunningham and colleagues used a vocational interest scale to measure Canadian assistant coaches' interest in becoming a head coach (Cunningham et al., 2007). The study suggested that female assistant coaches had less interest than assistant male coaches to become a head coach. However, early studies suggested that NCAA female CAs perceive greater coaching valence than male CAs (Everhart \& Chelladurai, 1998, 2004). It was also suggested that female CAs who had a female coach had greater coaching valence and were less concerned with perceived discrimination than those who had a male coach (Everhart \& Chelladurai, 1998).

The first official coaching interest survey was developed in 2008, by Kamphoff and Gill. The coaching interest scale measures an individual's level of interest in entering coaching based upon their response towards five categories associated with coaching. The five categories are: (1) to develop young people, (2) like the coaching role, (3) to stay in the sport, (4) minority and women's issues, and (5) the love of the sport. The scale was reported to be valid and reliable; however, the scale has only been used in one study (Kamphoff \& Gill, 2008).

The results of the study suggested that there was a significant difference between genders for category one, but there was not a significant difference for ethnicity (Kamphoff \& Gill, 2008). It was suggested that female CAs' interests were more likely to be influenced by their desire "to enhance character development of young people," "I like working with people," and "I am interested in working with young people." For category two, three, and five there was no significant difference between the groups. In category four, there was a significant difference between gender and ethnicity. Ethnic minority CAs reported higher levels of interest "to enter coaching to work for equal pay and opportunity for minority coaching," and "to help minority athletes reach their athletic potential" compared to Caucasians CAs. Female CAs had greater interest "to work for equal pay and opportunity for women," "to help minority athletes reach 
their athletic potential," and "to help female athletes reach their athletic potential" compared to male CAs.

The majority of the coaching research on individual's level of interest towards collegiate coaching did not examine its influence on an individual's level of intent to become a coach (e.g., Cunningham et al., 2007; Everhart \& Chelladurai, 2004; Kamphoff \& Gill, 2008; Moran-Miller \& Flores, 2011) except one study (Everhart \& Chelladurai, 1998). This study suggested that an individual's level of coaching valence did not significantly correlate with an individual's intent to coach at any level. The inconstancy of coaching interest scales makes drawing reliable findings difficult. The use of a standard coaching interest scale should increase reliability and allow for comparisons of future coaching research findings. Furthermore, additional coaching research is needed to determine if an individual's level of interest towards coaching is predictive of one's level of intent to become a coach.

\section{Coaching intent.}

Coaching research on individual's intent to pursue collegiate coaching as a profession has mainly focused on examining CAs (e.g., Bernhard, 2010; Cunningham, 2003; Cunningham \& Singer, 2010; Everhart \& Chelladurai, 1994, 2004; Kamphoff \& Gill, 2008). However, there are two studies that examined a group other than CAs (Pease \& Drabelle, 1988; Sage, 1989). One study examined individuals in a coaching-oriented course (Pease \& Drabelle, 1988), and the other study examined high school coaches recollection of when they knew they wanted to become a coach (Sage, 1989). Despite researchers examining both CAs and non-CAs, researchers have yet to compare the differences between CAs and non-CAs and their intent to pursue collegiate coaching as a full-time career. This study not only compared the differences between CAs and SSMs, but it also examined AMs intent to become a full-time collegiate coach. 
This study provided more information on the impact group membership (personal inputs) has on individual's decision to pursue collegiate coaching as a profession.

An individual's collegiate coaching intentions have been mainly measured through either the Desire to Coach Scale (DCS; Everhart, 1994) or the Coaching Intent Scale (CIS;

Cunningham \& Singer, 2010). The DCS measures how interested an individual is to coach fulltime at five different coaching levels (high school, two-year colleges, Division III, Division II, and Division I). The DCS has been used by researchers to examine CAs' intent to coach at various coaching levels (Everhart \& Chelladurai, 1998, 2004; Kamphoff \& Gill, 2008; MoranMiller \& Flores, 2011).

The CIS was adapted from Hagger and colleagues' intention scale that measured an individual's level of intent towards physical activity (Hagger, Chatzisarantis, \& Biddle, 2001) and is based on the theory of planned behavior. The scale assesses one's level of intent based on the extent to which they plan to, intend to, and would try to complete a certain task or behavior. The CIS has been used to measure CAs' intent to become a collegiate coach and assistant coaches' intent to become a head coach (Bernhard, 2010; Cunningham et al., 2007; Cunningham \& Singer, 2010; Sagas et al., 2006a). Findings from both the DCS and CIS will be discussed when examining individual's level of intent to become a collegiate coach.

\section{Collegiate athletes' coaching intent.}

Coaching research suggests that male CAs report a higher level of intent to become a full-time coach at the high school level, Division I, and professional level compared to female CAs (Everhart \& Chelladurai, 1998; Kamphoff \& Gill, 2008). In addition, female CAs report a higher level of intent to coach full-time at the youth sport/community/recreational level compared to male CAs (Kamphoff \& Gill, 2008). Furthermore, it was suggested that female 
collegiate coaches have lower levels of intent to become a collegiate head coach compared to males (Cunningham et al., 2007; Sagas et al., 2006a).

While studying CAs' intent on entering collegiate coaching, researchers also compared the differences between genders and ethnic groups (Bernhard, 2010; Cunningham, 2003; Cunningham et al., 2007; Cunningham \& Singer, 2010). The findings have been mixed on the effect that ethnicity plays on a CAs' intent to become a full-time collegiate coach. There are studies that suggest there are no racial differences between Caucasians and ethnic minority CAs when it comes to their intent to become a full-time collegiate coach (Bernhard, 2010; Cunningham, 2003). However, another study suggested that ethnic minority CAs had greater positive outcome expectations and intentions to become a collegiate coach than Caucasians CAs (Cunningham \& Singer, 2010). The study also noted that ethnic minority CAs felt they would experience discrimination and prejudice no matter what profession they choose; so they rather deal with the barriers in collegiate coaching than another profession.

\section{Non-collegiate athletes' coaching intent.}

The majority of coaching research on individual's intent to become a coach has focused on CAs; however, there are two early studies that did not examine CAs (Pease \& Drabelle, 1988; Sage, 1989). The first study examined non-CAs who were enrolled in a coaching-oriented course and their perceptions of coaching as a profession (Pease \& Drabelle, 1988). The study suggested that $59.5 \%$ of the males and $46.8 \%$ of females viewed coaching as their primary career goal. The majority of females (63.3\%) listed junior high and high school coaching as the highest level of coaching they would want to coach, followed by wanting to coach at a small college (22.4\%), and lastly wanting to coach at a major college $(14.3 \%)$. The majority of males also wanted to coach at the junior high and high school level (48.8\%), followed by wanting to coach 
at a major college (32.5\%), and lastly wanting to coach at a small college (18.\%). In addition, $40 \%$ of females and $65.4 \%$ of males reported that they felt they would be very successful in their coaching career.

The second study examined high school male coaches and found that $50 \%$ of the coaches knew they wanted to become a high school coach before they entered college (Sage, 1989). The coaches reported that their experience playing athletics, observations of their coaches, and personal characteristics were the influencing factors in their decision to become a high school coach. The coaches developed their perceptions and expectations of the coaching profession by observation and speaking with experienced coaches.

The research on individual's intent to pursue collegiate coaching as a profession is limited and has focused primarily on CAs (Bernhard, 2010; Cunningham, 2003; Cunningham \& Singer, 2010; Sage, 1989). Further research is needed to understand better what impacts an individual's intent to pursue collegiate coaching as a profession. The criteria for becoming NCAA collegiate coach could impact an individual's perceptions of the supports and barriers when trying to enter the collegiate coaching profession and thus impact their intent to pursue collegiate coaching as a full-time career.

\section{NCAA Collegiate Coaching Requirements}

Within the U.S., coaching education requirements are set by the institutions and sport organizations. In order to be hired as a NCAA collegiate coach, the job requirements are dependent upon what each institution has set as the criteria (Siegl \& Newhof, 1992; T. Howes, personal communication, September 7, 2014). Most institutions require a bachelor's degree and many prefer a master's degree; however, it does not matter the field in which the degree is attained (NCAA “The Market”, n.d; Siegel \& Newhof, 1992). In addition, very few institutions 
(6\%) require their head coach to have a coaching certificate (Siegl \& Newhof, 1992).

Furthermore, NCAA collegiate coaching listings did not indicate having a coaching degree or coaching certificate as a requirement or preference (NCAA "The Market", n.d). However, most institutions and collegiate coaching job listings do require collegiate coaching experience and/or collegiate playing experience (NCAA “The Market”, n.d; Siegel \& Newhof, 1992).

A review of full-time collegiate coaching job announcements on the NCAA "The Market" suggest that most institutions require an individual to hold a bachelor's degree and note that a master's degree is preferred (NCAA “The Market”, n.d.). The requirement or preference for coaches to have formal coaching education was not listed in the job descriptions. However, an individual could pursue a coaching degree (minor, bachelor's, master's, or Ph.D.) as select universities offer these degree programs ("Coaching Education Accredited Program list," n.d). However, an individual can attain a collegiate coaching position without having a collegiate coaching degree. In addition, the NCAA does not require institutions to report what academic field the coach's degree is in, and thus there is no comprehensive report on this information (T. Howes, personal communication, September 7, 2014). Most institutions do not require a coaching degree; therefore, the training and pathway an individual may take to become a collegiate coach varies.

A study was conducted with ADs across all three NCAA divisions that managed women's athletic programs on their requirements for hiring a collegiate coach (Siegl \& Newhof, 1992). The study reported that $46.7 \%$ of ADs would prefer that their institutions require a master's degree. In addition, $38.5 \%$ of the institutions that were surveyed indicated that a bachelor's degree was required while $2.4 \%$ of the institutions reported that they would hire a 
coach without a bachelor's degree. The type of degree that the intuition or AD would require or prefer a coach to obtain was not mentioned.

The postings for collegiate coaching positions also listed collegiate playing experience and/or coaching experience as a requirement for the position ("NCAA The Market," n.d.). Similarly, $60 \%$ of the institutions surveyed reported that prior coaching experience (high school and/or collegiate) was a requirement (Siegl \& Newhof, 1992). Furthermore, collegiate coaching job postings listed some of the preferred as: knowledge of NCAA rules and regulations, experience recruiting, leadership skills, effective communication skills, first aid and CPR certification, and the ability to complete additional managerial tasks ("NCAA The Market," n.d.). Many of the required and preferred criteria of the full-time collegiate coaching postings did not require any type of academic coaching education or coaching certification.

In Siegel and Newhof's study, only $6 \%$ of the institutions surveyed required their fulltime head coaches to have a coaching certification (1992). Furthermore, ADs were asked to rank the importance of coaching-related courses for future collegiate coaches. ADs ranked supervised coaching to be the most important undergraduate course, followed by the psychology of sport, organization and administration, sports medicine, and coaching pedagogy. For graduate courses, ADs ranked exercise physiology as most important, followed by the psychology of sport, organization and administration, biomechanics, coaching pedagogy, and supervised coaching. Even though ADs were asked to rank the importance of sport-specific courses, ADs were not asked their perceptions on the importance of coaching education degree programs and certifications. 


\section{Coaching education.}

Once an individual is hired as a NCAA coach, they are required to complete a yearly certification test (NCAA “Recruiting Test”, n.d.). The certification test evaluates the coach's knowledge of NCAA compliance rules for recruiting. Coaches must pass this test in order to be eligible to recruit individuals for their athletic program. Though the NCAA has limited coaching education requirements for becoming a collegiate coach, other institutions such as United States Olympic Committee (USOC), U.S. National Governing Bodies (NGB), National Coaching Accreditation for Coaching Education (NCACE), and the Society of Health and Physical Educators (SHAPE America) are advocating for formal coaching education for coaches at all competitive levels.

In 2013, National Association for Sport and Physical Education (NASPE) released a position statement on proposed prerequisites for sport coaches (NASPE, 2013). At the collegiate coaching level, the proposed requisite for coaching education for beginner collegiate coach $(5+$ years) was current first aid/CPR, code of conduct form, organizational orientation, and level five basic coaching education through an NCACE accredited program. A level five accreditation is for coaches who work with elite athletes year-round, the athletes are the highest level of amateur competition, and the content focuses on advanced techniques and tactics, training and conditioning, and professional development (NCACE, 2006). Intermediate (8+ years) and master collegiate coaches (12+ years) have the same requirements as a beginner coach plus needing to attain a sport specific national governing body (NGB) certification and a master's degree (NASPE, 2013).

In order for an institution or organization to be an accredited coaching program or organization, the institution/organization must pass a program evaluation from NCACE 
(NCACE, n.d.). NCACE evaluates the program or institution to see if all the national standards for sport coaches (NSSC) have been met. Within the NSSC, there are eight domains and 40 specific coaching standards that outline the criteria and competencies that coaches should meet (NASPE, 2006). The eight coaching domains are: (a) philosophy and ethics, (b) safety and injury prevention, (c) physical conditioning, (d) growth and development, (e) teaching and communication, (f) sports skills and tactics, (g) organization and administration, and (h) evaluation. Under each of the eight domains, there are individual standards that outline specific items that a coach should be competent.

In addition to SHAPE America advocating for collegiate coaches to have a level five coaching certification, in 2014 the USOC began complying with NSSC and created the compliance with national standards (CNS) program (USOC, n.d). The CNS encourages U.S. NGBs to adhere to the NSSC, in order to promote a safe and positive coaching environment along with quality coaching. There are currently five U.S. NGBs that meet the CNS program requirements. The five U.S. NGBs that have met the CNS program requirements are U.S.A. figure skating, U.S.A. gymnastics, U.S.A. track and field, U.S.A. weight lifting, and U.S.A. wrestling.

While the criteria for becoming a NCAA collegiate coach is set by each institution and thus the path an individual may take to become a collegiate coach varies (Siegl \& Newhof, 1992; T. Howes, personal communication, September 7, 2014). However, coaching education organizations and governing bodies are advocating for accredited coaching education certifications to promote quality coaching at all competitive levels. One way to improve the quality of collegiate coaches is to recruit college students into coaching education programs who intend to pursue collegiate coaching as a career. Unfortunately, U.S. collegiate coaching 
research has mainly focused on examining CAs and their intent to become a collegiate coach (e.g., Bernhard, 2010; Cunningham, 2003; Cunningham \& Singer, 2010; Everhart \& Chelladurai, 1998; Kamphoff \& Gill, 2008; Moran-Miller \& Flores, 2011). However, there is no research to suggest that CAs are more likely to pursue collegiate coaching as a career than other sample populations. Due to there being limited research on non-CAs intent to pursue collegiate as a career, the research on the CAs and non-CAs' major choice will be examined. Research has suggested that the variables that comprise SCCT have also been found to influence undergraduate student's major choice (e.g., Beggs, Bantham, \& Taylor, 2008; Fountain \& Finley, 2011; Malgwi, Howe, \& Burnaby, 2005; Navarro, 2014; Zafar, 2013).

\section{Undergraduate Students' Major Choice}

Pursuing a career is often associated with pursuing an academic degree program that aligns with the individual's career choice. The variables that influence an individual's career choice have also been found to influence an individual's major choice (e.g., Beggs et al., 2008; Fountain \& Finley, 2011; Malgwi et al., 2005; Navarro, 2014; Zafar, 2013). Selecting an academic major can be influenced by different factors such as interest, job opportunity, perceived outcome expectations, knowledge of the field (Beggs et al., 2008; Malgwi et al., 2005), faculty role model influence (Rask \& Bailey, 2002), parental approval (Zafar, 2013), parental occupation, and socioeconomic status (Leppel, Williams, \& Waldauer, 2001; Saks \& Shore, 2005). Researchers have also examined the differences in academic major choice between demographic groups, specifically gender and ethnicity (Dickson, 2010; Leppel et al., 2001; Malgwi et al., 2005). In addition, it has been suggested that CAs' major choice can also be influenced by their coach, athletic advisor, and meeting NCAA eligibility standards for degree completion (Fountain \& Finley, 2009 \& 2011; NCAA “Remaining Eligible”, n.d.). 


\section{Non-collegiate athletes' major choice.}

Research has suggested that both male and female undergraduate students report interest in the subject area as the most important factor when selecting a major (Adams, Pryor, \& Adams, 1994; Beggs et al., 2008; Malgwi et al., 2005). The next most influential factor when choosing a major for women was knowledge in the subject area (Malgwi et al., 2005). However, men reported job opportunities, career advancement, and compensation higher than women. College students were more influenced to change majors upon learning new positive factors about a major, than changing because of negative factors related to their old major.

Researchers have also examined the influence of family and peers on an individual's decision to select a major (Leppel et al., 2001; Rask \& Bailey, 2002; Zafar, 2013). In a study completed on undergraduate students' major choice, the study indicated that students who had taken classes with faculty who were "like them", had a positive effect on students choosing that major (Rask \& Bailey, 2002). Not only does faculty role model influence play a factor in an individual's major selection, but so does parental approval (Zafar, 2013). Parental approval was one of the two highest factors (the other was enjoying coursework) that undergraduate students reported as influencing their major choices.

Parental occupation has also indicated to have an influence on an individual's major choice (Leppel et al., 2001). Both male and female students whose father held an executive or professional occupation were more likely to choose a science or engineering major. The impact of a parent having an executive or professional occupation was greater for females when the parent was a male. However, female students whose mother was in an executive or professional occupation were less likely to pursue education as a major. 
In addition to parental occupation, the impact of socioeconomic on female's major choice was greater than it was in males (Leppel et al., 2001). Male students who came from a business family were more likely to pursue a major in business compared to females. A similar study found that students' with a higher level of socioeconomic status were more likely to pursue a major that is considered riskier for gaining employment such as entertainment, sales, and business compared to student with a lower level of socioeconomic status (Saks \& Shore, 2005). Students with a lower level of socioeconomic status tending to choose a safer career choice such as health care, education, and engineering.

\section{Collegiate athletes' major choice.}

CAs are influenced by the same factors as non-collegiate athlete students when selecting a major; however, CAs are also influenced by their coaches, athletic advisors, team members, time constraints, academic skill set, professors, coursework, parents, family, interest, and meeting NCAA eligibility standards for degree completion (e.g., Fountain \& Finley, 2011; Navarro, 2014; NCAA "Remaining Eligible”, n.d.). In order for a NCAA CA to remain eligible to play, the athlete must follow the academic progress rate; this is also known as the 40/60/80 rule for degree completion (NCAA "Remaining Eligible", n.d.). CAs must complete $40 \%$ of their bachelor degree program by the end of their second year, complete $60 \%$ by the end of their third year, and complete $80 \%$ by the end of their fourth year to remain eligible.

The 40/60/80 rule was implemented to help increase the chances of CAs graduating with a degree, but it has also contributed to CAs being advised by academic advisors, coaches, and teammates to go into certain majors that are flexible to athletic schedules, has manageable coursework, and or to ensure degree progress (Fountain \& Finley, 2011). The term academic 
clustering refers to when $25 \%$ or more of a team have the same major (Case, Greer, \& Brown, 1987).

A study of academic clustering reported that African American male CAs that were high profile athletes were more likely to be clustered into social sciences (economics, social science, sociology, criminology, psychology, kinesiology, political science, and history) than females and other ethnicities (Sanders \& Hildenbrand, 2010). The findings also suggested that clustering became more prevalent as the athletes approached graduation. Sixty-four percent of African American male athletes were declared a social science major by their eighth semester.

Similar findings also suggested clustering of Division I football players in social science majors (Bernhard, 2010; Schneider, Ross, \& Fisher, 2010). One study reported 31\% of Division I football players were social science majors and $10 \%$ were sports management/sports administration majors (Bernhard, 2010). The other study reported 30.6\% of the football players were in social science major, and $21 \%$ were in business major (management, marketing, finance, or accounting) (Schneider et al., 2010). Additional studies have also found numerous universities who demonstrated academic clustering of football CAs (Bernhard, 2010; Fountain \& Finely, 2009, 2011). Clustering has also been reported in non-revenue producing sports and occurring to male and female CAs (Harrison \& Lawrence, 2004).

Research has suggested that interest and knowledge of the subject area, outcome expectations, perceptions of supports and barriers within the major, support from family and peers for major selection, faculty role model influence, parental occupation, and socioeconomic status can influence a college students' major choice (e.g., Beggs et al., 2008; Leppel et al., 2001; Malgwi et al., 2005; Rask \& Bailey, 2002; Saks \& Shore, 2005; Zafar, 2013). In addition, CAs are also influenced by their peers (teammates, coaches, athletic advisors, parents, and 
family), interest, and academic factors (eligibility status, coursework, and their academic skill set) (e.g., Fountain \& Finley, 2009, 2011; Navarro, 2014). Many of the factors that have been found to influence CAs and college students who are not CAs' major choice align with the variables that comprise SCCT. SCCT was applied to examine the differences among CAs, AMs, and SSMs level of intent to pursue full-time collegiate coaching as a career.

\section{Conclusion}

The research on individuals' intent to pursue collegiate coaching as a career is limited through the lens of SCCT and has focused only on CAs (Cunningham \& Singer, 2010; MoranMiller \& Flores, 2011). However, the research surrounding coaching and the predictive variables that comprise SCCT is substantial (e.g., Cunningham \& Singer, 2010; Kamphoff, 2010; LaVoi \& Dutove, 2012; Moran-Miller \& Flores, 2011). Furthermore, the coaching research has focused primarily on differences between gender and ethnicities when examining an individual's intent to pursue collegiate coaching as a full-time career (e.g., Bernhard, 2010; Cunningham, 2003; Cunningham et al., 2007; Cunningham \& Singer, 2010; Kamphoff \& Gill, 2008).

Research suggests that career models are important and can influence an individual's intent to pursue a career (Lent et al., 1994, 2000; Paa \& McWhirter, 2000). Within NCAA collegiate coaching, there is a lack of female and ethnicity minority coaches to serve as career role models (Acosta \& Carpenter, 2014; Lapchick, 2010). Additionally, an individual's personal inputs (gender and ethnicity) can impact the number and type of barriers that are perceived within a career (e.g., Bernhard, 2010; Cunningham et al., 2007; Cunningham et al., 2003). Furthermore, there are numerous contextual barriers that an individual may perceive when trying to enter collegiate coaching such as discriminating hiring practices, lack of networking, sexism, work and family conflict, gender discrimination, and homophobia (e.g., Acosta \& Carpenter, 
2014; Kamphoff, 2010; LaVoi \& Dutove, 2012; Walker \& Satore-Baldwin, 2013). Lack of pay is also suggested to be a perceived outcome expectation and potential barrier (Cooper et al., 2007; LaVoi \& Dutove, 2012). However, research also suggests that having support from family, friends, peers, and administrators can positively influence an individual's intent to pursue collegiate coaching as a career and decrease attrition rates (e.g., Blom et al., 2011; Cunningham \& Singer, 2010; Kamphoff et al., 2010; LaVoi \& Dutove, 2012).

An individual's level of coaching self-efficacy is suggested to be predictive of an individual's level of intent to pursue coaching (Cunningham et al., 2003; Everhart \& Chelladurai, 1998). Additionally, an individual's years of coaching experience and playing experience (learning experiences) can influence an individual's level of coaching self-efficacy (e.g., Feltz et al., 1999, 2009; Helper et al., 2007; Kavussanu et al., 2008). Some coaching research suggests that females and ethnic minority CAs have lower levels of self-efficacy compared to males and Caucasian CAs (Cunningham et al., 2003, 2007; Bernhard, 2010) while other coaching research suggests there are no significant differences (Cunningham \& Singer, 2010).

Coaching research suggests that females and ethnic minorities perceive more barriers (e.g., Bernhard, 2010; Cunningham et al., 2003, 2007); however, ethnic minorities reported having a higher level of outcome expectations and intent than Caucasians (Cunningham \& Singer, 2010). Yet, Cunningham's earlier study (2003) did suggest that racial minorities were less interested in becoming a collegiate coach and Sagas's study suggested that females had a lower level of intent on becoming a head coach (Sagas et al., 2006a). It is also suggested that female CAs have greater intent to coach full-time at the youth sport/community/recreational level (Kamphoff \& Gill, 2008) and male CAs have greater intent to coach full-time at the high 
school, Division I, and professional level (Everhart \& Chelladurai, 1998; Kamphoff \& Gill, 2008).

In order to increase the understanding of how and why an individual would pursue a career in collegiate coaching, future research should include a sample beyond CAs. Examining personal inputs other than gender and ethnicity and factoring in background contextual affordances such as coaching and playing experience, researchers can better understand the impact personal inputs and background contextual affordances can have on an individual's intent to pursue collegiate coaching as a career. Examining CAs, AMs, and SSMs will shed light on researchers' assumption that CAs are more likely to become collegiate coaches than other sample populations. Furthermore, if there is a significant number of CAs who want to become collegiate coaches, but are not pursuing a SSM, steps can be taken to recruit SSMs into coaching education programs for formal training.

\section{Proposed Study}

Based on the coaching research that has used SCCT and the coaching research on the variables that comprise SCCT, this study sought to explore the differences among CAs', AMs', and SSMs' level of intent to pursue full-time collegiate coaching as a career. Specifically, the study explored the following research questions: (1) were there differences among the three groups' level of intent in pursuing a career as a full-time collegiate coach, (2) were there differences among the three groups' level of perceived supports for entering collegiate coaching, (3) were there differences among the three groups' level of collegiate coaching self-efficacy, (4) were there differences among the three groups' level of perceived barriers to entering collegiate coaching, (5) were there differences among the three groups' desire to coach full-time at 2-year colleges, Division III, Division II, and Division I, and (6) of the evaluated independent variables 
(collegiate coaching self-efficacy, supports, and barriers), which predicted CAs', SSMs', and AMs' level of intent (dependent variable) to pursue full-time collegiate coaching as a career. Based on an evaluation of the current literature, the following hypotheses have been created for each research question. In response to research question (1) AMs will report having the highest level of intent to become a full-time collegiate coach compared to SSMs and CAs, (2) AMs will report having the highest level of perceived supports for entering collegiate coaching compared to SSMs and CAs, (3) AMs will report having the highest level of perceived collegiate coaching self-efficacy compared to SSMs and CAs, (4) AMs will report having the highest level of perceived barriers for entering collegiate coaching, compared to CAs and SSMs, (5) AMs will report having the highest level of desire to coach at all four levels (2-year colleges, DIII, DII, and DI), compared to CAs and AMs, and (6) the level of perceived barriers when entering collegiate coaching will have the strongest prediction of a CAs' and AMs' intent to become a full-time collegiate coach and perceived supports will have the strongest prediction of SSMs' intent to become a full-time collegiate coach. 


\section{Chapter 3}

\section{Methodology}

The methods will be presented in three sections. The first section describes the criteria used for sample selection and participants. The second section provides an overview of the instruments and survey construction. The third section outlines the procedures used during data collection and clean-up.

\section{Participants}

Purposive sampling was used to survey and explore SMMs', CAs', and AMs' levels of: intent to pursue full-time collegiate coaching as a career, desire to pursue collegiate coaching at the NCAA Division I, Division II, Division III, and two-year college level, perceived supports for entering collegiate coaching, collegiate coaching self-efficacy, and perceived barriers to entry into collegiate coaching.

The groups of participants were created based on a set of criteria (Patton, 1990). To participate in the study, the individual needed to be a current Division I varsity CA, a full-time undergraduate student pursuing an SSM, or a CA purseing a SMM (AM). The sample groups all came from the same land-grant university. The university had a large sport science department with a wide range of sport-related majors including athletic coaching, athletic training, exercise physiology, physical education, sport and exercise psychology, and sport management. The university was a part of NCAA Division I athletics and only non-revenue producing varsity sports teams were surveyed.

There were a total of 729 participants in the study. The sample included: $24.4 \%$ freshmen $(n=178), 18.2 \%$ sophomores $(n=133), 20.9 \%$ juniors $(n=152), 22.8 \%$ seniors $(n=$ $166), 5.5 \% 5^{\text {th }}$ year students $(n=40), 0.1 \% 6^{\text {th }}$ year student $(n=1)$, and $8.1 \%$ did not indicate 
their class rank $(n=59)$. In terms of gender, $42.4 \%$ were females $(n=309), 56.1 \%$ were males $(n=409)$, and $1.5 \%$ did not indicate their gender $(n=11)$. The range of age was $18-36$ years $(M$ $=20.01, S D=1.79)$. The breakdown of ethnicity was $83.4 \%$ Caucasian $(n=608), 8.9 \%$ African American $(n=65), 7.2 \%$ were another minority ethnicity $(n=53)$, and $0.4 \%$ did not indicated their ethnicity $(n=3)$. Demographic information for each sample group can be found in Table 1 . Of the total sample, $73.3 \%$ were SSMs $(n=535), 18.2 \%$ were CAs $(n=132)$, and $8.5 \%$ were AMs $(n=62)$. The SSM group was comprised of the following sport science majors: $9.3 \%$ athletic coaching education $(n=50), 15.9 \%$ athletic training $(n=85), 4.3 \%$ exercise physiology $(n=23), 8.8 \%$ physical education $(n=47), 40.7 \%$ sport and exercise psychology $(n=218)$, and $18.7 \%$ sport management $(n=100)$. The SSM sample included: $23.0 \%$ freshmen $(n=123)$, $17.0 \%$ sophomores $(n=91), 21.7 \%$ juniors $(n=116), 24.7 \%$ seniors $(n=132)$, and $7.1 \% 5^{\text {th }}$ year students $(n=38)$. In terms of gender, $40.2 \%$ were female $(n=215)$ and $58.7 \%$ were male $(n=$ 314). The range of age was $18-36$ years $(M=20.15, S D=1.91)$. Participants were $84.3 \%$ Caucasian $(n=451), 8.8 \%$ African American $(n=47)$, and $6.1 \%$ were another ethnicity $(n=33)$. The demographic information for SSMs can be found in Table 1 and major selection information can be found in Table 2 .

The CA group was comprised of the following varsity collegiate teams: $17.4 \%$ baseball $(n=23), 11.4 \%$ men's soccer $(n=15), 0.8 \%$ women's soccer $(n=1), 5.3 \%$ rifle $(n=7), 26.5 \%$ rowing $(n=35), 26.5 \%$ swimming and diving $(n=35,0.8 \%$ women's tennis $(n=1), 5.3 \%$ volleyball $(n=7), 0.8 \%$ wrestling $(n=1)$, and $5.3 \%$ x-country and track $(n=7)$. The CA sample included: $30.3 \%$ freshmen $(n=40), 22.0 \%$ sophomores $(n=29), 19.7 \%$ juniors $(n=26)$, and $17.4 \%$ seniors $(n=23)$. In terms of gender, $52.3 \%$ were females $(n=69)$ and $45.5 \%$ were males $(n=60)$. The age of the CA group ranged from $18-24$ years of age $(M=19.58, S D=1.27)$. The 
participants were $84.8 \%$ Caucasian $(n=112), 6.8 \%$ were African American $(n=9)$, and $8.3 \%$ were another ethnicity $(n=11)$. The CA demographic information is located in Table 1 and varsity sports information in Table 3.

The AM group was comprised of the following sport science majors: $22.6 \%$ athletic coaching education $(n=14), 24.2 \%$ exercise physiology $(n=15), 3.2 \%$ physical education $(n=$ 2), $24.2 \%$ sport and exercise psychology $(n=15)$, and $24.2 \%$ sport management $(n=15)$. The AM group was comprised of the following varsity teams: $14.5 \%$ baseball $(n=9), 1.6 \%$ men's basketball $(n=1), 1.6 \%$ women's basketball $(n=1), 8.1 \%$ men's soccer $(n=5), 6.5 \%$ women's soccer $(n=4), 1.6 \%$ rifle $(n=1), 12.9 \%$ rowing $(n=8), 19.4 \%$ swimming and diving $(n=12)$, $1.6 \%$ women's tennis $(n=1), 4.8 \%$ volleyball $(n=3), 3.2 \%$ wrestling $(n=2)$, and $8.1 \% \mathrm{x}-$ country and track $(n=5)$. The AM sample included: $24.2 \%$ freshmen $(n=15), 21.0 \%$ sophomores $(n=13), 16.1 \%$ juniors $(n=10)$, and $17.7 \%$ seniors $(n=11)$. In terms of gender, $40.3 \%$ were female $(n=25)$ and $56.5 \%$ were male $(n=35)$. The range of age of the AM group was 18 -24 years $(M=19.69, S D=1.43)$. Participants were $72.6 \%$ Caucasian $(n=45), 14.5 \%$ African American $(n=9)$, and $11.9 \%$ were another ethnicity $(n=7)$. The demographic information for AMs can be found in Table 1, major selection in Table 2, and varsity sports information in Table 3.

\section{Instruments and Survey Construction}

All participants completed a paper-based survey that contained a series of questionnaires that explored their: (a) intent to pursue full-time collegiate coaching as a career (Appendix B; Cunningham \& Singer, 2010), (b) desire to pursue collegiate coaching at NCAA Division I, Division II, Division III, and two-year college level (Appendix C; Everhart, 1994), (c) perceived supports for entering collegiate coaching (Appendix D; Cunningham \& Singer, 2010), (d) 
perceived collegiate coaching self-efficacy (Appendix E; Everhart, 1994), and (e) perceived barriers to entry into collegiate coaching (Appendix F; Kamphoff \& Gill, 2008). In addition, participants were asked open ended questions about what has influenced their view about collegiate coaching as a profession (Appendix N) and demographic questions (Appendix $\mathrm{G}$ ).

\section{Coaching intention scale.}

Section one of the survey (Appendix B) incorporated the Coaching Intention Scale (CIS; Cunninghman \& Singer, 2010). The CIS measures an individual's level of intent to pursue collegiate coaching as a career. The CIS was adapted from Hagger and colleagues Intention Scale that measures an individual's level of intent towards physical activity using the theory of planned behavior (Hagger, Chatzisarantis, \& Biddle, 2001). The Intention Scale assesses an individual's level of intent based upon how strongly one plans to, intend to, and would try to complete a certain task or behavior. Cunningham and colleagues applied the Intention Scale to measure an assistant coach's intent to become a head coach (CIS; Cunningham, Doherty, \& Gregg, 2007). The CIS was also applied to CAs to measure their level of intent to become a college coach after graduation (Cunningham \& Singer, 2010).

The CIS contains three items that ask the participant to indicate on a 7-point Likert scale $(1=$ strongly agree to $7=$ strongly disagree $)$ one's intentions of becoming a full-time collegiate coach. For this study, the scoring of CIS scale was reversed $(1=$ strongly disagree to $7=$ strongly agree) to provide consistency among the scales and reduce potential participant confusion. The three items on the CIS are "I plan to become a full-time collegiate coach as a career," "I intend to become a full-time collegiate coach as a career," and "I would try to become a full-time collegiate coach as a career." The CIS demonstrated an acceptable level of reliability $(\alpha=.93$ - .76; Cunningham et al., 2007; Cunningham \& Singer, 2010). 


\section{Support scale.}

Section two of the survey (Appendix C) incorporated the Support Scale (SS; Cunningham $\&$ Singer, 2010). The SS measures a number of contextual supports an individual perceives when entering collegiate coaching. Items from the SS were drawn from Cunningham and colleagues' Contextual Supports and Barriers Scale (CSBS; Cunningham, Bruening, Sartore, Sagas, \& Fink, 2005). The subscale of the CSBS contained 7 items that measure an individual's level of perceived supports on a 7-point Likert scale $(1=$ strongly disagree to $7=$ strongly agree $)$ concerning the sport and leisure industry (Cunningham et al., 2005). The CSBS scale was then applied to CAs to measure their perceived level of supports (SS) for becoming a collegiate coach (Cunningham \& Singer, 2010). Sample items from the SS include "I have sufficient contacts to help me become a college coach," "I have the experience needed to become a college coach," and "I have a large enough network contacts to make entering the collegiate coaching profession possible." One item on the items on the SS is negatively worded, and thus was reverse-scored during data analysis. The SS has demonstrated an acceptable level of reliability $(\alpha=.82-.89$; Cunningham, Doherty, \& Gregg, 2007; Cunningham \& Singer, 2010).

\section{Coaching self-efficacy scale.}

Section three of the survey (Appendix D) incorporated the Coaching Self-Efficacy Scale (CSES; Everhart, 1994). The CSES measures an individual's level of perceived self-efficacy in coaching. The scale contains 35 items, in which the participants indicate on a 9-point Likert scale $(1=$ no confidence to $9=$ complete confidence $)$ their level of confidence in completing a variety of coaching-related tasks. Everhart's CSES was selected for this study because the items within the scale include coaching-related tasks that are associated with collegiate coaching. Sample items include "effectively manage the recruiting process," "control players and assistant 
coaches in game situations," and "select players best suited for your strategies." The CSES has demonstrated an acceptable level of reliability $(\alpha=.96-.82$; Everhart \& Chelladurai, 1994; Cunningham \& Singer, 2010).

\section{Perceived hindrance scale.}

Section four of the survey (Appendix E) incorporated the Perceived Hindrance Scale (PHS; Kamphoff \& Gill, 2008). The PHS measures an individual's level of perceived hindrances (barriers) for entry into collegiate coaching. The PHS has evolved to reflect current barriers within collegiate coaching. The original PHS was constructed by the NCAA in 1989, and contained 13 items that measured female CAs' perception of the barriers within intercollegiate athletics (NCAA, 1989). These items focused on work/family conflict, time commitment, job opportunities (salary and promotions), and external pressures (parents, media, other coaches, and alumni). Twelve more items were added to the PHS to measure the level of perceived discrimination as a barrier for women in collegiate coaching (Everhart \& Chelladurai, 1998). These 12 items focused on organizational constructs (hiring processes, treatment of women, support from supervisors, and information access), fear of being considered unattractive or unfeminine, lack of acceptance by male coaches and players, lack of support from male and female coaches, and lack of an informal work group for women. In 2008, Kamphoff and Gill added nine additional items to the PHS following a pilot study. These nine items focused on measuring barriers that were not previously on the scale, barriers regarding gender and ethnicity.

Kamphoff and Gill's version of the PHS (2008) was used for this study. The PHS contains 34 items that ask the participant to indicate on a 9-point Likert scale $(1=$ would not hinder at all to $9=$ completely hinder) how much of a perceived hindrance each item is in for entering collegiate coaching. The 35 items are categorized into five sub-scales: (a) minority and 
gender bias, (b) gender issues, (c) nature of coaching, (d) conflict with others, and (e)

professional issues. Sample items include "coaching takes too much time," "coaching conflicts with family commitments," "low salary," "perceptions of homosexuality among coaches," and "racial/ethnic minority coaches are treated unfairly." The PHS has demonstrated an acceptable level of reliability ( $\alpha=.87-.94$; Everhart \& Chelladurai, 1998, 2004). However, Kamphoff and Gill did not report a level of reliability for the PHS (2008) because each item within the scale was treated as a single-item scale.

\section{Desire to coach scale.}

Section five of the survey (Appendix F) incorporated the Desire to Coach Scale (DCS) (Everhart, 1994). The DCS measures how interested an individual is in becoming a paid fulltime coach at various collegiate levels. The DCS asked participants to indicate on a 9-point Likert scale $(1=$ not at all to $9=$ very much) their level of interest to coach full-time at five different levels: (a) high school, (b) 2-year colleges, (c) NCAA Division III institutions, (d) NCAA Division II institutions, and (e) NCAA Division I institutions. No reliability scores have been reported for the DCS, due to the items on the scale being treated as a single-item scale.

\section{Demographics.}

The sixth and final section of the survey (Appendix G) asked participants to answer eight demographic questions. The demographic questions included: (a) age, (b) gender, (c) ethnicity, (d) class rank, (e) intended major(s), (f) why they choose their major, (g) what career do they intend to pursue after graduation, (h) intended minor(s), (i) level of athletic participation in high school and collegiate sport, (j) coaching experience, and (k) if they intend to pursue collegiate coaching as a career and explain why or why not. 


\section{Survey construction.}

Due to the length of the survey, steps were implemented to check for response validity. Two check for reading questions were inserted on items 15 and 30 of the CSES and PHS. Item 15 of the CSES and PHS asked the participant to select number two and on item 30 of the CSES and PHS participants were asked to select number eight. This measure was implemented to ensure participants were reading the questions before selecting their answers. Response rates for CSES and PHS check for reading questions are presented in the procedures section.

\section{Procedures}

Internal Review Board (IRB) approval was obtained prior to the start of the study. The department chair of the introductory and major sport studies courses was contacted via e-mail about the study (Appendix H). The e-mail included the purpose of the study, IRB approval number, and permission to speak to the instructors of the sports studies introductory and major courses about having their students complete the survey. Once permission to conduct the study was granted, the course instructors were contacted via e-mail for permission to survey their students (Appendix I). The course instructors were e-mailed about the purpose of study, IRB approval number, and an explanation that the survey is paper-based and will take approximately 15 minutes to complete. After permission was granted, time and date for the lead researcher to administer the survey was set.

The associate athletic director was contacted via e-mail about the study (Appendix J), to survey the CAs. The e-mail included the purpose of the study, IRB approval number, and permission to speak to the head coaches of the teams about having the athletes complete the survey. Once permission was granted to conduct the study, the head coaches of the varsity sports teams were contacted for permission to survey their athletes. The e-mail included the purpose of 
study, IRB approval number, and that the survey is paper-based and will take approximately 15 minutes to complete (Appendix K). After permission was granted by the head coaches to survey their athletes, a time and date for the lead researcher to administer the survey in practice was set.

Before administering the survey, the lead researcher read the survey script (Appendix L) to the participants that explained the purpose of the study, that their participation is strictly voluntary and that there is no punishment or reward associated with the study, explained the entry for gift card, that they must be least 18 years of age, that survey should take approximately 15 minutes to complete, and that they have taken the survey already, they should not take it again. This information, along with additional information concerning the study was stated on the participant cover letter (Appendix M) that was attached to the front of each survey (Appendix N)

Completed surveys remained in a secure folder in the lead researcher's possession until the completion of the study; at which point the surveys will be shredded. Only the lead researcher and co-investigators had access to the raw data. Each completed survey was numbered and entered in to Excel using a code sheet. After all the surveys were entered in to Excel, the original file was saved and a duplicate file was created to clean and prepare the data for analysis.

The duplicate file containing all the surveys was then uploaded to SPSS 23.0 for data cleanup. Survey items that were not answered or were answered incorrectly (circled two answers or out-of-range) were left blank for data analysis. The open-ended questions regarding the participant's major selection, ethnicity, and collegiate sport were reformatted into a numerical representation for data analysis. Due to question seven on the SS being negatively worded, this item was reversed scored before data analysis. Responses were removed from the 
CSES and/or the PHS if the participant did not correctly answer both check for reading questions for each scale. Out of the 729 completed surveys, 658 passed the CSES (90.2\%) and 666 passed the PHS $(91.3 \%)$ check for reading questions. There were $634(86.9 \%)$ surveys that passed both check for readings questions on the CSES and PHS. After the data was cleaned, mean scores were then calculated for the CIS, DCS, CSES, SS, and the five sub-scales of the PHS.

Open-ended questions were removed and entered in to a separate file for content analysis. The raw data points were grouped into major themes and sub-themes that were identified by the primary investigator. A second independent reviewer then reviewed the major themes and subthemes and revisions were made until a consensus was reached. The primary researcher then coded each raw data response based upon the identified themes. A reliability check was then employed on one third of the raw data points to ensure the coding met at least $80 \%$ agreement, as recommended by Krippendorff (1980). If there were any discrepancies, the items were discussed until an agreement was reached. This process was completed for the open-ended questions concerning their major selection and intent to become a full-time collegiate coach. Example responses, along with supporting research, were given in the discussion section. 


\section{Chapter 4}

\section{Results}

To explore this study's research questions, a variety of statistical analysis were employed once the data were prepared. Descriptive statistics were compiled for the demographic questions regarding age, gender, ethnicity, class rank, intended major, and varsity sport participation, which are reported in Tables 1-3. Descriptive statistics were also compiled for the DCS (Everhart, 1994; Table 6), CIS (Cunningham \& Singer, 2010; Table 4), SS (Cunningham \& Singer, 2010; Table 4), CSES (Everhart, 1994; Table 4), and PHS (Kamphoff \& Gill, 2008; Table 5). After descriptive statistics were compiled, steps were taken to examine and control the effect of the confounding variables gender, ethnicity, and class rank before data analysis.

ANOVAS were ran for each of the confounding variables (gender, ethnicity, and class rank), to examine if there was a statistically significant difference $(p<.05)$ among the three groups. The only confounding variable that had a statistically significant difference among the three groups was class rank. Follow-up ANOVAS were then ran for each of the study's research questions to examine if there was a statistically significant difference among class rank for each predictive variable. There were statistically significant differences among class ranks for PHS 1 and PHS 2. These differences are reported in research question number four. A follow-up MANOVA was then employed to examine the effects class rank and group membership had on the predictive variables that impact intent (research question six). Due to small sample sizes, no significant differences were found for PHS 1 and PHS 2. Thus, the results for sub-scales PHS 1 and PHS 2 should be interpreted with caution.

After examining and controlling for confounding variables, the study's research questions were then examined. To examine the study's research questions, descriptive analysis, ANOVAS, multiple regressions, and a content analysis were employed. Descriptive analysis 
were run to determine the mean, range, and standard deviations of survey responses. ANOVAS were utilized for research questions one through five to determine if there were any statistically significant differences among three groups (SSM, CA, and AM). Multiple regressions were applied to research question six that examined which independent variable impacted each group's level of intent (dependent variable) to become a full-time collegiate coach. Content analysis were applied to the open-ended questions regarding individuals' major choice and intent to pursue collegiate coaching as a career. For all statistical analysis, the significance level was set at an alpha level of .05.

Prior to running data analysis, the assumption of normality of the data distribution for each predictive variable (CIS, DCS, PHS, and SS) were tested. Each predictive variable's skewness and Kurtosis levels were one or below except for the PHS5 (skew -1.42; Kurtosis 3.23). A reflected $\log 10$ transformation was run on the PHS5. After the data were transformed for PHS5, skew and Kurtosis were then below one. The Kolmogorov-Smirnov (K-S) test was selected as a parametric test to assess normality due to the sample sizes being larger than 50 and unequal. The K-S test was run for each predictive variable and none of the predictive variables were normally distributed (<.05). Thus, each variable was also assessed visually for normality using Q-Q plots, P-P plots, box plots, and histograms. Outliers were removed if they were more than two standard deviations away from the mean, were above the critical value $(p<.05)$ on Mahalanobis distance (Barnett \& Lewis, 1978) or more than one on Cook's distance (Cook \& Weisberg, 1982). If Levene's test of homogeneity was violated $(p<.05)$, the Kruskal-Wallis $\mathrm{H}$ test was used as the non-parametric test. The Kruskal-Wallis test was selected because there were more than two comparison groups. For statistically significant non-parametric tests, the 
Mann-Whiney U post-hoc was utilized. Games-Howell post-hoc was chosen for significant parametric tests due to the unequal sample sizes and unequal variances.

ANOVAs were run to examine if there were significant differences among the three groups (CA, SSM, and AM) when considering level of intent to become a full-time collegiate coach, perceived supports for entry into collegiate coaching, collegiate coaching self-efficacy, perceived barriers for entry into collegiate coaching, and desire to coach full-time at 2-year colleges, Division III, Division II, and Division I.

\section{Research Question 1}

An ANOVA was conducted for research question one to determine if there were significant differences among the three group's (SSM, CA, and AM) level of intent to become a full-time collegiate coach. Prior to running the ANOVA, it was determined that the data were not normally distributed according to visual inspection of the Q-Q plots, P-P plots, box plots, and histograms. However, there were no outliers that needed to be removed based upon their standard deviation, Mahalanobis distance, and Cook's distance. The assumption of homogeneity was violated according to Levene's $F$ test, $[F(2,726)=18.21, p=.000]$. The Kruskal-Wallis non-parametric test was conducted and revealed that intent varied significantly across group membership (SSM, CA, and AM), $\chi^{2}(2)=26.01, p<.05$. Thus, the null hypothesis of no differences between groups was rejected. To examine the differences between the three means further, Mann-Whiney U post-hoc was utilized. SMMs $(M=2.68, S D=1.91)$ had a statistically significant higher mean level of intent than CAs $(M=2.07, S D=1.38)$. AMs $(M=3.71, S D=$ 1.89) had a statistically significant higher mean level of intent than SMMs $(M=2.68, S D=$ 1.91). Finally, AMs $(M=3.71, S D=1.89)$ had a statistically significant higher mean level of 
intent than CAs $(M=2.07, S D=1.38)$. The means and standard deviations for research question one are located in Table 4 and non-parametric results are located in Table 7.

Participants were also asked the open-ended question "Do you intend to pursue collegiate coaching as a career?" If the participant responded yes, then they were asked "If yes, what has influenced your decision to pursue collegiate coaching as a career?" If the participant answered no, then they were asked "If no, why have you decided not to pursue collegiate coaching as a career?" Participants' responses were coded using raw data points. Of the 729 completed surveys, 147 participants indicated yes $(20.16 \%)$, providing 188 raw responses, 543 indicated no (74.48\%), providing 575 raw data points, 27 were undecided (3.70\%), and $12(1.64 \%)$ did not answer the question. Results reflect the number of raw data points that were coded for each major theme and sub-theme.

A separate content analysis was performed on the yes and no responses for intent to become a collegiate coach. The raw data points were grouped into major themes and sub-themes that were identified by the primary investigator. A second independent reviewer then reviewed the major themes and sub-themes; revisions were made until a consensus was reached. The researcher then coded each raw data point based upon the identified themes. A reliability check was then employed on one third of the raw data points to ensure the coding met at least $80 \%$ agreement, as recommended by Krippendorff (1980). If there were any discrepancies, the items were discussed until an agreement was reached.

The following five major themes emerged from participants that indicated yes, they do intend to pursue collegiate coaching as a career. Love of sports accounted for 64 of the 188 raw data points (34.0\%), sport experiences 42 (22.3\%), influencing factors 35 (18.6\%), desire to make a difference $25(14.1 \%)$, and suitability $22(11.7 \%)$. The major theme love of sport, was 
comprised of four sub-themes: passion for sports (45), stay involved in sports (12), interest in sports (4), and love working with athletes (3). The second largest major theme was sport experiences, and this theme had four sub-themes: playing experiences (21), coaching experience (10), sport experiences undefined (6), and experience working with teams (5). Sport experiences undefined refers to raw data points that did not specify the type of sport experience. The subtheme experience working with teams included coaching internships and working as a graduate assistant or student manager for a varsity collegiate sport team. The third largest major theme was influencing factors, which was made up of seven sub-themes: previous coaches (19), family (6), schooling (3), connections (2), media (2), salary (2), and opportunities (1). The fourth largest theme was desire to make a difference, which was made up of five sub-themes: improve athletes (12), share knowledge (5), share passion (3), to give back (3), and influence others (2). The final major theme was suitability, which was made up six sub-themes: coach at a high level (7), atmosphere (4), be a good coach (3), competitive (3), knowledge (3), and confidence (2). In the context of this study, suitability refers to the reasons why the individual feels they would be a good fit for collegiate coaching. The major themes, sub-themes, and the number of raw data points for the yes responses are presented in Table 18.

There were five major themes that emerged from the participants that indicated no they do not intend to pursue collegiate coaching as a career. Influencing factors accounted for 308 of the 575 raw data points $(53.5 \%)$, perceived professional barriers $133(23.1 \%)$, interested in coaching at a different level $64(11.1 \%)$, job qualifications $62(10.7 \%)$, and negative experiences $8(1.3 \%)$. Influencing factors was the largest major theme and was comprised of seven subthemes: pursuing a different profession (73), no interest (75), not suited for me (69), other interest (29), not my passion (14), and better career options (10). The major theme perceived 
professional barriers for collegiate coaching was broken down into ten sub-themes: low salary (30), long work hours (26), high pressure and stress (17), lack of job stability (16), difficult entry (12), limited job availability (15), conflict with family time (7), too competitive (6), discrimination (2), and politics (2). The third largest major theme was interest to coach at different level than the collegiate and had four sub-themes: high school (27), youth sport (9), recreationally (8), and professional level (4). The recreational level was comprised of coaching recreationally, as a hobby or volunteer. The fourth largest major theme was job qualifications and had seven sub-themes: lacking experience (15), not a good fit (14), not qualified (11), not good at it (9), lacking skills or training (5), lack of playing experience (5), and lacking confidence (3). The last and smallest major theme was negative experiences and only had two sub-themes: burnout (6) and negative experience with a coach (2). Example raw data points for burnout include 'Done with the sport', 'Just been around the game too much', and 'Rowing is not fun, four years is enough.' The major themes, sub-themes, and the number of raw data points for the no responses are presented in Table 19.

\section{Research Question 2}

An ANOVA was conducted for research question two to determine if there were significant differences among the three group's (SSM, CA, and AM) level of perceived supports for entering collegiate coaching. Prior to running the ANOVA, it was determined that the data were not normally distributed according to visual inspections of the Q-Q plots, P-P plots, box plots, and histograms. There were six cases that were above the critical value (5.991), resulting in these six cases being removed prior to data analysis, to prevent the results from being skewed. The assumption of homogeneity was evaluated and was met based upon Levene's $F$ test, [ $F(2$, $720)=.389, p=.678]$. 
The independent between-groups ANOVA produced a statistically significant effect, $[F(2,720)=37.146, p=.000]$. Thus, the null hypothesis of no differences between groups was rejected. To examine the differences between the three means further, the statistically significant ANOVA was followed-up with Games-Howell post-hoc. CAs $(M=3.51, S D=1.56)$ had a statistically significant higher mean level of supports than SMMs $(M=2.73, S D=1.46)$. AMs $(M=4.24, S D=1.48)$ had a statistically significant higher mean level of supports than SMMs $(M=2.73, S D=1.46)$. Finally, AMs $(M=4.24, S D=1.48)$ had a statistically significant higher mean level of supports than CAs $(M=3.51, S D=1.56)$. The means and standard deviations for research question two are located in Table 4 and ANOVA results are located in Table 9.

\section{Research Question 3}

An ANOVA was conducted for research question three to determine if there were significant differences among the three group's (SSM, CA, and AM) level of collegiate coaching self-efficacy by conducting an ANOVA. Prior to running the ANOVA, it was determined that the data were normally distributed according to visual inspections of the Q-Q plots, P-P plots, box plots, and histograms. There were 18 cases above the critical value (5.991), resulting in these 18 cases being removed prior to data analysis, to prevent the results from being skewed. The assumption of homogeneity was violated based upon Levene's $F$ test, $[F(2,637)=4.988, p$ $=.007]$.

The Kruskal-Wallis non-parametric test was conducted and revealed that coaching selfefficacy varied significantly across group membership (SSM, CA, and AM), $\chi^{2}(2)=7.36, p<.05$. Thus, the null hypothesis of no differences between groups was rejected. To examine the differences between the three means further, Mann-Whiney U post-hoc was utilized. AMs $(M=$ $7.13, S D=.76$ ) had a statistically significant higher mean level of coaching self-efficacy than SMMs $(M=6.84, S D=1.06)$. Also, AMs $(M=7.13, S D=.76)$ had a statistically significant 
higher mean level of coaching self-efficacy than CAs $(M=6.67, S D=1.06)$. The means and standard deviations for research question three are located in Table 4 and non-parametric results are located in Table 7.

\section{Research Question 4}

An ANOVA was conducted for research question four to determine if there were significant differences among the three group's (SSM, CA, and AM) level of perceived barriers for entering collegiate coaching, an ANOVA was conducted on each of the five sub-scales of the PHS. Prior to running the ANOVA for PHS1 (minority and gender bias), it was determined that the data were normally distributed according to visual inspection of the Q-Q plots, P-P plots, box plots, and histograms. There were five cases that were above the critical value (5.991), resulting in these five cases being removed prior to data analysis, to prevent the results from being skewed. The assumption of homogeneity was evaluated and was met based upon Levene's $F$ test, $[F(2,658)=.287, p=.750]$.

The independent between-groups ANOVA produced a statistically significant effect, $[F(2,658)=13.885, p=.000]$. Thus, the null hypothesis of no differences between groups was rejected. To examine the differences between the three means further, the statistically significant ANOVA was followed-up with Games-Howell post-hoc. SMMs $(M=4.43, S D=1.46)$ had a statistically significant higher mean level of perceived barriers (PHS1/minority and gender bias) than CAs $(M=3.65, S D=1.50)$. The means and standard deviations for research question four are located in Table 5 and ANOVA results are located in Tables 10 and 11.

Due to class rank being a statistically significant confounding variable for PHS 1, an additional ANOVA was ran. The results of the class rank ANOVA produced a statistically significant effect for PHS $1[F(5,659)=3.915, p=.002]$. Thus, the null hypothesis of no 
differences between groups was rejected. To examine the differences between class ranks further, the statistically significant ANOVA was followed-up with Games-Howell post-hoc. Freshman $(M=3.86, S D=1.36)$ had a statistically significant lower mean level of perceived barriers (PHS1/minority and gender bias) than sophomores $(M=4.53, S D=1.63)$, juniors $(M=$ 4.48, $S D=1.6)$, and seniors $(M=4.29, S D=1.51)$.

Prior to running the ANOVA for PHS2 (gender issues), the assumption of normality was evaluated visually. It was determined that the data were normally distributed according to visual inspection of the Q-Q plots, P-P plots, box plots, and histograms. There were two cases that were above the critical value (5.991), resulting in these two cases being removed prior to data analysis, to prevent the results from being skewed. The assumption of homogeneity was evaluated and was met based upon Levene's $F$ test, $[F(2,661)=.445, p=.445]$.

The independent between-groups ANOVA produced a statistically significant effect, $[F(2,661)=18.615, p=.000]$. Thus, the null hypothesis of no differences between groups was rejected. To examine the differences between the three means further, the statistically significant ANOVA was followed-up with Games-Howell post-hoc. SMMs $(M=4.48, S D=1.69)$ had a statistically significant higher mean level of perceived barriers (PHS2/gender issues) than CAs $(M=3.47, S D=1.70)$. SMMs $(M=4.48, S D=1.69)$ had a statistically significant higher mean level of perceived barriers (PHS2/gender issues) than AMs $(M=3.87, S D=1.51)$.

Due to class rank being a statistically significant confounding variable for PHS 2, an additional ANOVA was ran. The results of the class rank ANOVA produced a statistically significant effect for PHS $1[F(5,659)=3.291, p=.006]$. Thus, the null hypothesis of no differences between groups was rejected. To examine the differences between class ranks further, the statistically significant ANOVA was followed-up with Games-Howell post-hoc. 
Freshman $(M=3.87, S D=1.60)$ had a statistically significant lower mean level of perceived barriers (PHS2/gender issues) than sophomores $(M=4.58, S D=1.83)$. Freshman $(M=3.87, S D$ $=1.60)$ also had a statistically significant lower mean level of perceived barriers (PHS2/gender issues) than juniors $(M=4.46, S D=1.80)$.

Prior to running the ANOVA for PHS3 (nature of coaching), it was determined that the data were normally distributed according to visual inspections of the Q-Q plots, P-P plots, box plots, and histograms. There were 15 cases that were above the critical value (5.991), resulting in these 15 cases being removed prior to data analysis, to prevent the results from being skewed. The assumption of homogeneity was evaluated and was met based upon Levene's $F$ test, [ $F(2$, $648)=1.881, p=.153]$

The independent between-groups ANOVA produced a statistically significant effect, $[F(2,648)=7.046, p=.001]$. Thus, the null hypothesis of no differences between groups was rejected. To examine the differences between the three means further, the statistically significant ANOVA was followed-up with Games-Howell post-hoc. SMMs $(M=5.73, S D=1.21)$ had a statistically significant higher mean level of perceived barriers (PHS3/nature of coaching) than and CAs $(M=5.26, S D=1.40)$.

Prior to running the ANOVA for PHS4 (conflict with others), it was determined that the data were normally distributed according to visual inspections of the Q-Q plots, P-P plots, box plots, and histograms. There were nine cases that were above the critical value (5.991), resulting in these nine cases being removed prior to data analysis, to prevent the results from being skewed. Furthermore, the assumption of homogeneity was evaluated and was met based upon Levene's $F$ test, $[F(2,654)=.626, p=.535]$. However, the independent between-groups 
ANOVA did not produce a statistically significant effect, $[F(2,654)=2.634, p=.073]$. Thus, the null hypothesis was accepted, that there were no significant differences between groups.

Prior to running the ANOVA for PHS5 (professional issues), it was determined that the data were not normally distributed according to visual inspection of the Q-Q plots, P-P plots, box plots, and histograms. There were 16 cases that were above the critical value (5.991), resulting in these 16 cases being removed prior to data analysis, to prevent the results from being skewed. The assumption of homogeneity was evaluated and was met based upon Levene's $F$ test, [ $F(2$, 639) $=2.216, p=.110]$.

The independent between-groups ANOVA produced a statistically significant effect, $[F(2,639)=4.211, p=.015]$. Thus, the null hypothesis of no differences between groups was rejected. To examine the differences between the three means further, the statistically significant ANOVA was followed-up with Games-Howell post-hoc. AMs $(M=7.49, S D=1.19)$ had a statistically significant higher mean level of perceived barriers (PHS5/professional issues) than CAs $(M=6.95, S D=1.22)$.

\section{Research Question 5}

An ANOVA was conducted for research question five to determine if there were significant differences among the three group's (SSM, CA, and AM) level of desire to coach full-time at 2-year colleges, DIII, DII, and DI. An ANOVA was conducted on each of the four collegiate coaching levels to analyze if there were any differences. Prior to running the ANOVA for 2-year colleges, it was determined that the data were not normally distributed according to visual inspections of the Q-Q plots, P-P plots, box plots, and histograms. There were 19 cases that were above the critical value (5.991), resulting in these 19 cases being removed prior to data 
analysis, to prevent the results from being skewed. The assumption of homogeneity was evaluated and was violated based upon Levene's $F$ test, $[F(2,699)=.12 .823, p=.000]$.

The Kruskal-Wallis non-parametric test was conducted and revealed that desire to coach at 2-year colleges varied significantly across group membership (SSM, CA, and AM), $\chi^{2}(2)=$ $18.12, \mathrm{p}<.05$. Thus, the null hypothesis of no differences between groups was rejected. To examine the differences between the three means further, Mann-Whiney U post-hoc was utilized. SMMs $(M=2.83, S D=2.15)$ had a statistically significant higher mean level of desire to coach full-time at 2-year colleges than CAs $(M=2.05, S D=1.65)$. AMs $(M=3.03, S D=2.08)$ had a statistically significant higher mean level of desire to coach full-time at 2-year colleges than CAs $(M=2.05, S D=1.65)$. The means and standard deviations for research question five are located in Table 6 and non-parametric results are located in Table 8.

Prior to running the ANOVA for the DIII level, it was determined that the data were not normally distributed according to visual inspections of the Q-Q plots, P-P plots, box plots, and histograms. There were zero cases that were above the critical value (5.991), therefore no cases were removed. The assumption of homogeneity was evaluated and was violated based upon Levene's $F$ test, $[F(2,718)=19.885, p=.000]$.

The Kruskal-Wallis non-parametric test was conducted and revealed that desire to coach at DIII colleges varied significantly across group membership (SSM, CA, and AM), $\chi^{2}(2)=$ $31.96, p<.05$. Thus, the null hypothesis of no differences between groups was rejected. To examine the differences between the three means further, Mann-Whiney U post-hoc was utilized. SMMs $(M=3.57, S D=2.59)$ had a statistically significant higher mean level of desire to coach full-time at DIII level than CAs $(M=2.28, S D=1.98)$. AMs $(M=3.68, S D=2.24)$ had a 
statistically significant higher mean level of desire to coach full-time at DIII level than CAs $(M=$ $2.28, S D=1.98)$.

Prior to running the ANOVA for the DII level, it was determined that the data were not normally distributed according to visual inspections of the Q-Q plots, P-P plots, box plots, and histograms. There were zero cases that were above the critical value (5.991), therefore no cases were removed. The assumption of homogeneity was evaluated and was violated based upon Levene's $F$ test, $[F(2,721)=17.208, p=.000]$.

The Kruskal-Wallis non-parametric test was conducted revealed that desire to coach at DII colleges varied significantly across group membership (SSM, CA, and AM), $\chi^{2}(2)=33.40$, $p<.05$. Thus, the null hypothesis of no differences between groups was rejected. To examine the differences between the three means further, Mann-Whiney U post-hoc was utilized. SMMs ( $M$ $=3.91, S D=2.79$ ) had a statistically significant higher mean level of desire to coach full-time at DII level than CAs $(M=2.46, S D=2.16)$. AMs $(M=4.33, S D=2.56)$ had a statistically significant higher mean level of desire to coach full-time at DII level than CAs $(M=2.46, S D=$ 2.16).

Prior to running the ANOVA for the DI level, it was determined that the data were not normally distributed according to visual inspections of the Q-Q plots, P-P plots, box plots, and histograms. There were zero cases that were above the critical value (5.991) therefore, no cases were removed. The assumption of homogeneity was evaluated and was violated based upon Levene's $F$ test, $[F(2,724)=8.646, p=.000]$.

The Kruskal-Wallis non-parametric test was conducted and revealed that desire to coach at DI colleges varied significantly across group membership (SSM, CA, and AM), $\chi^{2}(2)=23.08$, $p<.05$. Thus, the null hypothesis of no differences between groups was rejected. To examine the 
differences between the three means further, Mann-Whiney U post-hoc was utilized. SMMs ( $M$ $=4.88, S D=2.89$ ) had a statistically significant higher mean level of desire to coach full-time at DI level than CAs $(M=3.83, S D=2.89)$. AMs $(M=6.20, S D=2.97)$ had a statistically significant higher mean level of desire to coach full-time at DI level than SMMs $(M=4.88, S D=$ 2.89). Finally, AMs $(M=6.20, S D=2.97)$ had a statistically significant higher mean level of desire to coach full-time at DI level than CAs $(M=3.83, S D=2.89)$.

\section{Research Question 6}

Research question six examined the independent variables (coaching self-efficacy, supports, and barriers) to see which group membership predicts (SSM, CA, \& AM) intent (dependent variable) to pursue full-time collegiate coaching as a career; a standard multiple regression was conducted for each group. Only cases that had completed data for each of the predictive variables were included in the analysis. Additionally, all the predictive variables were entered in at the same time for each of the multiple regressions that were conducted.

Assumptions were checked prior to running the data analysis. Each groups' DurbinWatson test reported between 1.425-1.659, indicating there was no auto-correlation. All three groups failed the assumption of linearity, homoscedasticity, and normally distributed errors. The intercorrelation table reported high multicollinearity (>.80) between CSES and PHS5 and the PHS1 and PHS2 (Field, 2009). The variance inflation factor (VIF) tolerance for all of the groups was below 10 (Myers, 1990) and the tolerance level was below .10 (Menard, 1995), which suggests there are no major concerns of multicollinearity. To examine the concern of multicollinearity between PHS 1 and PHS 2, two approaches were employed. The first approach dropped each sub-scale separately and reran the multiple regression. The second approach combined the two sub-scales into a dummy variable and reran the multiple regression. The 
results of the multiple regression (one for each group) did not change with either approach. Confirming that multicollinearity was not an issue for PHS1 and PHS 2, and did not impact the findings of the study. Thus, PHS 1 and PHS 2 remained as separate sub-scales of the PHS. Due to the violations of assumptions of linearity, homoscedasticity, and normal distribution, the results of these multiple regressions should be interpreted with caution.

A multiple regression was conducted to examine if collegiate coaching self-efficacy, perceived supports, and perceived barriers (five areas) predicted SSM's intent to become a fulltime collegiate coach. The results of the multiple regression for the SSM group indicated that the model was statistically significant, and accounted for $35.1 \%$ of variance in intent $[F(7,459)=$ $35.369, p=.000, \mathrm{R}^{2}=.351, \mathrm{R}^{2}$ adjusted $\left.=.341\right]$. The analysis showed that perceived supports $(\beta=$ $.435, t(466)=10.78, p=.000)$ and collegiate coaching self-efficacy $(\beta=.442, t(466)=4.06, p=$ .000) significantly predicted SSM's intent to become a full-time collegiate coach. The remaining predictive variables associated with perceived barriers did not significantly predict SSM's intent to become a full-time collegiate coach. Mean, standard deviations, and intercorrelations among the predictive variables for SSMs are located in Table 12 and the results from the multiple regression are presented in Table 15.

A second multiple regression was conducted to see if collegiate coaching self-efficacy, perceived supports, and perceived barriers (five areas) predicted CA's intent to become a fulltime collegiate coach. The results from the multiple regression for the CA group indicated that the model was statistically significant, and accounted for $1.4 \%$ of variance in intent $[F(7,106)=$ $2.679, p=.014, \mathrm{R}^{2}=.150, \mathrm{R}^{2}$ adjusted $\left.=.094\right]$. The analysis showed that perceived supports significantly predicted CA's intent to become a full-time collegiate coach $(\beta=.303, t(113)=$ $3.12, p=.002$ ). The remaining predictive variables (coaching self-efficacy and perceived 
barriers) did not significantly predict CA's intent to become a full-time collegiate coach. Mean, standard deviations, and intercorrelations among the predictive variables for CAs are located in Table 13 and results from the multiple regression are presented in Table 16.

A third multiple regression was conducted to see if collegiate coaching self-efficacy, perceived supports, and perceived barriers (five areas) predicted AM's intent to become a fulltime collegiate coach. The results from the multiple regression for the AM group indicated that the model was not statistically significant $\left[F(7,45)=1.925, p=.088, \mathrm{R}^{2}=.230, \mathrm{R}^{2}\right.$ adjusted $=$ .111]. Thus, indicating that none of the predictive variables (coaching self-efficacy, supports, and barriers) significantly predict AM's intent to become a full-time collegiate coach. Mean, standard deviations, and intercorrelations among the predictive variables for AMs are located in Table 14 and results from the multiple regression are presented in Table 17.

While not a directly a part of the study's research questions, an examination of the descriptive statistics from the CIS combined with group membership revealed connections in regards to major selection and an individuals' level of intent to become a full-time collegiate coach. AMs and SSMs who reported a mean score of five or higher on the CIS, $55 \%$ of SSMs were either a PETE, SEP, or SM major. Within the AM sample group, 35\% of AMs who reported a five or higher on the CIS were either an SM or SEP major. Just under 70\% of all ACE majors reported a mean score of five or higher on the CIS. This information gives more insight on the group differences presented in research question one.

To better understand how a students' major influences their intent to become a full-time collegiate coach, a content analysis was performed on the open-ended question "Why did you choose your intended major?" Of the 729 completed surveys, 679 participants answered the question (93.1\%) providing 741 raw data points, and 50 participants did not respond (68\%). A 
content analysis was performed on the reasons why the participant chose their major. The raw data points were grouped into major themes and sub-themes that were identified by the primary investigator. A second independent reviewer then reviewed the major themes and sub-themes and revisions were made until a consensus was reached. The researcher then coded each raw data point based upon the identified themes. A reliability check was then employed on one third of the raw data points to ensure the coding met at least $80 \%$ agreement, as recommended by Krippendorff (1980). If there were any discrepancies, the items were discussed until an agreement was reached.

The following six major themes emerged from the content analysis: personal interest accounted for 424 of the 741 raw data points (57.2\%), future goals 172 (25.3\%), outside influence $69(9.3 \%)$, perceived occupational opportunities 37 (4.9\%), perceived personal abilities $20(2.6 \%)$, and personal experience $19(2.5 \%)$. The largest major theme was personal interest, and was comprised of seven identified sub-themes: what I love (117), interested (108), improve lives (56), what I like (45), enjoyment (44), stay involved with sports (33), and passion (21). Under the second major theme of future goals, there were three sub-themes: future profession (145), grad school (23), and degree (4). Almost $20 \%$ of the total raw data points indicated that their major choice was due to the profession the individual is wanting to pursue after college. The third largest major theme was outside influence had seven sub-themes: in-state tuition (50), exposure to the profession (6), family (6), advisor (2), eligibility (2), career test (1), coach (1), and teacher (1). The reason for in-state tuition being the largest sub-theme for the major theme influencing factors is due to the University having a sport degree program that is not offered in many states. This allows the student receive in-state tuition prices, even though they are out-ofstate residents. The fourth largest major theme was perceived occupational opportunities and it 
was comprised of four sub-themes: job opportunities (22), job security (7), salary (6), and work hours (2). The fifth largest major theme was perceived personal abilities and it had three subthemes: a good fit (7), interpersonal skills (7), and content knowledge (6). Interpersonal skills included communication skills, being able to work with others, and identifying as a people person. The final and smallest major theme was personal experiences and it only had two the sub-themes: coaching experience (14) and playing experience (5). Each major theme and subtheme along with the proportions (percentages) that were identified for major selection can be found in Table 20. 


\section{Chapter 5}

\section{Discussion}

This section will discuss the findings and implications of the results of this study. The first section will examine the study's research questions and hypothesis findings in relation to previous coaching education and SCCT literature, followed by the implications for coaching education programs and sport organizations. Then, study limitations will be examined to contextualize generalizability of the study. Finally, suggestions for future coaching education research based on the present study will be explored.

\section{Research Findings}

Previous coaching education researchers have used social cognitive career theory as a framework for examining individuals' intent to pursue collegiate coaching as a full-time career (Cunningham \& Singer, 2010; Moran-Miller \& Flores, 2011). This information has helped to shed light on how various predictive variables such as coaching self-efficacy, outcome expectations, perceived supports, and barriers, and interest impact a collegiate athlete's decision to pursue collegiate coaching as a career. However, previous coaching education research has only examined collegiate athletes' perceptions of the coaching profession and compared the differences between genders and ethnicities (Cunningham \& Singer, 2010). While this work has provided a good foundation, it has overlooked the potential collegiate coaching career interests of individuals who, for a wide variety of reasons (e.g., injury, ability, interest, etc.), are not participating in varsity collegiate sport.

In order to gain a broader understanding of how personal inputs and learning experience impact an individual's career intent to become a collegiate coach, this study examined not only collegiate athletes, but also sport science majors and athlete majors. To test the assumption that collegiate athletes are more likely to pursue collegiate coaching in comparison to other sample 
populations, research question one sought to explore the differences among sport science majors', collegiate athletes', and athlete majors' level of intent to pursue full-time collegiate coaching as a career post-graduation. The findings supported the study's hypothesis that athlete majors would have a statistically higher level of intent to become full-time collegiate coaches compared to sport science majors and collegiate athletes. Athlete majors demonstrated an interest in the topic area by pursuing an academic study in a sport-related degree program.

The study's findings were consistent with major selection (e.g., Adams, Pryor, \& Adams, 1994; Beggs et al., 2008; Malgwi et al., 2005) and social cognitive career theory (Lent \& Brown, 2006; Lent et al., 1994, 2000) research that suggests having an interest or passion is a predictor of the intent to pursue a degree or career path. The major theme personal interest accounted for over half of the total raw data points as to why the respondent chose their major. Under the major theme love of sports, sub-theme passion for sports accounted for $23 \%$ of the total raw data points from those who indicated that yes, they do intend to pursue collegiate coaching as a career. Thus, it is important for coaching education programs to identify individuals who have a passion for sports and high level of interest in pursuing collegiate coaching as career to provide opportunities and resources for entry into the profession.

This study's findings suggest that the assumption that collegiate athletes are more likely than other sample populations to pursue a career in collegiate coaching is not an accurate assumption. An individual's interest in pursuing a sport science major is a stronger indication of an individual's level of intent to become a collegiate coach, than solely being a varsity collegiate athlete. When examining individuals' intent to become a collegiate coach, it is essential that coaching education researchers expand their sample population to include individuals who are 
pursuing a sport science major, as this is an important contributing factor in their intent to pursue collegiate coaching as a career.

Within collegiate coaching education research, it has been suggested that an individual's level of perceived supports can impact their intent to pursue collegiate coaching as a career and how long they will remain in the profession (e.g., Blom et al., 2011; Cunningham \& Singer, 2010; Kamphoff et al., 2010; LaVoi \& Dutove, 2012). To better understand how learning experiences and personal inputs impact an individual's level of perceived supports, research question two explored the differences among the three groups' level of perceived supports for entering collegiate coaching. The findings of the study supported the hypothesis that athlete majors would report having a higher level of perceived supports for entry into collegiate coaching compared to sport science majors and collegiate athletes not pursing sport science degrees. This finding might suggest that varsity athletes pursing sport science studies feel they have better access to collegiate coaching networks due to being a collegiate athlete. These network connections could have impacted their perceived level of support. Due to many Division I varsity athletes receiving athletic scholarships; financial support could have allowed more freedom to pursue a sport science degree, which in turn may have impacted their level of perceived support for entry into collegiate coaching. More research is needed to clearly identify why athlete majors reported the highest level of perceived supports.

In addition to an individual's level of perceived support, an individual's level of coaching self-efficacy has been suggested to be predictive of both male and female assistant coaches' intent to become head coaches (Cunningham et al., 2003), female collegiate athletes' level of interest towards collegiate coaching (Moran-Miller \& Flores, 2011), and collegiate athletes' intent to coach full-time at various competitive levels (Everhart \& Chelladurai, 1998). In order 
to better understand how collegiate athletes' learning experiences affect their coaching selfefficacy, research question three explored the differences among the three groups' level of perceived collegiate coaching self-efficacy. The results of the study supported the hypothesis that athlete majors would report having a statistically higher level of perceived collegiate coaching self-efficacy compared to sport science majors and collegiate athletes. The study suggests that athlete majors' exposure to the collegiate coaching profession, in addition to their academic sport studies knowledge, appears to provide athlete majors with a high sense of perceived collegiate coaching self-efficacy in comparison to sport science majors and collegiate athletes.

Within NCAA collegiate coaching environment, numerous barriers have been examined in relation to an individual's likelihood to enter collegiate coaching and how long they will remain (e.g., Cunningham \& Singer, 2010; Kampoff, 2010; LaVoi \& Dutove, 2012; Walker \& Bopp, 2011). When the perception of entry into collegiate coaching as a career barriers were examined among the three groups in this study, non-varsity sport science majors perceived minority and gender bias, gender issues, nature of coaching, and conflict with others to be challenges to entry at a greater level than did their sport science major peers who were also athletes. Professional issues (e.g., low salary, lack of job security, other professions are more attractive, and difficult to obtain an entry coaching position) had the highest mean score among all three groups. Collegiate athletes were also found to have the lowest level of perceived barriers related to minority and gender bias, gender issues, nature of coaching, conflict with others, and professional issues. Thus, the hypothesis that athlete majors would report having the highest level of perceived barriers for entering collegiate coaching compared to collegiate athletes and sport science majors was rejected, except for professional issues. This suggests that 
exposure to collegiate coaching as a profession does not necessarily increase one's level of perceived barriers within the profession; more research is needed to better understand why these differences occurred.

Approximately a quarter of the total raw data points from those that responded no to pursuing collegiate coaching as a career were coded under the major theme professional barriers. Professional barriers was the second largest major theme noted among those not choosing to purse college coaching as a major. Among those barriers, low salary was the most frequently raised concern followed by long work hours, high pressure and stress, and job security. Coaching education programs and sport organizations could help to address concerns of professional issues within their coaching resources/education and curriculums to help reduce an individual's level of perceived barriers for entry into collegiate coaching and potentially increase the individual's (specifically athlete majors) level of intent to become a collegiate coach.

Even though athlete majors had the highest scores regarding perceived barriers for professional issues, athlete majors also reported the highest level of intent to pursue collegiate coaching as a career. This finding contradicts the social cognitive career theory point that states individuals who are aware of the potential barriers within a profession are less likely to pursue that profession (Lent et al., 2000). Examining individuals' level of coping self-efficacy (Lent et al., 2000) in relation to perceived barriers in collegiate coaching could shed light on why individuals who perceive a high level of perceived barriers may still have a high level of intent.

It is important to note that when class rank was examined, freshman had a statistically significant difference between sophomores, juniors, and seniors for minority and gender bias. Freshman also had a statistically significant difference between sophomores and juniors for gender issues. These findings suggest that between individuals' freshmen year and their 
subsequent academic years, their perceptions of minority and gender bias barriers within collegiate coaching increase. Similarly, freshmens' perceptions of perceived gender issues in collegiate coaching were lower compared to sophomores and juniors. More research is needed to better understand why freshmen's mean level of perceived barriers for minority and gender bias and gender issues are lower than the other class ranks and what contributes to these differences.

Coaching education research that has employed social cognitive career theory has suggested that female collegiate athletes' level of interest towards collegiate coaching as a career is impacted by contextual factors (working hours, perceived discrimination, and female coaching role models), outcome expectations, and their perceived level of coaching self-efficacy (MoranMiller \& Flores, 2011). To examine how personal inputs and learning experiences impact an individual's level of desire to coach at all four collegiate levels, all three groups' levels of desire were examined. The results of the study supported the hypothesis that athlete majors would report having a statistically higher level of desire to coach at all four collegiate levels (2-year colleges, DIII, DII, and DI) compared to sport science majors and collegiate athletes. These findings support social cognitive career theory and the concept that an individual's level of interest (desire) impacts their level of intent to pursue a career (Lent \& Brown, 2006; Lent et al., 1994, 2000). It also suggests that coaching education research that did not examine athlete majors and sport science majors has overlooked two sample populations that reported a higher level of intent and desire to coach full-time time at each collegiate level in comparison to collegiate athletes.

Social cognitive career theory examines how various predictive variables such as selfefficacy, supports, barriers, and interest impact an individual's level of intent to pursue a career. 
To expand upon previous coaching education research findings on collegiate athletes' intent to become a collegiate coach, the final research question examined the impact coaching selfefficacy, perceived supports, and barriers have on each group's level of intent to become a fulltime collegiate coach. Due to collegiate athletes' and athlete majors' exposure to collegiate coaching, it was hypothesized that collegiate athletes' and athlete majors' level of perceived barriers would have the strongest prediction of their respective levels of intent to become a collegiate coach. However, the study's findings did not support this research hypothesis. The results contradict social cognitive career theory and the notion that the more perceived barriers an individual associates with a profession, the less likely the individual is to pursue that profession (Lent et al., 2000). The rejection of the hypothesis may have been due to all three groups reporting a low level of perceived barriers (except professional issues) or extraneous factors that were not examined within the current study. More research is needed to better understand why perceived professional barriers did not impact the participants' level of intent to pursue collegiate coaching, even though there is substantial coaching research on the numerous professional barriers.

Of particular note in this study is the positive effect of perceived supports and coaching self-efficacy on the intent to become a full time collegiate coach among those pursing sport science majors. Similarly, within the coaching literature, perceived supports are suggested to be a factor for entry into collegiate coaching and remaining in the profession (e.g., Blom et al., 2011; Cunningham \& Singer, 2010; Kamphoff et al., 2010; LaVoi \& Dutove, 2012). Coaching self-efficacy also suggested to impact an individual's level of interest and intent to pursue collegiate coaching as a career (Everhart \& Chelladurai, 1998; Moran-Miller \& Flores, 2011). Coaching education and sport organizations can provide opportunities for individuals to increase 
their level of supports and coaching self-efficacy to help increase individuals' level of intent to pursue collegiate coaching as a career.

\section{Implications of the Study}

The findings from this study contribute to the coaching literature by providing valuable information on the differences among collegiate athletes, sport science majors, and athlete majors in relation to SCCT predictive variables and their impact on each groups' level of intent to pursue collegiate coaching as a career. This information can be used to guide future coaching education research, coaching education recruitment, and structure coaching education programs and sport organizations in ways that will increase an individual's level of intent to pursue fulltime collegiate coaching as a career. Increasing individual's level of intent could help increase the number of individuals who pursue collegiate coaching as a career and decrease attrition rates.

Traditionally, research on college student athletes' intent to coach has assumed that this population is more likely to pursue collegiate coaching as a profession compared to other sample collegiate populations based upon the college athletes' playing experience and exposure to the profession. However, coaching research has excluded groups that have indicated a statistically higher level of desire and intent to become a full-time collegiate coach compared to collegiate athletes. Interest in pursuing a sport science related degree has been identified as being an important factor in future career choices for both varsity college athletes and non-athletes.

Within this study, collegiate athletes' and sport science majors' level of perceived supports impacted their level of intent to become a full-time collegiate coach. Previous coaching education research has demonstrated the importance of supports for entry into collegiate coaching and remaining in the profession (e.g., Blom et al., 2011; Cunningham \& Singer, 2010; LaVoi \& Dutove, 2012; Kamphoff et al., 2010). Thus, it is important for coaching education 
programs and sport organizations to provide support resources such as how to develop a network of professional contacts, structured coaching internships, mentorship, and coaching education to enhance individual's level of supports. These types of supports can help assist individuals for entry into collegiate coaching and decrease attrition rates.

Sport science majors' level of coaching self-efficacy impacted their level of intent to become a full-time collegiate coach, which is congruent with previous coaching education research (Everhart \& Chelladurai, 1998; Moran-Miller \& Flores, 2011). Coaching education research also suggests that coaching experience (Feltz et al., 1999; Helper et al., 2007) and role model influence (Moran-Miller \& Flores, 2011) can influence an individual's level of coaching self-efficacy. Coaching education programs and sport organizations can use this information to provide opportunities for individuals to increase their level of coaching self-efficacy via structured coaching internships, formal mentorship, and coaching education. Increasing an individual's level of coaching self-efficacy could also increase their level of intent to become a full-time collegiate coach.

Coaching education degree programs can use this information by focusing program recruiting efforts on identifying sport athletes with an interest or passion in sport that goes beyond playing. Program recruiters could implement the Desire to Coach Scale (DCS; Everhart, 1994) and Coaching Intention Scale (CIS; Cunningham \& Singer, 2010) to identify and recruit individuals who are pursuing a sport science major that have a high level of intent and desire to become a full-time collegiate coach into a coaching education program to become formally trained as a collegiate coach. Coaching education programs can then structure their curriculums to provide support resources and create opportunities for individuals to increase their level of coaching self-efficacy. Additionally, sport organizations can use this information to provide 
necessary resources to increase individuals' likelihood of attaining a collegiate coaching position and remain in the profession longer.

The use of social cognitive career theory has helped to demonstrate the impact that perceived supports and coaching self-efficacy on individuals' level of intent to pursue collegiate coaching as a career. Furthermore, there is a need for more coaching education research to better understand why athlete majors reported a statistically higher level of desire and intent to become a full-time collegiate coach compared to sport science majors, and collegiate athletes compared to sport science majors and collegiate athletes.

\section{Limitations}

While the findings from this study help provide guidance for identifying and recruiting individuals into coaching education programs and for sport organizations and coaching education programs to provide opportunities for individuals to increase their level of perceived supports and coaching self-efficacy, there were limitations. The two main limitations included sample size balance and sample diversity. Due to the different population sizes for athletic vs. academic programs and the challenges of gaining athletic program access across all sports, the study had unequal sample sizes and the CA sample was comprised of non-revenue producing sports. While this presented challenges during data analysis, efforts were made to appropriately account for these differences as noted in the results section.

The second limitation of note was a lack of sample diversity. Previous coaching education research suggested that personal inputs such as gender, ethnicity, and sexual orientation can impact an individual's level of perceived barriers towards collegiate coaching as a career (e.g., Cunningham \& Singer, 2010; Kampoff, 2010; LaVoi \& Dutove, 2012; Walker \& Bopp, 2011). Social cognitive career theory suggests that perceived supports and barriers for 
entry into a profession can influence an individual's level of self-efficacy, intent, and choice actions in regards to a profession (Lent et al., 2003). Due to the importance of these factors, the lack of diversity within the study sample should be noted. Although the sample groups had relatively equal representation of gender, other variables such as race could not be examined within this population, thus limiting the generalizability of the study.

\section{Suggestions for Future Research}

To expand upon the findings and generalizability of this study, future studies examining individuals' intent to coach among the college student population should consider including gender, ethnicity, and both revenue and non-revenue producing sports teams (personal inputs) when examining the impact coaching self-efficacy, perceived supports, and barriers have on an individual's intent to become a full-time collegiate coach. This information could be used by coaching educators and sport organizations to provide resources that specifically address the needs of certain groups that intend to pursue collegiate coaching as a career.

There is also a need to better understand why athlete majors indicated a higher level of intent to become a full-time collegiate coach compared to sport science majors and collegiate athletes. One approach could be to use interviews to provide more insight on what influences an individual's level of intent to become a full-time collegiate coach. Another approach could be to utilize a longitudinal study to examine individuals who reported a high level of desire and intent to become a full-time collegiate coach while in college, and examine how many individuals became collegiate coaches 5 to 10 years after graduation. This information would help determine how valid the application of the Desire to Coach Scale (Everhart, 1994) and Coaching Intention Scale (Cunningham \& Singer, 2010) are in regards to an individual pursuing collegiate coaching as a full-time career. 


\section{Conclusion}

Current efforts to improve the professional development pathways and preparation of the next generation of collegiate coaches may be positively influenced through further exploration of the motives and perceptions of individuals other than collegiate athletes' who express an interest in collegiate coaching as a career, and by taking a closer look at varsity athletes interested in sport science studies. The findings of this study suggest a rationale for program identification and recruitment efforts of future students among both varsity and non-varsity athletes who are pursuing a sport science major that have indicated a high level of intent and desire to become a full-time collegiate coach into coaching education programs. Coaching education programs and sport organizations can use the information from this study to create resources and structure coaching education curriculums to incorporate methods to increase an individual's level of coaching self-efficacy and supports. Thus, individuals could increase their level of intent and supports for entry into full-time collegiate coaching as a career. 


\section{References}

Abney, R., \& Richey, D. (1991). Barriers encountered by black female athletic administrators and coaches. Journal of Physical Education, Recreation, and Dance, 62(6), 19-21. doi: 10.1080/07303084.1991.10609884

Acosta, V., \& Carpenter, L. (2014). Women in intercollegiate sport: A longitudinal, national study thirty-seven-year update. Retrieved from http://www.acostacarpenter.org/

Adams, S. J., Pryor, L. J., \& Adams, S. L. (1994). Attraction and retention of high-aptitude students in accounting: An exploratory longitudinal study. Issues in Accounting Education, 9(1), 45.

Allen, J. B., \& Shaw, S. (2009). Women coaches' perceptions of their sport organizations' social environment: Supporting coaches' psychological needs? The Sport Psychologist, 23(3), 346-366.

Bandura, A. (1977). Self-efficacy: Toward a unifying theory of behavioral change. Psychological Review, 84(2), 191-215.

Bandura, A. (1982). Self-efficacy theory in human agency. American Psychologist, 37, 122147. doi: 10.1037/0003-066X.37.2.122

Bandura, A. (1986). Social foundations of thought and action: A social cognitive theory. Englewood Cliffs, NJ: Prentice- Hall.

Bandura, A. (1997). Self-efficacy: The exercise of control. New York, NY: Freeman.

Bandura, A. (2003). Bandura's social cognitive theory: An introduction. Retrieved from http://digital.films.com/PortalPlaylists.aspx?aid=12032\&xtid=44898

Barnett, V., \& Lewis, T. (1978). Outliers in statistical data. New York: Wiley. 
Beggs, J. M., Bantham, J. H., \& Taylor, S. (2008). Distinguishing the factors influencing college students' choice of major. College Student Journal, 42(2), 381-394.

Bernhard, L. (2010). Along ethnic lines: A quantitative analysis of football athletes' interest in coaching as a career. Retrieved from http://search.proquest.com/docview/614048451?accountid=2837

Blom, L. C., Abrell, L., Wilson, M. J., Lape, J., Halbrook, M., \& Judge, L. W. (2011). Working with male athletes: The experiences of U.S. female head coaches. Journal of Research, $6(1), 54-61$.

Borland, J. F., \& Bruening, J. E. (2010). Navigating barriers: A qualitative examination of the under-representation of Black females as head coaches in collegiate basketball. Sport Management Review, 13, 407-420. doi:10.1016/j.smr.2010.05.002

Bracken, N. (2009). Gender Equity in College Coaching and Administration: Perceived Barriers Report. Retrieved from http://files.eric.ed.gov/fulltext/ED516194.pdf

Bracken, N. M., \& Irick, E. (2012). 2004-10 NCAA Gender-Equity Report. Retrieved from http://r.search.yahoo.com/_ylt=A0LEVoCTB6xUe8gAhAkPxQt.;_ylu=X3oDMTByMG0 4Z2o2BHN1YwNzcgRwb3MDMQRjb2xvA2JmMQR2dGlkAw-$/ \mathrm{RV}=2 / \mathrm{RE}=1420589076 / \mathrm{RO}=10 / \mathrm{RU}=\mathrm{http} \% 3 \mathrm{a} \% 2 \mathrm{f} \% 2 \mathrm{fwww}$. ncaapublications.com\%2fpr oductdownloads\%2fGEQS10.pdf/RK=0/RS=KBusWkAvBnntNL6mwb2_DHzfxP0-

Bruening, J. E., \& Dixon, M. A. (2008). Situating work-family negotiations within a life course perspective: Insights on the gendered experiences of NCAA division I head coaching mothers. Sex Roles, 58(1-2): 10-23. doi: 10.1007/s11199-007-9350-x

Case, B. H., Greer, S., \& Brown, J. (1987). Academic clustering in athletics: Myth or reality? ARENA Review, 11(2), 48-56. 
Chen, G., \& Hu, X. (1997). Attitudes toward the physical education profession: A comparative study of career choice in Asian-American and Caucasian students. International Council for Health, Physical Education, Recreation, Sport and Dance, 33(3), 29-32.

Chung, Y. B. (2002). Career decision-making self-efficacy and career commitment: Gender and ethnic differences among college students. Journal of Career Development, 28(2), 277 284. doi:10.1023/A:1015146122546

Cook, R. D., \& Weisberg, S. (1982). Residuals and influence in regression. New York: Chapman and Hall.

Cooper, M., Hunt, K., \& Camille P., O. (2007). Women in coaching: Exploring female athletes' interest in the profession. Chronicle of Kinesiology \& Physical Education in Higher Education, 18(2), 8-19.

Cunningham, G. B. (2003). Already aware of the glass ceiling: Race-related effects of perceived opportunity on the career choices of college athletes. Journal of African American Studies, 7(1), 57-71. doi: 10.1007/s12111-003-1003-8

Cunningham, G. B., Bruening, J., Sartore, M. L., Sagas, M., \& Fink, J. S. (2005). The application of social cognitive career theory to sport and leisure career choices. Journal of Career Development, 32(2), 122-138. doi: 10.1177/0894845305279164

Cunningham, G. B., Bruening, J. E., \& Straub, T. (2006). The underrepresentation of African Americans in NCAA division I-A head coaching positions. Journal of Sport Management, 20(3), 387-413.

Cunningham, G. B., \& Singer, J. N. (2010). You'll face discrimination wherever you go: Student-athletes' intentions to enter the coaching profession. Journal of Applied Psychology, 40(7), 1708-1727. doi: 10.1111/j.1559-1816.2010.00636.x 
Cunningham, G. B., Doherty, A. J., \& Gregg, M. J. (2007). Using social cognitive career theory to understand head coaching intentions among assistant coaches of women's teams. Sex Roles, 56, 365-372. doi: 10.1007/s11199-006-9175-z

Cunningham, G. B., \& Sagas, M. (2005). Access discrimination in intercollegiate athletics. Journal of Sport \& Social Issues, 29(2), 148-163. doi: 10.1177/0193723504271706

Cunningham, G. B., Sagas, M., \& Ashley, F. B. (2003). Coaching self-efficacy, desire to become a head coach, and occupational turnover intent: Gender differences between NCAA assistant coaches of women's teams. International Journal of Sport Psychology, $34,125-137$.

Daniels, L. M., Stewart, T. L., Stupnisky, R. H., Perry, R. P., \& LoVerso, T. (2011). Relieving career anxiety and indecision: The role of undergraduate students perceived control and faculty affiliations. Social Psychology of Education, 14(3), 409-426. doi:10.1007/s11218-010-9151-x

Dickson, L. (2010). Race and gender differences in college major choice. Annals of the American Academy of Political and Social Science, 627(1), 108-124. doi: $10.1177 / 0002716209348747$

Diegelman, N. M., \& Subich, L. M. (2001). Academic and vocational interests as a function of outcome expectancies in social cognitive career theory. Journal of Vocational Behavior, 59, 394-405. doi: 10.1006/jvbe.2001.1802

Dixon, M. A., \& Bruening, J. E. (2007). Work-family conflict in coaching I: Managing role conflict. Journal of Sport Management, 21(4), 471-496.

Dunn, S. (2013). Average pay increases for academic professional's trailed inflation this year. The Chronicle of Higher Education, A16. 
Everhart, C. B. (1994). Gender differences in the choice of coaching as an occupation: The role of self-efficacy, valence, and perceived barriers. ProQuest Dissertations and Theses. Retrieved from http://search.proquest.com/docview/304114617?accountid=2837.

Everhart, B. C., \& Chelladurai, P. (1998). Gender differences in preferences for coaching as an occupation: The role of self-efficacy, valence, and perceived barriers. Research Quarterly for Exercise and Sport, 69(2), 188-200. doi:

10.1080/02701367.1998.10607683

Everhart, B. C., \& Chelladurai, P. (2004). Racial differences in coaching self-efficacy, occupational valence, and perceived barriers. International Journal of Sport Management, 5, 27-42.

Field, A. P. (3 ${ }^{\text {rd }}$ ed.). (2009). Discovering statistics using SPSS. Los Angeles, CA: Sage.

Felder, D. D., \& Wishnietsky, D. D. (1990). Role conflict, coaching burnout and the reduction in the number of female interscholastic coaches. Physical Educator, 47(2), 7-13.

Feltz, D. L., Chase, M. A., Moritz, S. E., \& Sullivan, P. J. (1999). A conceptual model of coaching efficacy: Preliminary investigation and instrument development. Journal of Educational Psychology, 91, 765-776. doi: 10.1037/0022-0663.91.4.765

Feltz, D. L., Hepler, T. J., Roman, N., \& Paiement, C. (2009). Coaching efficacy and volunteer youth sport coaches. Sport Psychologist, 23(1), 24-41.

Fountain, J. J., \& Finley, P. S. (2009). Academic majors of upperclassmen football players in the Atlantic Coast Conference: An analysis of academic clustering comparing white and minority players. Journal of Issues in Intercollegiate Athletics, 2(1), 1-13.

Fountain, J. J., \& Finley, P. S. (2011). Academic clustering: A longitudinal analysis of division I football program. Journal of Issues in Intercollegiate Athletics, 4, 24-41. 
Hagger, M. S., Chatzisarantis, N., \& Biddle, S. J. (2001). The influence of self-efficacy and past behavior on the physical activity intentions of young people. Journal of Sports Sciences, 19, 71-725.

Harrison, K. C., \& Lawrence, S. M. (2004). Female and male student athletes' perceptions of career transition in sport and higher education: A visual elicitation and qualitative assessment. Journal of Vocational Education and Training, 56(4), 485-506.

Hepler, T. J., Feltz, D. L., Roman, N., \& Paiement, C. A. (2007). Validating the coaching efficacy scale for youth sport coaches. Journal of Sport \& Exercise Psychology, 29, S169.

Holland, J. L. (1997). Making vocational choices: A theory of vocational personalities and work environments ( $3^{\text {rd }}$ ed.). Odessa, FL: Psychological Assessment Resources.

House, C. J. C. (2004). Integrating barriers to Caucasian lesbians' career development and super's life-span, life-space approach. The Career Development Quarterly, 52(3), 246255.

Hutchinson, G. E., \& Buschner, C. A. (1996). Delayed-entry undergraduates in physical education teacher education: Examining life experiences and career choice. Journal of Teaching in Physical Education, 15, 205-223.

Inglis, S., Danylchuk, K. E., \& Pastore, D. L. (2000). Multiple realities of women's work experiences in coaching and athletic management. Women in Sport \& Physical Activity Journal, 9(2), 1.

Kamphoff, C. S. (2010). Bargaining with patriarchy: Former female coaches' experiences and their decision to leave collegiate coaching. Research Quarterly for Exercise \& Sport, $81(3), 360-372$. 
Kamphoff, C., Armentrout, S. M., \& Driska, A. (2010). The token female: Women's experiences as Division I collegiate head coaches of men's teams. Journal of Intercollegiate Sport 3(2), 297-315.

Kamphoff, C., \& Gill, D. (2008). Collegiate athletes' perceptions of the coaching profession. International Journal of Sports Science \& Coaching, 3(1), 55-72. doi: $10.1260 / 174795408784089351$

Kane, M. J., \& Stangl, J. M. (1991). Employment patterns of female coaches in men's athletics: Tokenism and marginalization as reflections of occupational sex segregation. Journal of Sport \& Social Issues, 15(1), 21-41.

Kanter, R. M. (1977). Men and women of the corporation. New York: Basic Books.

Kavussanu, M., Boardley, I. D., Jutkiewicz, N., Vincent, S., \& Ring, C. (2008). Coaching efficacy and coaching effectiveness: Examining their predictors and comparing coaches' and athletes' reports. The Sport Psychologist, 22, 383-404.

Kent, A., \& Sullivan, P. J. (2003). Coaching efficacy as a predictor of university coaches' commitment. International Sports Journal, 7, 78-88.

Kilty, K. (2006). Women in coaching. Sport Psychologist, 20(2), 222-234.

Krane, V., \& Barber, H. (2005). Identity tensions in lesbian intercollegiate coaches. Research Quarterly for Exercise and Sport, 76(1), 67-81.

Krippendorff, K. (1980). Content analysis: An introduction to its methodology. Beverly Hills, CA: Sage Publication.

Krumboltz, J. D., Foley, P. F., \& Cotter, E. W. (2013). Applying the happenstance learning theory to involuntary career transitions. The Career Development Quarterly, 61(1), 1526. 
Krumboltz, J. D., Mitchell, A. M., \& Jones, G. B. (1976). A social learning theory of career selection. The Counseling Psychologist, 6, 71-81. doi: 10.1177/001100007600600117

Lapchick, R. (2010). The 2010 Racial and Gender Report Card. The Institute for Diversity and Ethics in Sport. Retrieved from http://r.search.yahoo.com/_ylt=A0LEVjdVBqxUvQUA9ZMPxQt.;_ylu=X3oDMTBybn V2cXQwBHN1YwNzcgRwb3MDMgRjb2xvA2JmMQR2dGlkAw-$/ \mathrm{RV}=2 / \mathrm{RE}=1420588758 / \mathrm{RO}=10 / \mathrm{RU}=\mathrm{http} \% 3 \mathrm{a} \% 2 \mathrm{f} \% 2 \mathrm{fwww}$. bus.ucf.edu$\% 2 \mathrm{fdocuments} \%$ 2fsport\%2f2010-NFL-Racial-and-Gender-ReportCard.pdf/RK=0/RS=IoXqNBkVkJjb50AnD7Fp4ntn.58-

LaVoi, N. M., \& Dutove, J. K. (2012). Barriers and supports for female coaches: An ecological model. Sports Coaching Review, 1(1), 17-37. doi: 10.1080/21640629.2012.695891

Lent, R. W., \& Brown, S. D. (2006). On conceptualizing and assessing social cognitive constructs in career research: A measurement guide. Journal of Career Assessment, 14, 12-35. doi: $10.1177 / 1069072705281364$

Lent, R. W., Brown, S. D., \& Hackett, G. (1994). Toward a unifying social cognitive theory of career and academic interest, choice, and performance. Journal of Vocational Behavior, 45, 79-122. doi: 10.1006/jvbe.1994.1027

Lent, R. W., Brown, S. D., \& Hackett, G. (2000). Contextual supports and barriers to career choice: A social cognitive analysis. Journal of Counseling Psychology, 47(1), 36-49. doi: 10.1037/0022-0167.47.1.36

Lent, R. W., Brown, S. D., Brenner, B., Chopra, S., Davis, T., Talleyrand, R., \& Suthakaran, V. V. (2001). The role of contextual supports and barriers in the choice of math/science 
educational options: A test of social cognitive hypotheses. Journal of Counseling Psychology, 48(4), 474-483. doi: 10.1037/0022-0167.48.4.474

Lent, R. W., Brown, S. D., \& Larkin, K. C. (1986). Self-efficacy in the prediction of academic performance and perceived career options. Journal of Counseling Psychology, 33(3), 265-269. doi: 10.1037/0022-0167.33.3.265

Lent, R. W., Brown, S. D., Schmidt, J., Brenner, B., Lyons, H., \& Treistman, D. (2003). Relation of contextual supports and barriers to choice behavior in engineering majors: Test of alternative social cognitive models. Journal of Counseling Psychology, 50(4), 458-465. doi: 10.1037/0022-0167.50.4.458

Lent, R. W., Brown, S. D., Talleyrand, R., McPartland, E. B., Davis, T., Chopra, S. B., Chai, C. (2002). Career choice carriers, supports, and coping strategies: College students' experiences. Journal of Vocational Behavior, 60(1), 61-72. doi:10.1006/jvbe.2001.1814

Lent, R. W., Lopez, F. G., Sheu, H., \& Lopez, A. M. (2011). Social cognitive predictors of the interests and choices of computing majors: Applicability to underrepresented students. Journal of Vocational Behavior, 78, 184-192. doi: 10.1016/j.jvb.2010.10.006

Leppel, K., Williams, M. L., \& Waldauer, C. (2001). The impact of parental occupation and socioeconomic status on choice of college major. Journal of Family and Economic Issues, 22(4), 373-394. doi: 10.1023/A:1012716828901

Lovett, D. J., \& Lowry, C. D. (1994). Good old boys and good old girls clubs: Myth or reality? Journal of Sport Management, 8(1), 27-35.

Lumpkin, K., \& Anshel, M. H. (2012). Work addiction among intercollegiate sports coaches. Journal of Sport Behavior, 35(4), 406-432. 
Malgwi, C. A., Howe, M. A., \& Burnaby, P. A. (2005). Influences on students' choice of college major. The Journal of Education for Business, 80(5), 275-282. doi: 10.3200/JOEB.80.5.275-282

Mensch, J. M., \& Mitchell, M. F. (2008). Choosing a career in athletic training: Exploring the perceptions of potential recruits. Journal of Athletic Training, 43(1), 7-79. doi:10.4085/1062-6050-43.1.70

Monson, A. L. (2012). Characteristics of dental hygienists based on Holland's career choice theory. Journal of Dental Hygiene, 86(2), 141-149.

Moran-Miller, K., \& Flores, L. Y. (2011). Where are the women in women's sports? Predictors of female athletes' interest in a coaching career. Research Quarterly for Exercise and Sport, 82 (1), 109-117. doi: 10.1080/02701367.2011.10599727

Multon, K. D., Brown, S. D., \& Lent, R. W. (1991). Relation of self-efficacy beliefs to academic outcomes: A meta-analytic investigation. Journal of Counseling Psychology, 38(1), 3038. doi: 10.1037/0022-0167.38.1.30

Myers, R. (1990). Classical and modern regression with applications ( $2^{\text {nd }}$ ed.). Boston, MA: Duxbury.

National Association for Sport and Physical Education. (2006). Quality coaches, quality sports: National standards for sport coaches. Retrieved from http://www.shapeamerica.org/standards/coaching/coachingstandards.cfm National Association for Sport and Physical Education. (2013). Recommended requisites for sport coaches. Retrieved from http://www.shapeamerica.org/admin/loader.cfm?csModule=security/getfile \&pageid=457 4 
National Collegiate Athletic Association. (2009). Division I 20/8-hour rule materials. Retrieved from http://www.ncaa.org/division-i-20/8-hour-rule-materials

National Collegiate Athletic Association. (1989). NCAA women's study: Student-athlete report. Indianapolis, IN: National Collegiate Athletic Association. Retrieved from http://www.ncaa.org/sites/default/files/1989_Barriers.pdf

National Collegiate Athletic Association. (n.d.). NCAA the market. Retrieved from http://ncaamarket.ncaa.org/jobs?keywords=\&category=coaching\&type=fulltime\&level=experienced\&sort

National College Athletic Association. (n.d.). Recruiting (certification) test for coaches. Retrieved from http://www.ncaa.org/student-athletes/resources/recruitingcalendars/recruiting-certification-test-coaches

National Collegiate Athletic Association. (n.d.). Remaining eligible: Academics. Retrieved from http://www.ncaa.org/remaining-eligible-academics

National Council for Accreditation for Coaching Education. (2006). Guidelines for accreditation of coaching education. Retrieved from http://www.qualitycoachingeducation.org/pdf/ncace_guidelines_accreditation.pdf

Navarro, K. M. (2014). A conceptual model of division I student-athletes' career construction processes. College Student Affairs Journal, 32(1), 219-235.

Norman, L. (2011). Gendered homophobia in sport and coaching: Understanding the everyday experiences of lesbian coaches. International Review for the Sociology of Sport, 47(6), 705-723. doi:10.1177/1012690211420487 
Paa, H. K., \& McWhirter, E. H. (2000). Perceived influences on high school students' current career expectations. The Career Development Quarterly, 49(1), 29-44. doi: 10.1002/j.2161-0045.2000.tb00749.x

Parsons, F. (1909). Choosing a vocation. Boston, MA: Houghton Mifflin.

Patton, M. Q. (1990). Qualitative evaluation and research methods (2nd ed.). Newbury Park, CA: Sage.

Pease, D. G., \& Drabelle, J. J. (1988). Pre-entry coaching expectations of women and men. Journal of Physical Education, Recreation \& Dance, 59(4), 30-32. doi: 10.1080/07303084.1988.10609716

Rask, K. N., \& Bailey, E. M. (2002). Are faculty role models? Evidence from major choice in an undergraduate institution. Journal of Economic Education, 33(2), 99-124. doi:10.1080/00220480209596461

Rogers, M. E., \& Creed, P. A. (2011). A longitudinal examination of adolescent career planning and exploration using social cognitive career theory framework. Journal of Adolescence, 34(1), 163-172. doi: 10.1016/j.adolescence.2009.12.010

Sagas, M., Cunningham, G. B., \& Pastore, D. (2006). Predicting head coaching intentions of male and female assistant coaches: An application of the theory of planned behavior. Sex Roles, 54, 695-705. doi: 10.1007/s11199-006-9035-x

Sagas, M., Cunningham, G. B., \& Teed, K. (2006). An examination of homologous reproduction in the representation of assistant coaches of women's teams. Sex Roles, 55(7-8), 503510. doi: 10.1007/s11199-006-9104-1

Sage, G. H. (1989). Becoming a high school coach: From playing sports to coaching. Research Quarterly for Exercise and Sport, 60(1), 81-92. doi: 10.1080/02701367.1989.10607417 
Saks, R. E., \& Shore, S. H. (2005). Risk and career choice. Advances in Economic Analysis \& Policy, 5(1). doi:10.2202/1538-0637.1414

Sanders, J. P., \& Hildenbrand, K. (2010). Major concerns? A longitudinal analysis of student-athletes' academic majors in comparative perspective. Journal of Intercollegiate Sport, 3, 213-233.

Schneider, R. G., Ross, S. R., \& Fisher, M. (2010). Academic clustering and major selection of intercollegiate student-athletes. College Student Journal, 44(1), 64-70.

Sears, S. (1982). A definition of career guidance terms: A national vocational guidance association perspective. Vocational Guidance Quarterly, 31(2), 137-143. doi:10.1002/j.2164-585X.1982.tb01305.x

Siegel, D., \& Newhof, C. (1992). Setting the standards for coaching curriculums: What should it take to be a coach? Journal of Physical Education, Recreation \& Dance, 63(1), 60-63.

Singaravelu, H. D., White, L. J., \& Bringaze, T. B. (2005). Factors influencing international students' career choice. Journal of Career Development, 32(1), 46-59. doi: $10.1177 / 0894845305277043$

Stangl, J. M., \& Kane, M. J. (1991). Structural variables that offer explanatory power for the underrepresentation of women coaches since title IX: The case of homologous reproduction. Sociology of Sport Journal, 8, 47-60.

Super, D. E. (1980). A life-span, life-space approach to career development. Journal of vocational behavior, 16(3), 282-298.

Swanson, J. L., \& Woitke, M. B. (1997). Theory into practice in career assessment for women: Assessment and interventions regarding perceived career barriers. Journal of Career Assessment, 5, 431-450. doi: 10.1177/106907279700500405 
Taylor, K. M., \& Betz, N. E. (1983). Applications of self-efficacy theory to the understanding and treatment of career indecision. Journal of Vocational Behavior, 22(1), 63-81. doi:10.1016/0001-8791(83)90006-4

United Stated Olympic Committee. (n.d.). Compliance with National Standards (CNS) Program. Retrieved from http://www.teamusa.org/About-the-USOC/AthleteDevelopment/Coaching-Education/CNS-Program

Walker, N. A., \& Sartore-Baldwin, M. L. (2013). Hegemonic masculinity and the institutionalized bias toward women in men's collegiate basketball: What do men think? Journal of Sport Management, 27(4), 303-315.

Walker, N. A., \& Bopp, T. (2011). The underrepresentation of women in the male-dominated sport workplace: Perspectives of female coaches. Journal of Workplace Rights, 15(1), 47-64. doi: 10.2190/WR.15.1.d

Weiss, M., Barber, H. H., Sisley, B. L., \& Ebbeck, V. V. (1991). Developing competence and confidence in novice female coaches: II. Perceptions of ability and affective experiences following a season-long coaching internship. Journal of Sport \& Exercise Psychology, 13(4), 336-363.

Weiss, M. R., \& Stevens, C. (1993). Motivation and attrition of female coaches: An application of social exchange theory. Sport Psychologist, 7(3), 244-261.

Whisenant, W. A., Pedersen, P. M., \& Obenour, B. L. (2002). Success and gender: Determining the rate of advancement for intercollegiate athletic directors. Sex Roles, 47(9/10), 485491.

Whisenant, W., \& Smucker, M. (2009). Organizational justice and job satisfaction in coaching. Public Organization Review, 9(2), 157-167. doi: 10.1007/s11115-009-0077-8 
Wilson, R. (2007). Where have all the women gone? The Chronicle of Higher Education, $53(35)$.

Wood, R., \& Bandura, A. (1989). Social cognitive theory of organizational management. Academy of Management Review, 14(3), 361-384.

Zafar, B. (2013). College major choice and the gender gap. Journal of Human Resources, 48(3), 545-595. doi: 10.1353/jhr.2013.0022

Zeldin, A. L., Britner, S. L., \& Pajares, F. (2008). A comparative study of the self-efficacy beliefs of successful men and women in mathematics, science, and technology careers. Journal of Research in Science Teaching, 45(9), 1036-1058. doi:10.1002/tea.20195 
Figure 1. Social Cognitive Career Theory Mediated Model (Lent et al, 2003)

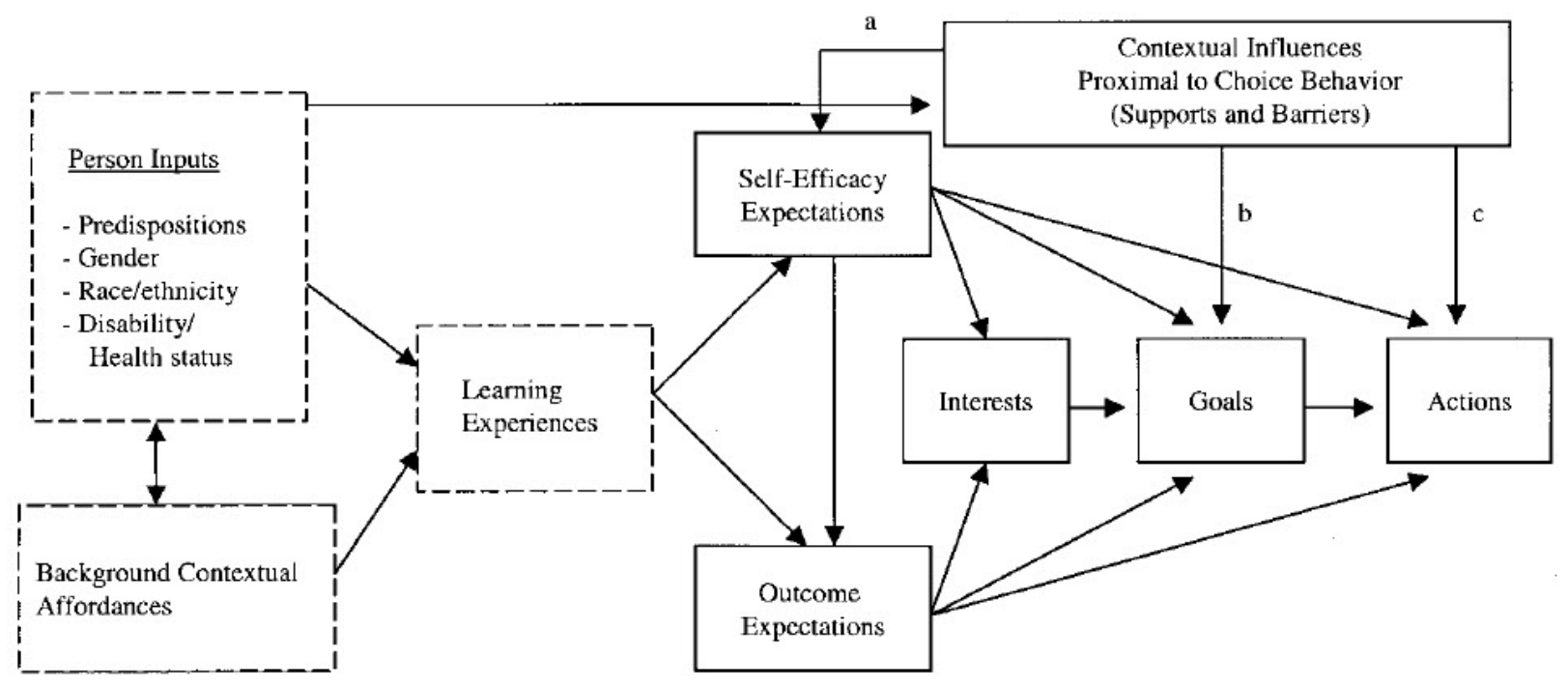

Lent, R. W., Brown, S. D., Schmidt, J., Brenner, B., Lyons, H., \& Treistman, D. (2003).

Relation of contextual supports and barriers to choice behavior in engineering majors:

Test of alternative social cognitive models. Journal of Counseling Psychology, 50(4), 458-465. doi: 10.1037/0022-0167.50.4.458 


\section{Appendix A}

Abbreviation Reference List

$\mathrm{AD}=$ Athletic director

$\mathrm{AM}=$ Varsity collegiate athlete and sport science undergraduate major

$\mathrm{CA}=$ Varsity collegiate athlete, not pursuing a sport science major

CIS $=$ Coaching Intention Scale (Cunningham \& Singer, 2010)

$\mathrm{CNS}=$ Compliance with national standards

CSBS $=$ Contextual Supports and Barriers Scale (Cunningham, Bruening, Sartore, Sagas, \&

Fink, 2005)

CSEC $=$ Coaching Self-Efficacy Scale (Everhart, 1994)

DCS $=$ Desire to Coach Scale (Everhart, 1994)

$\mathrm{IRB}=$ Internal review board

$\mathrm{K}-\mathrm{S}=$ Kolmogorov-Smirnov

$M=$ Mean

NASPE $=$ National Sport and Physical Education

NCAA $=$ National Collegiate Athletic Association

NCACE $=$ National Coaching Accreditation for Coaching Education

NGB = National governing body

NSSC $=$ National standards for sport coaches

PHS = Perceived Hindrance Scale (Kamphoff \& Gill, 2008)

PHS $1=$ Minority and gender bias within collegiate coaching

PHS $2=$ Gender issues within collegiate coaching

PHS 3 = Nature of coaching within collegiate coaching

PHS 4 = Conflicts with others within collegiate coaching 
PHS 5 = Professional issues within collegiate coaching

$S D=$ Standard Deviation

SS = Support Scale (Cunningham \& Singer, 2010)

SSM = Undergraduate sport science major, not a varsity athlete

SCCT $=$ Social cognitive career theory (Lent, Brown \& Hackett, 1994)

SCT $=$ Social cognitive theory (Bandura, 1986)

SHAPE $=$ Society for Health and Physical Education

USOC $=$ United States Olympic Committee

$\mathrm{VIF}=$ Variance inflation factor 


\section{Appendix B}

Coaching Intention Scale

(Cunningham \& Singer, 2010)

Directions: The following questions are designed to identify your intent to be a full-time collegiate coach as a career. Some people prefer to be a full-time collegiate coach and others may not. There are no right or wrong answers. Please select the response which indicates your intent to become a full-time collegiate coach as a career using a scale where 1 indicates you strongly agree with the statement and 7 indicates you strongly disagree.

How much would you like to become a full-time collegiate coach as a career?

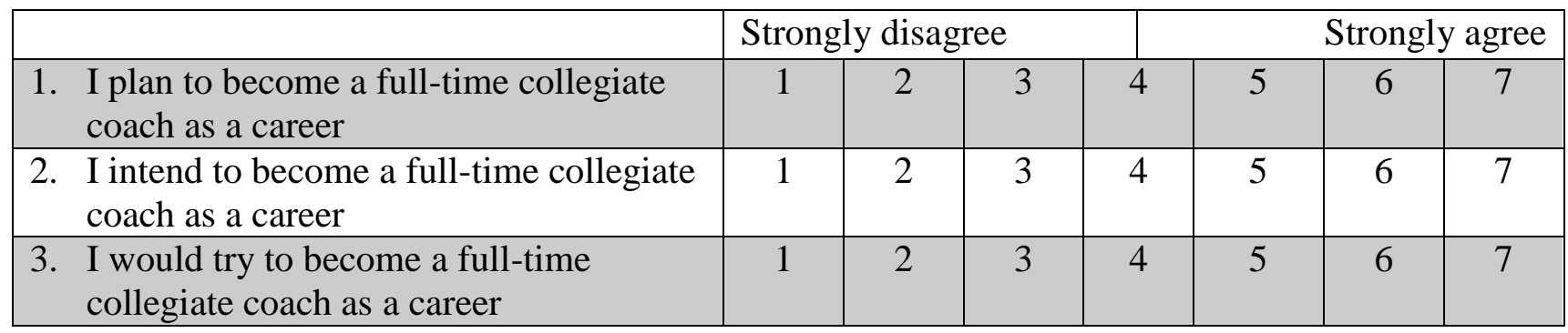




\section{Appendix C}

\section{Coaching Support Scale}

(Cunningham \& Singer, 2010)

Directions: The following questions are designed to identify how much support you perceive you would have if you decided to become a full-time collegiate coach. There are no right or wrong answers. Please select the response which indicates your perception of support for entering the collegiate coaching profession using a scale where 1 indicates you strongly disagree with the statement and 7 indicates you strongly agree.

How much support do you feel you have currently to become a full-time collegiate coach?

\begin{tabular}{|l|l|l|l|l|l|l|l|}
\hline & \multicolumn{3}{|l|}{ Strongly disagree } & \multicolumn{4}{|c|}{ Strongly agree } \\
\hline $\begin{array}{l}\text { 1. I have sufficient previous experience to } \\
\text { enter the collegiate coaching profession }\end{array}$ & 1 & 2 & 3 & 4 & 5 & 6 & 7 \\
\hline $\begin{array}{l}\text { 2. I have the training to enter the collegiate } \\
\text { coaching profession }\end{array}$ & 1 & 2 & 3 & 4 & 5 & 6 & 7 \\
\hline $\begin{array}{l}\text { 3. I have a large enough network of contacts } \\
\text { to make entering the collegiate coaching } \\
\text { profession possible }\end{array}$ & 1 & 2 & 3 & 4 & 5 & 6 & 7 \\
\hline $\begin{array}{l}\text { 4. } \text { feel as if I have sufficient contacts to } \\
\text { help me in entering the collegiate } \\
\text { coaching profession }\end{array}$ & 1 & 2 & 3 & 4 & 5 & 6 & 7 \\
\hline $\begin{array}{l}\text { 5. I feel as if I know enough people in the } \\
\text { field to obtain a position in the collegiate } \\
\text { coaching profession }\end{array}$ & 1 & 2 & 3 & 4 & 5 & 6 & 7 \\
\hline $\begin{array}{l}\text { 6. } \\
\text { My educational background has prepared } \\
\text { me for a job in the collegiate coaching } \\
\text { profession }\end{array}$ & 1 & 2 & 3 & 4 & 5 & 6 & 7 \\
\hline $\begin{array}{l}\text { I do not have the contacts to help me earn } \\
\text { a job in the collegiate coaching } \\
\text { profession }\end{array}$ & 1 & 2 & 3 & 4 & 5 & 6 & 7 \\
\hline
\end{tabular}


Appendix D

Coaching Self-Efficacy Scale

(Everhart, 1994)

Instructions: The following questions are designed to identify how much confidence you feel you have to complete collegiate coaching related tasks. There are no right or wrong answers. Please select the response which indicates your confidence to complete coaching related tasks using a scale where 1 indicates no confidence with the statement, and 9 indicates complete confidence.

How confident are you regarding each task as a collegiate coach?

\begin{tabular}{|c|c|c|c|c|c|c|c|c|c|}
\hline & \multicolumn{5}{|c|}{ No confidence } & \multicolumn{4}{|c|}{ Complete confidence } \\
\hline $\begin{array}{l}\text { 1. Be politically shrewd in dealing with } \\
\text { interest groups }\end{array}$ & 1 & 2 & 3 & 4 & 5 & 6 & 7 & 8 & 9 \\
\hline 2. Effectively manage the recruiting process & 1 & 2 & 3 & 4 & 5 & 6 & 7 & 8 & 9 \\
\hline $\begin{array}{l}\text { 3. Decide on what you most value in } \\
\text { coaching }\end{array}$ & 1 & 2 & 3 & 4 & 5 & 6 & 7 & 8 & 9 \\
\hline 4. Make intelligent choices & 1 & 2 & 3 & 4 & 5 & 6 & 7 & 8 & 9 \\
\hline 5. Become part of networks & 1 & 2 & 3 & 4 & 5 & 6 & 7 & 8 & 9 \\
\hline 6. Plan and conduct effective practices & 1 & 2 & 3 & 4 & 5 & 6 & 7 & 8 & 9 \\
\hline 7. Manage stress arising out of coaching & 1 & 2 & 3 & 4 & 5 & 6 & 7 & 8 & 9 \\
\hline $\begin{array}{l}\text { 8. Make decisions under conditions of } \\
\text { uncertainty }\end{array}$ & 1 & 2 & 3 & 4 & 5 & 6 & 7 & 8 & 9 \\
\hline $\begin{array}{l}\text { 9. Control players and assistant coaches in } \\
\text { game situations }\end{array}$ & 1 & 2 & 3 & 4 & 5 & 6 & 7 & 8 & 9 \\
\hline 10. Be effective in negotiating & 1 & 2 & 3 & 4 & 5 & 6 & 7 & 8 & 9 \\
\hline 11. Appraise your own work effectiveness & 1 & 2 & 3 & 4 & 5 & 6 & 7 & 8 & 9 \\
\hline 12. Maintain strict discipline within the team & 1 & 2 & 3 & 4 & 5 & 6 & 7 & 8 & 9 \\
\hline $\begin{array}{l}\text { 13. Stick to your plans under conditions of } \\
\text { uncertainty }\end{array}$ & 1 & 2 & 3 & 4 & 5 & 6 & 7 & 8 & 9 \\
\hline $\begin{array}{l}\text { 14. Have a good relationship with faculty } \\
\text { members and administrators }\end{array}$ & 1 & 2 & 3 & 4 & 5 & 6 & 7 & 8 & 9 \\
\hline 15. Determine your coaching strengths & 1 & 2 & 3 & 4 & 5 & 6 & 7 & 8 & 9 \\
\hline 16. Be tactful in dealing with media & 1 & 2 & 3 & 4 & 5 & 6 & 7 & 8 & 9 \\
\hline 17. Be confident in your decisions & 1 & 2 & 3 & 4 & 5 & 6 & 7 & 8 & 9 \\
\hline 18. Be firm in dealing with your players & 1 & 2 & 3 & 4 & 5 & 6 & 7 & 8 & 9 \\
\hline 19. Keep your composure at all times & 1 & 2 & 3 & 4 & 5 & 6 & 7 & 8 & 9 \\
\hline 20. Make sure that athletes work to capacity & 1 & 2 & 3 & 4 & 5 & 6 & 7 & 8 & 9 \\
\hline $\begin{array}{l}\text { 21. Sacrifice other needs and pleasures for } \\
\text { the sake of coaching }\end{array}$ & 1 & 2 & 3 & 4 & 5 & 6 & 7 & 8 & 9 \\
\hline $\begin{array}{l}\text { 22. Establish reasonable goals and objectives } \\
\text { for the team }\end{array}$ & 1 & 2 & 3 & 4 & 5 & 6 & 7 & 8 & 9 \\
\hline 23. Make quick decisions under pressure & 1 & 2 & 3 & 4 & 5 & 6 & 7 & 8 & 9 \\
\hline
\end{tabular}




\begin{tabular}{|l|l|l|l|l|l|l|l|l|l|}
\hline & \multicolumn{3}{|l|}{ No confidence } & \multicolumn{3}{|c|}{ Complete confidence } \\
\hline $\begin{array}{l}\text { 24. Develop tactics and strategies to suit the } \\
\text { skills and talents of players }\end{array}$ & 1 & 2 & 3 & 4 & 5 & 6 & 7 & 8 & 9 \\
\hline $\begin{array}{l}\text { 25. Resist the interference by parents, alumni } \\
\text { and other groups }\end{array}$ & 1 & 2 & 3 & 4 & 5 & 6 & 7 & 8 & 9 \\
\hline $\begin{array}{l}\text { 26. Accurately assess the ability of your } \\
\text { players }\end{array}$ & 1 & 2 & 3 & 4 & 5 & 6 & 7 & 8 & 9 \\
\hline $\begin{array}{l}\text { 27. Select an effective staff } \\
\text { 28. Change coaching strategies if they do not } \\
\text { work }\end{array}$ & 1 & 2 & 3 & 4 & 5 & 6 & 7 & 8 & 9 \\
\hline $\begin{array}{l}\text { 29. Select the players best suited for your } \\
\text { strategies }\end{array}$ & 1 & 2 & 3 & 4 & 5 & 6 & 7 & 8 & 9 \\
\hline $\begin{array}{l}\text { 30. Identify groups and individuals who } \\
\text { could help your program/team }\end{array}$ & 1 & 2 & 3 & 4 & 5 & 6 & 7 & 8 & 9 \\
\hline $\begin{array}{l}\text { 31. Attend to the details of eligibility, team } \\
\text { travel, etc. }\end{array}$ & 1 & 2 & 3 & 4 & 5 & 6 & 7 & 8 & 9 \\
\hline 32. Be self-assured in dealing with problems & 1 & 2 & 3 & 4 & 5 & 6 & 7 & 8 & 9 \\
\hline $\begin{array}{l}\text { 33. Modify your strategies according to the } \\
\text { strength and weakness of your opponent }\end{array}$ & 1 & 2 & 3 & 4 & 5 & 6 & 7 & 8 & 9 \\
\hline 34. Take the responsibility for the team & 1 & 2 & 3 & 4 & 5 & 6 & 7 & 8 & 9 \\
\hline 35. Communicate your thoughts effectively & 1 & 2 & 3 & 4 & 5 & 6 & 7 & 8 & 9 \\
\hline
\end{tabular}




\section{Appendix E}

Perceived Hindrance Scale

(Kamphoff \& Gill, 2008)

Instructions: The following questions are designed to identify your level of perceived hindrances within collegiate coaching. Please indicate which challenges you feel might be a hindrance for a full-time collegiate coach. There are no right or wrong answers. Please select the response that indicates your level of perceived hindrance for a full-time collegiate coach using a scale where 1 indicates not a hindrance at all with the statement, and 9 indicates a complete hindrance.

In your opinion, how much of a challenge is each of the following items for collegiate coaches?

\begin{tabular}{|c|c|c|c|c|c|c|c|c|c|}
\hline & \multicolumn{5}{|c|}{ Not at all } & & & \multicolumn{2}{|c|}{ Completely } \\
\hline 1. Coaching takes too much time & 1 & 2 & 3 & 4 & 5 & 6 & 7 & 8 & 9 \\
\hline 2. Women coaches are treated unfairly & 1 & 2 & 3 & 4 & 5 & 6 & 7 & 8 & 9 \\
\hline $\begin{array}{l}\text { 3. Lack of support for female coaches } \\
\text { from superiors }\end{array}$ & 1 & 2 & 3 & 4 & 5 & 6 & 7 & 8 & 9 \\
\hline 4. Pressures to win & 1 & 2 & 3 & 4 & 5 & 6 & 7 & 8 & 9 \\
\hline $\begin{array}{l}\text { 5. Women coaches are discriminated } \\
\text { against }\end{array}$ & 1 & 2 & 3 & 4 & 5 & 6 & 7 & 8 & 9 \\
\hline 6. Lack of opportunity for promotions & 1 & 2 & 3 & 4 & 5 & 6 & 7 & 8 & 9 \\
\hline $\begin{array}{l}\text { 7. Racial/ethnic minority coaches are } \\
\text { discriminated against }\end{array}$ & 1 & 2 & 3 & 4 & 5 & 6 & 7 & 8 & 9 \\
\hline 8. Difficulties with parents/spectators & 1 & 2 & 3 & 4 & 5 & 6 & 7 & 8 & 9 \\
\hline 9. Coaching interferes with social life & 1 & 2 & 3 & 4 & 5 & 6 & 7 & 8 & 9 \\
\hline $\begin{array}{l}\text { 10. Lack of support systems for female } \\
\text { coaches }\end{array}$ & 1 & 2 & 3 & 4 & 5 & 6 & 7 & 8 & 9 \\
\hline 11. Time spent traveling to competitions & 1 & 2 & 3 & 4 & 5 & 6 & 7 & 8 & 9 \\
\hline $\begin{array}{l}\text { 12. Coaching means working evening } \\
\text { and weekends }\end{array}$ & 1 & 2 & 3 & 4 & 5 & 6 & 7 & 8 & 9 \\
\hline $\begin{array}{l}\text { 13. Coaching conflicts with family } \\
\text { commitments }\end{array}$ & 1 & 2 & 3 & 4 & 5 & 6 & 7 & 8 & 9 \\
\hline $\begin{array}{l}\text { 14. Women coaches are perceived to be } \\
\text { unattractive }\end{array}$ & 1 & 2 & 3 & 4 & 5 & 6 & 7 & 8 & 9 \\
\hline $\begin{array}{l}\text { 15. Lack of role models for racial/ethnic } \\
\text { minority coaches }\end{array}$ & 1 & 2 & 3 & 4 & 5 & 6 & 7 & 8 & 9 \\
\hline 16. Other professions are more attractive & 1 & 2 & 3 & 4 & 5 & 6 & 7 & 8 & 9 \\
\hline $\begin{array}{l}\text { 17. Difficult to obtain an entry coaching } \\
\text { position }\end{array}$ & 1 & 2 & 3 & 4 & 5 & 6 & 7 & 8 & 9 \\
\hline $\begin{array}{l}\text { 18. Affirmative action has created extra } \\
\text { hassles }\end{array}$ & 1 & 2 & 3 & 4 & 5 & 6 & 7 & 8 & 9 \\
\hline $\begin{array}{l}\text { 19. Lack of training programs for women } \\
\text { coaches }\end{array}$ & 1 & 2 & 3 & 4 & 5 & 6 & 7 & 8 & 9 \\
\hline
\end{tabular}




\begin{tabular}{|l|c|c|c|c|c|c|c|c|c|}
\hline & \multicolumn{3}{|l}{ Not at all } & \multicolumn{4}{|c|}{ Completely } \\
\hline 20. Hassles with the media & 1 & 2 & 3 & 4 & 5 & 6 & 7 & 8 & 9 \\
\hline 21. Unfavorable work hours & 1 & 2 & 3 & 4 & 5 & 6 & 7 & 8 & 9 \\
\hline $\begin{array}{l}\text { 22. Perceptions of homosexuality among } \\
\text { coaches }\end{array}$ & 1 & 2 & 3 & 4 & 5 & 6 & 7 & 8 & 9 \\
\hline 23. Low salary & 1 & 2 & 3 & 4 & 5 & 6 & 7 & 8 & 9 \\
\hline $\begin{array}{l}\text { 24. Perceptions of women coaches as } \\
\text { unfeminine }\end{array}$ & 1 & 2 & 3 & 4 & 5 & 6 & 7 & 8 & 9 \\
\hline $\begin{array}{l}\text { 25. Lack of role models among female } \\
\text { coaches }\end{array}$ & 1 & 2 & 3 & 4 & 5 & 6 & 7 & 8 & 9 \\
\hline 26. Having to do a lot of training & 1 & 2 & 3 & 4 & 5 & 6 & 7 & 8 & 9 \\
\hline $\begin{array}{l}\text { 27. Male coaches do not accept female } \\
\text { coaches }\end{array}$ & 1 & 2 & 3 & 4 & 5 & 6 & 7 & 8 & 9 \\
\hline 28. Biases of “old boys' network" & 1 & 2 & 3 & 4 & 5 & 6 & 7 & 8 & 9 \\
\hline 29. Public scrutiny of personal life & 1 & 2 & 3 & 4 & 5 & 6 & 7 & 8 & 9 \\
\hline 30. Female players prefer male coaches & 1 & 2 & 3 & 4 & 5 & 6 & 7 & 8 & 9 \\
\hline $\begin{array}{l}\text { 31. Racial/ethnic minority coaches are } \\
\text { treated unfairly }\end{array}$ & 1 & 2 & 3 & 4 & 5 & 6 & 7 & 8 & 9 \\
\hline 32. Intrusions by alumni & 1 & 2 & 3 & 4 & 5 & 6 & 7 & 8 & 9 \\
\hline $\begin{array}{l}\text { 33. Lack of support for racial/ethnic } \\
\text { minority coaches }\end{array}$ & 1 & 2 & 3 & 4 & 5 & 6 & 7 & 8 & 9 \\
\hline 34. Lack of job security & 1 & 2 & 3 & 4 & 5 & 6 & 7 & 8 & 9 \\
\hline
\end{tabular}


Appendix F

Desire to Coach Scale

(Everhart, 1994)

Directions: The following questions are designed to identify your desire to be a full-time coach at various levels. Some people prefer to be a high-school coach or collegiate coach and others may not want to coach at all. There are no right or wrong answers. Please select the response which indicates your desire to become a full-time coach at various levels using a scale where 1 indicates you are not at all interested in the statement and 9 indicates you are very interested.

How much would you like to become a full-time coach?

\begin{tabular}{|l|l|l|l|l|l|l|l|l|l|l|}
\hline & \multicolumn{3}{|c|}{ Not at all interested } & \multicolumn{4}{|c|}{ Very interested } \\
\hline 1. & High school & 1 & 2 & 3 & 4 & 5 & 6 & 7 & 8 & 9 \\
\hline 2. In two-year colleges & 1 & 2 & 3 & 4 & 5 & 6 & 7 & 8 & 9 \\
\hline 3. In Division III institutions & 1 & 2 & 3 & 4 & 5 & 6 & 7 & 8 & 9 \\
\hline 4. In Division II institutions & 1 & 2 & 3 & 4 & 5 & 6 & 7 & 8 & 9 \\
\hline 5. In Division I institutions & 1 & 2 & 3 & 4 & 5 & 6 & 7 & 8 & 9 \\
\hline
\end{tabular}




\section{Appendix G}

\section{Demographic Questions}

Instructions: Please answer the following questions.

1. Age

2. Gender
a. Male
b. Female

3. Ethnicity
a. African American/Black
b. Asian
c. Caucasian/White
d. Hispanic/Latino
e. Native American/American Indian
f. Pacific Islander
g. Other (please specify)

4. Class Rank
a. Freshman
b. Sophomore
c. Junior
d. Senior
e. $5^{\text {th }}$ year Senior

5. Intended Minor(s)

a. Athletic coaching education

b. Sport and exercise psychology

c. Strength and conditioning

d. None

e. Undecided

f. Other (please specify)

6. Intended Major(s)

a. Athletic coaching education

b. Athletic training

c. Exercise physiology

d. Physical education

e. Sport and exercise psychology

f. Sport management

g. Undecided

h. Other (please specify)

7. Why did you choose this major?

8. After graduation, what career do you intend to pursue?

9. Athletic Participation

a. How many year/s were you on a high school or club sport team?
i. 0
ii. 1
iii. 2
iv. 3
v. 4

b. How many year/s will have you been on a collegiate sport team after this school year?
i. 0
ii. 1
iii. 2
iv. 3
v. 4
vi. 5

c. If you are currently on a collegiate sport team, please write which sport

10. Coaching Experience

a. Please fill in how many years you have coached at each level. If none, enter a zero for that level.

\begin{tabular}{|l|l|}
\hline Competitive Level & Number of years coached \\
\hline Youth sport/community/recreational league & \\
\hline High school & \\
\hline College & \\
\hline
\end{tabular}

11. Do you intend to pursue collegiate coaching as a career? Yes or No

a. If yes, what has influenced your decision to pursue collegiate coaching as a career?

b. If no, why have you decided not to pursue collegiate coaching as a career? 


\author{
Appendix $\mathrm{H}$ \\ Department Chair Cover Letter
}

Name

Department Chair

University

Department name

City, State, Zip

Dear Name:

I am a Ph.D. candidate at West Virginia University in Coaching and Teaching Studies and my faculty advisor is Dr. Kristen Dieffenbach. I am writing to request your permission to recruit students within your department to participant in my dissertation study. I am needing to survey students that that are premajors and majors in the following degree programs: Athletic Coaching Education, Athletic Training, Exercise Physiology, Physical Education Teacher Education, Sport and Exercise Psychology, and Sport Management. My study is titled, "A Comparison of Collegiate Athletes' and Undergraduate Sport science majors' Intent to Pursue Collegiate Coaching as a Career." It examines an individual's perceived level of supports, barriers, and self-efficacy toward collegiate coaching and their intent to pursue collegiate coaching as a career. By better understanding the differences between collegiate athletes' and sport science majors' intent to pursue collegiate coaching as a career, coaching educators can use this information to help recruit individuals who want to become collegiate coaches. This research has been approved by the Institutional Review Board at the West Virginia University (protocol \# ).

Students will be informed on the purpose of the study, that their participation is strictly voluntary and that there is no punishment or reward associated with the study, and that survey should take approximately 15 minutes to complete. All survey information will remain anonymous. Individuals who complete the study will be entered in to win a \$15 Dicks Sporting Goods electronic gift card. There are 75 gift cards that have been allocated for this study. Winners will be sent their gift cards via their student e-mail account that they provided on the index card that was handed in at the completion of the survey. The survey will be administered by the primary investigator, Lauren Deckelbaum and at a class time that is convenient for the instructor.

With your permission, I will contact the instructor of the courses to ask for their help with this project. I will arrange a time for me to attend the class and administer the survey. If you have any questions or need any additional information, please feel free to contact me at any time. My cell phone number is 301707-9142 and my e-mail address is ldeckelb@mix.wvu.edu. You may also contact my adviser Dr. Kristen Dieffenbach by phone at 304-293-0847, by e-mail at Kristen.Dieffenbach@ mail.wvu.edu or stop her office in the Health and Education Building in room 253.

Thank you so much for your assistance with this project.

Sincerely,

Lauren Deckelbaum

Doctoral Candidate

College of Physical Activity and Sport Science

West Virginia University 


\section{Appendix I}

Course Instructor Cover Letter

Name

Instructor

University

City, State, Zip

Dear Name:

I am a Ph.D. candidate at West Virginia University in Coaching and Teaching Studies and my faculty advisor is Dr. Kristen Dieffenbach. I am writing to request your permission to recruit your students' in your course [name of the course] to participate in my dissertation study. My study is titled, "A Comparison of Collegiate Athletes' and Undergraduate Sport science majors' Intent to Pursue Collegiate Coaching as a Career." It examines an individual's perceived level of supports, barriers, and self-efficacy toward collegiate coaching and their intent to pursue collegiate coaching as a career. By better understanding the differences between collegiate athletes' and sport science majors' intent to pursue collegiate coaching as a career, coaching educators can use this information to help recruit individuals who want to become collegiate coaches. This research has been approved by the Institutional Review Board at the West Virginia University (protocol \# ).

I have already spoken with your department chair [name of the department chair] and have received permission to contact you about arranging a time to come into your class and administer the survey. Prospective participants will be informed that their participation in the research is strictly voluntary and that their consent or refusal to participate will not affect their standing in the course. The survey should take approximately 15 minutes to complete. All survey information will remain anonymous. Individuals who complete the study will be entered in to win a \$15 Dicks Sporting Goods electronic gift card. There are 75 gift cards that have been allocated for this study. Winners will be sent their gift cards via their student e-mail account that they provided on the index card that was handed in at the completion of the survey. The survey will be administered by the primary investigator, Lauren Deckelbaum and at a class time that is convenient for you.

If you have any questions or need any additional information, please feel free to contact me at any time. My cell phone number is 301-707-9142 and my e-mail address is ldeckelb@ mix.wvu.edu. You may also contact my adviser Dr. Kristen Dieffenbach by phone at 304-293-0847, by e-mail at Kristen.Dieffenbach@mail.wvu.edu or stopping by her office in the Health and Education Building in room 253.

Thank you so much for your assistance with this project. Sincerely,

Lauren Deckelbaum

Doctoral Candidate

College of Physical Activity and Sport Science

West Virginia University 


\author{
Appendix $\mathbf{J}$ \\ Associate Athletic Director Cover Letter
}

Name

Associate Athletic Director

University

Department name

City, State, Zip

Dear Name:

I am a Ph.D. candidate at West Virginia University in Coaching and Teaching Studies and my faculty advisor is Dr. Kristen Dieffenbach. I am writing to request your permission to recruit athletes in your athletic program. My study is titled, “A Comparison of Collegiate Athletes' and Undergraduate Sport science majors' Intent to Pursue Collegiate Coaching as a Career." It examines an individual's perceived level of supports, barriers, and self-efficacy toward collegiate coaching and their intent to pursue collegiate coaching as a career. By better understanding the differences between collegiate athletes' and sport science majors' intent to pursue collegiate coaching as a career, coaching educators can use this information to help recruit individuals who want to become collegiate coaches. This research has been approved by the Institutional Review Board at the West Virginia University (protocol \#).

Athletes who choose to participate in the study will be asked to sign a waiver at the beginning of the survey and then complete a short survey that should take approximately 15 minutes. Prospective participants will be informed that their participation in the research is strictly voluntary and that their consent or refusal to participate will not affect their standing on the team. All survey information will remain anonymous. Individuals who complete the study will be entered in to win a \$15 Dicks Sporting Goods electronic gift card. There are 75 gift cards that have been allocated for this study. Winners will be sent their gift cards via their student e-mail account that they provided on the index card that was handed in at the completion of the survey. Students in the sport science majors were also included in the drawing for the gift cards, in order to follow NCAA compliance regulations. The survey will be administered by the primary investigator, Lauren Deckelbaum and at a practice that is convenient for head coach.

With your permission, I will contact the head coaches to ask for their help with this project. I will arrange a time for me to attend a practice and administer the survey. If you have any questions or need any additional information, please feel free to contact me at any time. My cell phone number is 301-707-9142 and my e-mail address is ldeckelb@mix.wvu.edu. You may also contact my adviser Dr. Kristen Dieffenbach by phone at 304-293-0847, by e-mail at Kristen.Dieffenbach@mail.wvu.edu or stopping by her office in the Health and Education Building in room 253.

Thank you so much for your assistance with this project.

Sincerely,

Lauren Deckelbaum

Doctoral Candidate

College of Physical Activity and Sport Science

West Virginia University 
Appendix K

Head Coach Cover Letter

Name

Head Coach

University

City, State, Zip

Dear Name:

I am a Ph.D. candidate at West Virginia University in Coaching and Teaching Studies and my faculty advisor is Dr. Kristen Dieffenbach. I am writing to request your permission to recruit your athletes on your [name of the team] to participate in my dissertation study. My study is titled, "A Comparison of Collegiate Athletes and Undergraduate Sport science majors' Intent to Pursue Collegiate Coaching as a Career." It examines an individual's perceived level of supports, barriers, and self-efficacy toward collegiate coaching and their intent to pursue collegiate coaching as a career. By better understanding the differences between collegiate athletes' and sport science majors' intent to pursue collegiate coaching as a career, coaching educators can use this information to help recruit individuals who want to become collegiate coaches. This research has been approved by the Institutional Review Board at the West Virginia University (protocol \# ).

I have already spoken with your associate athletic director [name of the director] and have received permission to contact you about arranging a time that is convenient for you for me to come to practice and administer the survey. Prospective participants will be informed that their participation in the research is strictly voluntary and that their consent or refusal to participate will not affect their standing on the team. The survey should take approximately 15 minutes to complete. All survey information will remain anonymous. Individuals who complete the study will be entered in to win a \$15 Dicks Sporting Goods electronic gift card. There are 75 gift cards that have been allocated for this study. Winners will be sent their gift cards via their student e-mail account that they provided on the index card that was handed in at the completion of the survey. Students in the sport science majors were also included in the drawing for the gift cards, in order to follow NCAA compliance regulations. The survey will be administered by the primary investigator, Lauren Deckelbaum and during a day and practice time that is convenient for you.

If you have any questions or need any additional information, please feel free to contact me at any time. My cell phone number is 301-707-9142 and my e-mail address is ldeckelb@mix.wvu.edu. You may also contact my adviser Dr. Kristen Dieffenbach by phone at 304-293-0847, by e-mail at Kristen.Dieffenbach@mail.wvu.edu or stop by her office in the Health and Education Building in room 253.

Thank you so much for your assistance with this project. Sincerely,

Lauren Deckelbaum

Doctoral Candidate

College of Physical Activity and Sport Science

West Virginia University 


\section{Appendix L}

\section{Survey Script}

Hello, my name is Lauren Deckelbaum. I am a WVU doctoral candidate in Coaching and Teaching Studies, and one of my benchmarks requires me to complete a dissertation in relation to my studies. I am as a result; I am conducting a research study that compares collegiate athletes' and sport science majors' and their intent to become a full-time collegiate coach as a career. The study will explore individual's level of collegiate coaching self-efficacy, perceptions of their supports for entering collegiate coaching, perceived barriers for entry into collegiate coaching, and which of these variables has the strongest relationship on an individual's level of intent to pursue full-time collegiate coaching as a career.

I have a brief survey that would take about 15 minutes of your time to complete. Participation in this research study is completely voluntary. You have the right to not participate without jeopardizing to your academic or playing status. You may only participate in the study if you are over the age of 18. I will only report combined results and never reporting individual ones in my research study report. All survey information will remain anonymous. The data files containing this information will be destroyed at the completion of the study. If you have already taken the study, you should not complete it again.

Individuals who complete the study will be entered in to win a \$15 Dicks Sporting Goods electronic gift card. There are 75 gift cards that have been allocated for this study. Winners will be sent their gift cards via their student e-mail account that they provided on the index card that was handed in at the completion of the survey.

Does anyone any questions about the study?

If you are willing to participate in the study, please raise your hand, and I will provide you with a survey. Once you have completed the survey, you may raise your hand, and I will come and pick up the survey.

Thank you for your participation in my study. If you have any questions or need any additional information, please feel free to contact me at any time. My contact information, along with my advisors contact information is located on the cover letter that is attached to the survey. You may separate the cover letter from the survey and take that information with you. 


\section{Appendix M}

\section{Student Cover Letter}

This letter is a request for you to take part in a research project to compare collegiate athletes and sport science majors' intent to pursue collegiate coaching as a career. This project is being conducted by Lauren Deckelbaum, Doctoral Candidate in Coaching and Teaching Studies at WVU with supervision of Dr. Kristen Dieffenbach, an assistant professor in the College of Physical Activity and Sport Sciences, for a Doctoral Degree in Coaching and Teaching Studies. Your participation in this project is greatly appreciated and will take approximately 15 minutes to fill out the attached questionnaire.

Your involvement in this project will be kept as confidential as legally possible. All data will be reported in the aggregate. You must be 18 years of age or older to participate. I will not ask any information that should lead back to your identity as a participant. Your participation is completely voluntary. You may skip any question that you do not wish to answer and you may discontinue at any time. Your class standing or playing status will not be affected if you decide either not to participate or to withdraw. West Virginia University's Institutional Review Board acknowledgement of this project is on file.

If you have any questions or need any additional information, please feel free to contact me at any time. My cell phone number is 301-707-9142 and my e-mail address is ldeckelb@mix.wvu.edu. You may also contact my adviser Dr. Kristen Dieffenbach by phone at 304-293-0847, by e-mail at Kristen.Dieffenbach@ mail.wvu.edu or stop by her office in the Health and Education Building in room 253.

Thank you so much for your assistance with this project.

Sincerely,

Lauren Deckelbaum

Doctoral Candidate

College of Physical Activity and Sport Science

West Virginia University 


\section{Appendix N}

\section{Participant Survey}

\section{Part I}

Directions: The following questions are designed to identify your desire to be a full-time coach at various levels. Some people prefer to be a high-school coach or collegiate coach and others may not want to coach at all. There are no right or wrong answers. Please select the response which indicates your desire to become a full-time coach at various levels using a scale where 1 indicates you are not at all interested in the statement and 9 indicates you are very interested.

How much would you like to become a full-time coach?

\begin{tabular}{|l|l|l|l|l|l|l|l|l|l|c|}
\hline & \multicolumn{3}{|c|}{ Not at all interested } & \multicolumn{4}{|c|}{ Very interested } \\
\hline 1. High-school & 1 & 2 & 3 & 4 & 5 & 6 & 7 & 8 & 9 \\
\hline 2. In two-year colleges & 1 & 2 & 3 & 4 & 5 & 6 & 7 & 8 & 9 \\
\hline 3. In Division III institutions & 1 & 2 & 3 & 4 & 5 & 6 & 7 & 8 & 9 \\
\hline 4. In Division II institutions & 1 & 2 & 3 & 4 & 5 & 6 & 7 & 8 & 9 \\
\hline 5. In Division I institutions & 1 & 2 & 3 & 4 & 5 & 6 & 7 & 8 & 9 \\
\hline
\end{tabular}

\section{Part II}

Directions: The following questions are designed to identify your intent to be a full-time collegiate coach as a career. Some people prefer to be a full-time collegiate coach and others may not. There are no right or wrong answers. Please select the response which indicates your intent to become a full-time collegiate coach as a career using a scale where 1 indicates you strongly agree with the statement and 7 indicates you strongly disagree.

How much would you like to become a full-time collegiate coach as a career?

\begin{tabular}{|c|c|c|c|c|c|c|c|}
\hline & \multicolumn{3}{|c|}{ Strongly disagree } & & \multicolumn{3}{|c|}{ Strongly agree } \\
\hline $\begin{array}{l}\text { 1. I plan to become a full-time collegiate } \\
\text { coach as a career }\end{array}$ & 1 & 2 & 3 & 4 & 5 & 6 & 7 \\
\hline $\begin{array}{l}\text { 2. I intend to become a full-time collegiate } \\
\text { coach as a career }\end{array}$ & 1 & 2 & 3 & 4 & 5 & 6 & 7 \\
\hline $\begin{array}{l}\text { 3. I would try to become a full-time } \\
\text { collegiate coach as a career }\end{array}$ & 1 & 2 & 3 & 4 & 5 & 6 & 7 \\
\hline
\end{tabular}

What has influenced your perception towards collegiate coaching as a profession? 


\section{Part III}

Instructions: The following questions are designed to identify how much confidence you feel you have to complete collegiate coaching related tasks. There are no right or wrong answers. Please select the response which indicates your confidence to complete coaching related tasks using a scale where 1 indicates no confidence with the statement and 9 indicates complete confidence.

How confident are you regarding each task as a collegiate coach?

\begin{tabular}{|c|c|c|c|c|c|c|c|c|c|}
\hline & \multicolumn{5}{|c|}{ No confidence } & \multicolumn{4}{|c|}{ Complete confidence } \\
\hline $\begin{array}{l}\text { 1. Be politically shrewd in dealing with } \\
\text { interest groups }\end{array}$ & 1 & 2 & 3 & 4 & 5 & 6 & 7 & 8 & 9 \\
\hline 2. Effectively manage the recruiting process & 1 & 2 & 3 & 4 & 5 & 6 & 7 & 8 & 9 \\
\hline $\begin{array}{l}\text { 3. Decide on what you most value in } \\
\text { coaching }\end{array}$ & 1 & 2 & 3 & 4 & 5 & 6 & 7 & 8 & 9 \\
\hline 4. Make intelligent choices & 1 & 2 & 3 & 4 & 5 & 6 & 7 & 8 & 9 \\
\hline 5. Become part of networks & 1 & 2 & 3 & 4 & 5 & 6 & 7 & 8 & 9 \\
\hline 6. Plan and conduct effective practices & 1 & 2 & 3 & 4 & 5 & 6 & 7 & 8 & 9 \\
\hline 7. Manage stress arising out of coaching & 1 & 2 & 3 & 4 & 5 & 6 & 7 & 8 & 9 \\
\hline $\begin{array}{l}\text { 8. Make decisions under conditions of } \\
\text { uncertainty }\end{array}$ & 1 & 2 & 3 & 4 & 5 & 6 & 7 & 8 & 9 \\
\hline $\begin{array}{l}\text { 9. Control players and assistant coaches in } \\
\text { game situations }\end{array}$ & 1 & 2 & 3 & 4 & 5 & 6 & 7 & 8 & 9 \\
\hline 10. Be effective in negotiating & 1 & 2 & 3 & 4 & 5 & 6 & 7 & 8 & 9 \\
\hline 11. Appraise your own work effectiveness & 1 & 2 & 3 & 4 & 5 & 6 & 7 & 8 & 9 \\
\hline 12. Maintain strict discipline within the team & 1 & 2 & 3 & 4 & 5 & 6 & 7 & 8 & 9 \\
\hline $\begin{array}{l}\text { 13. Stick to your plans under conditions of } \\
\text { uncertainty }\end{array}$ & 1 & 2 & 3 & 4 & 5 & 6 & 7 & 8 & 9 \\
\hline $\begin{array}{l}\text { 14. Have a good relationship with faculty } \\
\text { members and administrators }\end{array}$ & 1 & 2 & 3 & 4 & 5 & 6 & 7 & 8 & 9 \\
\hline 15. Please circle the number two & 1 & 2 & 3 & 4 & 5 & 6 & 7 & 8 & 9 \\
\hline 16. Determine your coaching strengths & 1 & 2 & 3 & 4 & 5 & 6 & 7 & 8 & 9 \\
\hline 17. Be tactful in dealing with media & 1 & 2 & 3 & 4 & 5 & 6 & 7 & 8 & 9 \\
\hline 18. Be confident in your decisions & 1 & 2 & 3 & 4 & 5 & 6 & 7 & 8 & 9 \\
\hline 19. Be firm in dealing with your players & 1 & 2 & 3 & 4 & 5 & 6 & 7 & 8 & 9 \\
\hline 20. Keep your composure at all times & 1 & 2 & 3 & 4 & 5 & 6 & 7 & 8 & 9 \\
\hline 21. Make sure that athletes work to capacity & 1 & 2 & 3 & 4 & 5 & 6 & 7 & 8 & 9 \\
\hline $\begin{array}{l}\text { 22. Sacrifice other needs and pleasures for } \\
\text { the sake of coaching }\end{array}$ & 1 & 2 & 3 & 4 & 5 & 6 & 7 & 8 & 9 \\
\hline $\begin{array}{l}\text { 23. Establish reasonable goals and objectives } \\
\text { for the team }\end{array}$ & 1 & 2 & 3 & 4 & 5 & 6 & 7 & 8 & 9 \\
\hline 24. Make quick decisions under pressure & 1 & 2 & 3 & 4 & 5 & 6 & 7 & 8 & 9 \\
\hline $\begin{array}{l}\text { 25. Develop tactics and strategies to suit the } \\
\text { skills and talents of players }\end{array}$ & 1 & 2 & 3 & 4 & 5 & 6 & 7 & 8 & 9 \\
\hline $\begin{array}{l}\text { 26. Resist the interference by parents, alumni } \\
\text { and other groups }\end{array}$ & 1 & 2 & 3 & 4 & 5 & 6 & 7 & 8 & 9 \\
\hline
\end{tabular}




\begin{tabular}{|l|l|l|l|l|l|l|l|l|l|}
\hline & \multicolumn{3}{|l}{ No confidence } & \multicolumn{4}{|c|}{ Complete confidence } \\
\hline $\begin{array}{l}\text { 27. Accurately assess the ability of your } \\
\text { players }\end{array}$ & 1 & 2 & 3 & 4 & 5 & 6 & 7 & 8 & 9 \\
\hline 28. Select an effective staff & 1 & 2 & 3 & 4 & 5 & 6 & 7 & 8 & 9 \\
\hline $\begin{array}{l}\text { 29. Change coaching strategies if they do not } \\
\text { work }\end{array}$ & 1 & 2 & 3 & 4 & 5 & 6 & 7 & 8 & 9 \\
\hline 30. Please circle the number eight & 1 & 2 & 3 & 4 & 5 & 6 & 7 & 8 & 9 \\
\hline $\begin{array}{l}\text { 31. Select the players best suited for your } \\
\text { strategies }\end{array}$ & 1 & 2 & 3 & 4 & 5 & 6 & 7 & 8 & 9 \\
\hline $\begin{array}{l}\text { 32. Identify groups and individuals who } \\
\text { could help your program/team }\end{array}$ & 1 & 2 & 3 & 4 & 5 & 6 & 7 & 8 & 9 \\
\hline $\begin{array}{l}\text { 33. Attend to the details of eligibility, team } \\
\text { travel, etc. }\end{array}$ & 1 & 2 & 3 & 4 & 5 & 6 & 7 & 8 & 9 \\
\hline 34. Be self-assured in dealing with problems & 1 & 2 & 3 & 4 & 5 & 6 & 7 & 8 & 9 \\
\hline $\begin{array}{l}\text { 35. Modify your strategies according to the } \\
\text { strength and weakness of your opponent }\end{array}$ & 1 & 2 & 3 & 4 & 5 & 6 & 7 & 8 & 9 \\
\hline 36. Take the responsibility for the team & 1 & 2 & 3 & 4 & 5 & 6 & 7 & 8 & 9 \\
\hline 37. Communicate your thoughts effectively & 1 & 2 & 3 & 4 & 5 & 6 & 7 & 8 & 9 \\
\hline
\end{tabular}

Part IV

Directions: The following questions are designed to identify how much support you perceive you would have if you decided to become a full-time collegiate coach. There are no right or wrong answers. Please select the response which indicates your perception of support for entering the collegiate coaching profession using a scale where 1 indicates you strongly disagree with the statement and 7 indicates you strongly agree.

How much support do you feel you have currently to become a full-time collegiate coach?

\begin{tabular}{|c|c|c|c|c|c|c|c|}
\hline & \multicolumn{3}{|c|}{ Strongly disagree } & & \multicolumn{3}{|c|}{ Strongly agree } \\
\hline $\begin{array}{l}\text { 2. I have sufficient previous experience to } \\
\text { enter the collegiate coaching profession }\end{array}$ & 1 & 2 & 3 & 4 & 5 & 6 & 7 \\
\hline $\begin{array}{l}\text { 3. I have the training to enter the collegiate } \\
\text { coaching profession }\end{array}$ & 1 & 2 & 3 & 4 & 5 & 6 & 7 \\
\hline $\begin{array}{l}\text { 4. I have a large enough network of contacts } \\
\text { to make entering the collegiate coaching } \\
\text { profession possible }\end{array}$ & 1 & 2 & 3 & 4 & 5 & 6 & 7 \\
\hline $\begin{array}{l}\text { 5. I feel as if I have sufficient contacts to } \\
\text { help me in entering the collegiate } \\
\text { coaching profession }\end{array}$ & 1 & 2 & 3 & 4 & 5 & 6 & 7 \\
\hline $\begin{array}{l}\text { 6. I feel as if I know enough people in the } \\
\text { field to obtain a position in the collegiate } \\
\text { coaching profession }\end{array}$ & 1 & 2 & 3 & 4 & 5 & 6 & 7 \\
\hline $\begin{array}{l}\text { 7. My educational background has prepared } \\
\text { me for a job in the collegiate coaching } \\
\text { profession }\end{array}$ & 1 & 2 & 3 & 4 & 5 & 6 & 7 \\
\hline $\begin{array}{l}\text { 8. I do not have the contacts to help me earn } \\
\text { a job in the collegiate coaching profession }\end{array}$ & 1 & 2 & 3 & 4 & 5 & 6 & 7 \\
\hline
\end{tabular}




\section{Part V}

Instructions: The following questions are designed to identify your level of perceived hindrances within collegiate coaching. Please indicate which challenges you feel might be a hindrance for a full-time collegiate coach. There are no right or wrong answers. Please select the response that indicates your level of perceived hindrance for a full-time collegiate coach using a scale where 1 indicates not a hindrance at all with the statement, and 9 indicates a complete hindrance.

In your opinion, how much of a challenge is each of the following items for collegiate coaches?

\begin{tabular}{|c|c|c|c|c|c|c|c|c|c|}
\hline & \multicolumn{5}{|c|}{ Not at all } & & \multicolumn{3}{|c|}{ Completely } \\
\hline 1. Coaching takes too much time & 1 & 2 & 3 & 4 & 5 & 6 & 7 & 8 & 9 \\
\hline 2. Women coaches are treated unfairly & 1 & 2 & 3 & 4 & 5 & 6 & 7 & 8 & 9 \\
\hline $\begin{array}{l}\text { 3. Lack of support for female coaches } \\
\text { from superiors }\end{array}$ & 1 & 2 & 3 & 4 & 5 & 6 & 7 & 8 & 9 \\
\hline 4. Pressures to win & 1 & 2 & 3 & 4 & 5 & 6 & 7 & 8 & 9 \\
\hline $\begin{array}{l}\text { 5. Women coaches are discriminated } \\
\text { against }\end{array}$ & 1 & 2 & 3 & 4 & 5 & 6 & 7 & 8 & 9 \\
\hline 6. Lack of opportunity for promotions & 1 & 2 & 3 & 4 & 5 & 6 & 7 & 8 & 9 \\
\hline $\begin{array}{l}\text { 7. Racial/ethnic minority coaches are } \\
\text { discriminated against }\end{array}$ & 1 & 2 & 3 & 4 & 5 & 6 & 7 & 8 & 9 \\
\hline 8. Difficulties with parents/spectators & 1 & 2 & 3 & 4 & 5 & 6 & 7 & 8 & 9 \\
\hline 9. Coaching interferes with social life & 1 & 2 & 3 & 4 & 5 & 6 & 7 & 8 & 9 \\
\hline $\begin{array}{l}\text { 10. Lack of support systems for female } \\
\text { coaches }\end{array}$ & 1 & 2 & 3 & 4 & 5 & 6 & 7 & 8 & 9 \\
\hline 11. Time spent traveling to competitions & 1 & 2 & 3 & 4 & 5 & 6 & 7 & 8 & 9 \\
\hline $\begin{array}{l}\text { 12. Coaching means working evening and } \\
\text { weekends }\end{array}$ & 1 & 2 & 3 & 4 & 5 & 6 & 7 & 8 & 9 \\
\hline $\begin{array}{l}\text { 13. Coaching conflicts with family } \\
\text { commitments }\end{array}$ & 1 & 2 & 3 & 4 & 5 & 6 & 7 & 8 & 9 \\
\hline $\begin{array}{l}\text { 14. Women coaches are perceived to be } \\
\text { unattractive }\end{array}$ & 1 & 2 & 3 & 4 & 5 & 6 & 7 & 8 & 9 \\
\hline 15. Please circle the number two & 1 & 2 & 3 & 4 & 5 & 6 & 7 & 8 & 9 \\
\hline $\begin{array}{l}\text { 16. Lack of role models for racial/ethnic } \\
\text { minority coaches }\end{array}$ & 1 & 2 & 3 & 4 & 5 & 6 & 7 & 8 & 9 \\
\hline 17. Other professions are more attractive & 1 & 2 & 3 & 4 & 5 & 6 & 7 & 8 & 9 \\
\hline $\begin{array}{l}\text { 18. Difficult to obtain an entry coaching } \\
\text { position }\end{array}$ & 1 & 2 & 3 & 4 & 5 & 6 & 7 & 8 & 9 \\
\hline $\begin{array}{l}\text { 19. Affirmative action has created extra } \\
\text { hassles }\end{array}$ & 1 & 2 & 3 & 4 & 5 & 6 & 7 & 8 & 9 \\
\hline $\begin{array}{l}\text { 20. Lack of training programs for women } \\
\text { coaches }\end{array}$ & 1 & 2 & 3 & 4 & 5 & 6 & 7 & 8 & 9 \\
\hline 21. Hassles with the media & 1 & 2 & 3 & 4 & 5 & 6 & 7 & 8 & 9 \\
\hline 22. Unfavorable work hours & 1 & 2 & 3 & 4 & 5 & 6 & 7 & 8 & 9 \\
\hline 23. Low salary & 1 & 2 & 3 & 4 & 5 & 6 & 7 & 8 & 9 \\
\hline
\end{tabular}




\begin{tabular}{|l|c|c|c|c|c|c|c|c|c|}
\hline & \multicolumn{3}{|l}{ Not at all } & \multicolumn{5}{|c|}{ Completely } \\
\hline $\begin{array}{l}\text { 24. Perceptions of homosexuality among } \\
\text { coaches }\end{array}$ & 1 & 2 & 3 & 4 & 5 & 6 & 7 & 8 & 9 \\
\hline $\begin{array}{l}\text { 25. Perceptions of women coaches as } \\
\text { unfeminine }\end{array}$ & 1 & 2 & 3 & 4 & 5 & 6 & 7 & 8 & 9 \\
\hline $\begin{array}{l}\text { 26. Lack of role models among female } \\
\text { coaches }\end{array}$ & 1 & 2 & 3 & 4 & 5 & 6 & 7 & 8 & 9 \\
\hline 27. Having to do a lot of training & 1 & 2 & 3 & 4 & 5 & 6 & 7 & 8 & 9 \\
\hline $\begin{array}{l}\text { 28. Male coaches do not accept female } \\
\text { coaches }\end{array}$ & 1 & 2 & 3 & 4 & 5 & 6 & 7 & 8 & 9 \\
\hline 29. Biases of “old boys' network" & 1 & 2 & 3 & 4 & 5 & 6 & 7 & 8 & 9 \\
\hline 30. Please cirle the number eight & 1 & 2 & 3 & 4 & 5 & 6 & 7 & 8 & 9 \\
\hline 31. Public scrutiny of personal life & 1 & 2 & 3 & 4 & 5 & 6 & 7 & 8 & 9 \\
\hline 32. Female players prefer male coaches & 1 & 2 & 3 & 4 & 5 & 6 & 7 & 8 & 9 \\
\hline $\begin{array}{l}\text { 33. Racial/ethnic minority coaches are } \\
\text { treated unfairly }\end{array}$ & 1 & 2 & 3 & 4 & 5 & 6 & 7 & 8 & 9 \\
\hline 34. Intrusions by alumni & 1 & 2 & 3 & 4 & 5 & 6 & 7 & 8 & 9 \\
\hline $\begin{array}{l}\text { 35. Lack of support for racial/ethnic } \\
\text { minority coaches }\end{array}$ & 1 & 2 & 3 & 4 & 5 & 6 & 7 & 8 & 9 \\
\hline 36. Lack of job security & 1 & 2 & 3 & 4 & 5 & 6 & 7 & 8 & 9 \\
\hline
\end{tabular}




\section{Part VI}

Instructions: Please answer the following questions.

12. Age

13. Gender
a. Male
b. Female

14. Ethnicity
a. African American/Black
b. Asian
c. Caucasian/White
d. Hispanic/Latino
e. Native American/American Indian
f. Pacific Islander
g. Other (please specify)

15. Class Rank
a. Freshman
b. Sophomore
c. Junior
d. Senior
e. $5^{\text {th }}$ year Senior

16. Intended Minor(s)

a. Athletic coaching education

b. Sport and exercise psychology

c. Strength and conditioning

d. None

e. Undecided

f. Other (please specify)

17. Intended Major(s)

a. Athletic coaching education

b. Athletic training

c. Exercise physiology

d. Physical education

e. Sport and exercise psychology

f. Sport management

g. Undecided

h. Other (please specify)

18. Why did you choose this major?

19. After graduation, what career do you intend to pursue?

20. Athletic Participation

a. How many year/s were you on a high school or club sport team?
i. 0
ii. 1
iii. 2
iv. 3
v. 4

b. How many year/s will have you been on a collegiate sport team after this school year?
i. 0
ii. 1
iii. 2
iv. 3
v. 4
vi. 5

c. If you are currently on a collegiate sport team, please write which sport

21. Coaching Experience

b. Please fill in how many years you have coached at each level. If none, enter a zero for that level.

\begin{tabular}{|l|l|}
\hline Competitive Level & Number of years coached \\
\hline Youth sport/community/recreational league & \\
\hline High school & \\
\hline College & \\
\hline
\end{tabular}

22. Do you intend to pursue collegiate coaching as a career? Yes or No

c. If yes, what has influenced your decision to pursue collegiate coaching as a career?

d. If no, why have you decided not to pursue collegiate coaching as a career? 
Table 1

Demographic Information for SSM, CA, and AM Groups

\begin{tabular}{lccc}
\hline & $\begin{array}{c}\text { SSM } \\
(n=533)\end{array}$ & $\begin{array}{c}\text { CA } \\
(n=132)\end{array}$ & $\begin{array}{c}\text { AM } \\
(n=62)\end{array}$ \\
\hline Age M (SD) & $20.15(1.91)$ & $19.58(1.27)$ & $19.69(1.43)$ \\
\hline Gender $n(\%)$ & & \\
Female & $215(40.2)$ & $69(52.3)$ & $25(40.3)$ \\
Male & $314(58.7)$ & $60(45.5)$ & $35(56.5)$ \\
\hline Ethnicity $n(\%)$ & & & \\
Caucasian & $451(84.3)$ & $112(84.8)$ & $95(72.6)$ \\
African American & $47(8.8)$ & $9(6.8)$ & $9(14.5)$ \\
Other & $33(6.1)$ & $11(8.3)$ & $11.9)$ \\
\hline Class Rank $n(\%)$ & & & $13(24.2)$ \\
Freshman & $123(23.0)$ & $40(30.3)$ & $10(16.1)$ \\
Sophomore & $91(17.0)$ & $29(22.0)$ & $11(17.7)$ \\
Junior & $116(21.7)$ & $26(19.7)$ & $1(1.6)$ \\
Senior & $132(24.7)$ & $23(17.4)$ & $0(0.0)$ \\
$5^{\text {th Year }}$ & $38(7.1)$ & $1(0.8)$ & \\
$6^{\text {th }}$ Year & $1(0.1)$ & $0(0.0)$ & \\
\hline
\end{tabular}


Table 2

Sport Science Majors Breakdown for SSM and AM Groups

\begin{tabular}{lcc}
\hline & $\begin{array}{c}\text { SSM } \\
(n=533)\end{array}$ & $\begin{array}{c}\text { AM } \\
(n=62)\end{array}$ \\
\hline SSM Major $n(\%)$ & & \\
Athletic Coaching & $50(9.3)$ & $14(22.6)$ \\
Athletic Training & $85(15.9)$ & $0(0.0)$ \\
Exercise Physiology & $23(4.3)$ & $5(24.2)$ \\
Physical Education & $47(8.8)$ & $2(3.2)$ \\
Sport \& Exercise Psychology & $218(40.7)$ & $15(24.2)$ \\
Sport Management & $100(18.7)$ & $15(24.2)$ \\
Pursuing Dual SSM & $8(1.5)$ & $1(1.6)$ \\
\hline
\end{tabular}

Note. The CA sample subgroup is comprised of varsity college athletes who are not pursuing sport science degrees and as such are not represented in this table. 
Table 3

Varsity Sport Participation Representation for CA and AM Groups

\begin{tabular}{lcc}
\hline & $\begin{array}{c}\text { CA } \\
(n=132)\end{array}$ & $\begin{array}{c}\text { AM } \\
(n=62)\end{array}$ \\
\hline Varsity Sport $n(\%)$ & & \\
Baseball & $23(17.4)$ & $9(14.5)$ \\
Men's Basketball & $0(0.0)$ & $1(1.6)$ \\
Women's Basketball & $0(0.0)$ & $1(1.6)$ \\
Men's Soccer & $15(11.4)$ & $5(8.1)$ \\
Women's Soccer & $1(0.8)$ & $4(6.5)$ \\
Rifle & $7(5.3)$ & $1(1.6)$ \\
Rowing & $35(26.5)$ & $8(12.9)$ \\
Swimming & $35(26.5)$ & $12(19.4)$ \\
Women's Tennis & $1(0.8)$ & $1(1.6)$ \\
Volleyball & $7(5.3)$ & $3(4.8)$ \\
Wrestling & $1(0.8)$ & $2(3.2)$ \\
Cross-country \& Track & $7(5.3)$ & $5(8.1)$ \\
\hline
\end{tabular}

Note. The SSM category sample subgroup is comprised of students who are not collegiate varsity sport athletes and as such are not represented in this table. 
Table 4

Means and Standard Deviations for the Coaching Intent Scale, Support Scale, and Coaching Self-Efficacy Scale for SSM, CA, and AM Groups

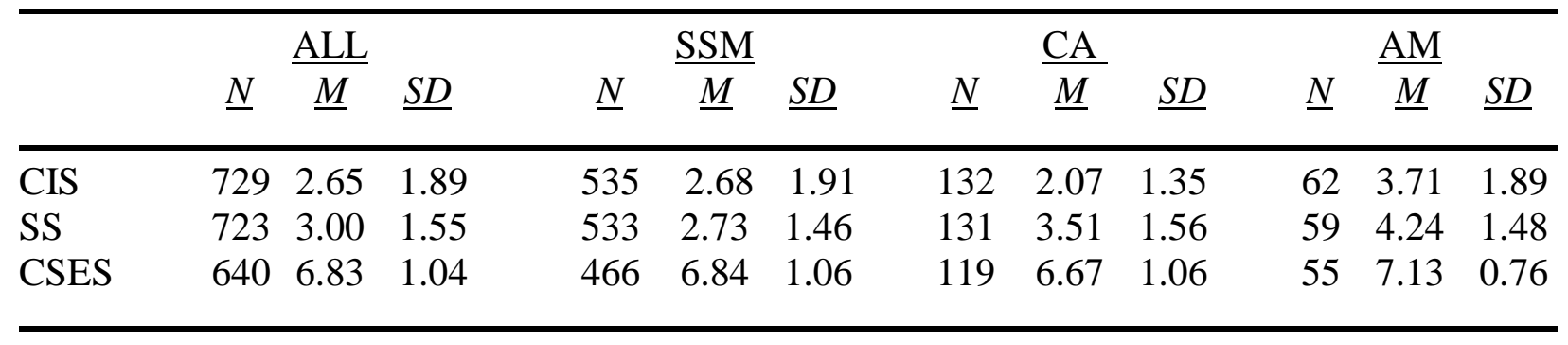


Table 5

Means and Standard Deviations for the Perceived Hindrance Sub-Scales of the for SSM, CA, and AM Groups

\begin{tabular}{|c|c|c|c|c|c|c|c|c|c|c|c|c|}
\hline & \multicolumn{3}{|c|}{ ALL } & \multicolumn{3}{|c|}{ SSM } & \multicolumn{3}{|c|}{ CA } & \multicolumn{3}{|c|}{$\underline{\mathrm{AM}}$} \\
\hline & $\underline{N}$ & $\underline{M}$ & $\underline{S D}$ & $\underline{N}$ & $\underline{M}$ & $\underline{S D}$ & $\underline{N}$ & $\underline{M}$ & $\underline{S D}$ & $\underline{N}$ & $\underline{M}$ & $\underline{S D}$ \\
\hline PHS1 & 661 & 4.26 & 1.50 & 487 & 4.43 & 1.46 & 119 & 3.65 & 1.50 & 55 & 4.04 & 1.46 \\
\hline PHS2 & 664 & 4.25 & 1.72 & 490 & 4.48 & 1.69 & 119 & 3.47 & 1.70 & 55 & 3.87 & 1.51 \\
\hline PHS3 & 651 & 5.63 & 1.26 & 482 & 5.73 & 1.21 & 116 & 5.26 & 1.40 & 53 & 5.50 & 1.26 \\
\hline PHS4 & 657 & 6.08 & 1.54 & 483 & 6.16 & 1.51 & 119 & 5.83 & 1.56 & 55 & 5.89 & 1.68 \\
\hline PHS5 & 642 & 7.19 & 1.19 & 466 & 7.22 & 1.19 & 121 & 6.95 & 1.22 & 55 & 7.49 & 1.19 \\
\hline
\end{tabular}


Table 6

Means and Standard Deviations for each Collegiate Level on the Desire to Coach Scale for SSM, $C A$, and AM Groups

\begin{tabular}{|c|c|c|c|c|c|c|c|c|c|c|c|c|}
\hline & \multicolumn{3}{|c|}{ ALL } & \multicolumn{3}{|c|}{$\underline{\mathrm{SSM}}$} & \multicolumn{3}{|c|}{$\underline{\mathrm{CA}}$} & \multicolumn{3}{|c|}{$\underline{\mathrm{AM}}$} \\
\hline & $\underline{N}$ & $\underline{M}$ & $\underline{S D}$ & $\underline{N}$ & $\underline{M}$ & $\underline{S D}$ & $\underline{N}$ & $\underline{M}$ & $\underline{S D}$ & $\underline{N}$ & $\underline{M}$ & $\underline{S D}$ \\
\hline 2-year & 702 & 2.08 & 2.08 & 516 & 2.83 & 2.15 & 126 & 2.05 & 1.65 & 60 & 3.03 & 2.08 \\
\hline DIII & 721 & 3.35 & 2.51 & 530 & 3.57 & 2.59 & 130 & 2.28 & 1.98 & 61 & 3.68 & 2.24 \\
\hline DII & 724 & 3.69 & 2.73 & 543 & 3.91 & 2.79 & 130 & 2.46 & 2.16 & 60 & 4.33 & 2.56 \\
\hline DI & 727 & 4.80 & 3.25 & 535 & 4.88 & 3.29 & 132 & 3.83 & 2.89 & 60 & 6.20 & 2.97 \\
\hline
\end{tabular}


Table 7

Kruskal-Wallis Non-Parametric Results for Significant Difference among CAs, SSMs, and AMs for the Coaching Intent Scale and Coaching Self-Efficacy Scale

\begin{tabular}{lllrl}
\hline & $\underline{N}$ & $\underline{d f}$ & $\chi^{2}$ & $\underline{p}$ \\
\hline CIS & 729 & 2 & 26.01 & $.00^{*}$ \\
CSES & 640 & 2 & 7.36 & $.02^{*}$ \\
\hline
\end{tabular}

Note. ${ }^{*} p<.05$. 
Table 8

Kruskal-Wallis Non-Parametric Results for Significant Difference among CAs, SSMs, and AMs for the Desire to Coach Scale

\begin{tabular}{lcccc}
\hline & $\underline{N}$ & $\underline{d f}$ & $\chi^{2}$ & $\underline{p}$ \\
\hline 2-year colleges & 702 & 2 & 18.12 & $.00^{*}$ \\
DIII colleges & 721 & 2 & 31.96 & $.00^{*}$ \\
DII colleges & 724 & 2 & 33.40 & $.00^{*}$ \\
DI colleges & 727 & 2 & 23.08 & $.00^{*}$ \\
\hline
\end{tabular}

Note. ${ }^{*} p<.05$. 
Table 9

One-Way Analysis of Variance Results for Significant Difference among CAs, SSMs, and AMs for the Support Scale

\begin{tabular}{llrrrr}
\hline & $d f$ & $\underline{S S}$ & $\underline{M S}$ & $\underline{F}$ & $\underline{p}$ \\
\hline SS & \multicolumn{1}{c}{2} & 163.49 & 81.74 & 37.14 & $.001^{*}$ \\
& Between groups & 1584.54 & 2.20 & & \\
Within groups & 720 & & & \\
\hline
\end{tabular}

Note. ${ }^{*} p<.05$. 
Table 10

One-Way Analysis of Variance Results for Significant Difference among the CAs, SSMs, and AMs for the Perceived Hindrance Scale

\begin{tabular}{llrrrr}
\hline & $d f$ & $\underline{S}$ & $\underline{M S}$ & $\underline{F}$ & $\underline{p}$ \\
\hline PHS1 & & & & & \\
$\quad$ Between groups & 2 & 60.48 & 30.24 & 13.88 & $.000^{*}$ \\
$\quad$ Within groups & 658 & 1433.09 & 2.17 & & \\
PHS2 & & & & & $.000^{*}$ \\
$\quad$ Between groups & 2 & 105.57 & 52.78 & 18.61 & \\
$\quad$ Within groups & 661 & 1874.47 & 2.83 & & $.001^{*}$ \\
PHS3 & 2 & 22.12 & 11.06 & 7.04 & \\
$\quad$ Between groups & 648 & 1017.18 & 1.57 & & .073 \\
$\quad$ Within groups & 2 & 12.52 & 6.26 & 2.63 & \\
PHS4 & 654 & 1555.34 & 2.37 & & $.015^{*}$ \\
$\quad$ Between groups & & 11.83 & 5.91 & 4.21 & \\
$\quad$ Within groups & 2 & 897.68 & 1.40 & & \\
PHS5 & 639 & & & \\
$\quad$ Between groups & & & & \\
$\quad$ Within groups & & & & & \\
\hline
\end{tabular}

Note. ${ }^{*} p<.05$. 
Table 11

One-Way Analysis of Variance Results for Significant Difference among Class Ranks for the Perceived Hindrance Sub-Scale 1 and 2

\begin{tabular}{llrrrr}
\hline & $d f$ & $\underline{S S}$ & $\underline{M S}$ & $\underline{F}$ & $\underline{p}$ \\
\hline PHS1 & & & & & \\
$\quad$ Between groups & 5 & 45.53 & 9.10 & 3.91 & $.002^{*}$ \\
$\quad$ Within groups & 659 & 1533.15 & 2.32 & & \\
PHS2 & & & & & $.006^{*}$ \\
$\quad$ Between groups & 5 & 49.32 & 9.86 & 3.29 & \\
$\quad$ Within groups & 659 & 1975.56 & 2.99 & & \\
\hline
\end{tabular}

Note. ${ }^{*} p<.05$. 
Table 12

Means, Standard Deviations, and Intercorrelations for SSMs' Intent to Coach and Predictive Variables

\begin{tabular}{lccccccccc}
\hline & $\underline{M}$ & $\underline{S}$ & 1 & 2 & 3 & 4 & 5 & 6 & 7 \\
\hline CIS & 3.64 & 2.12 & $.28^{*}$ & $.27^{*}$ & .21 & .16 & -.08 & -.14 & $.23^{*}$ \\
1. SS & 4.40 & 1.50 & & $.25^{*}$ & -.09 & -.05 & -.16 & .00 & $.24^{*}$ \\
2. CSES & 7.12 & 0.77 & & & -.10 & -.11 & -.16 & -.08 & $.82^{*}$ \\
3. PHS1 & 4.09 & 1.45 & & & & $.86^{*}$ & $.56^{*}$ & .15 & -.06 \\
4. PHS2 & 3.95 & 1.48 & & & & & $.58^{*}$ & .17 & -.08 \\
5. PHS3 & 5.41 & 1.38 & & & & & & $.69^{*}$ & -.08 \\
6. PHS4 & 5.96 & 1.64 & & & & & & & -.01 \\
7. PHS5 & 7.48 & 1.03 & & & & & & & \\
\hline
\end{tabular}

Note. ${ }^{*} p<.05$. 
Table 13

Means, Standard Deviations, and Intercorrelations for CAs' Intent to Coach and Predictive Variables

\begin{tabular}{lccccccccl}
\hline & $\underline{M}$ & $\underline{S D}$ & 1 & 2 & 3 & 4 & 5 & 6 & 7 \\
\hline CIS & 2.07 & 1.38 & $.32 *$ & .08 & -.06 & -.02 & $-.20^{*}$ & $-.19^{*}$ & .10 \\
1. SS & 3.54 & 1.60 & & $.27^{*}$ & -.01 & -.00 & $-.18^{*}$ & -.03 & $.26^{*}$ \\
2. CSES & 6.65 & 1.11 & & & .01 & .03 & -.04 & -.01 & $.89^{*}$ \\
3. PHS1 & 3.65 & 1.52 & & & & $.88^{*}$ & $.49^{*}$ & $.30^{*}$ & -.02 \\
4. PHS2 & 3.47 & 1.72 & & & & & $.53^{*}$ & $.35^{*}$ & -.01 \\
5. PHS3 & 5.22 & 1.47 & & & & & & $.77^{*}$ & -.02 \\
6. PHS4 & 5.87 & 1.55 & & & & & & & -.00 \\
7. PHS5 & 7.02 & 1.20 & & & & & & & \\
\hline
\end{tabular}

Note. ${ }^{*} p<.05$. 
Table 14

Means, Standard Deviations, and Intercorrelations for AMs' Intent to Coach and Predictive Variables

\begin{tabular}{lccccccccc}
\hline & $\underline{M}$ & $\underline{S}$ & 1 & 2 & 3 & 4 & 5 & 6 & 7 \\
\hline CIS & 3.64 & 2.12 & $.28^{*}$ & $.27^{*}$ & .21 & .16 & -.08 & -.14 & $.23^{*}$ \\
1. SS & 4.40 & 1.50 & & $.25^{*}$ & -.09 & -.05 & -.16 & .00 & $.24^{*}$ \\
2. CSES & 7.12 & 0.77 & & & .10 & -.11 & -.16 & -.08 & $.82^{*}$ \\
3. PHS1 & 4.09 & 1.45 & & & & $.86^{*}$ & $.56^{*}$ & .15 & -.06 \\
4. PHS2 & 3.95 & 1.48 & & & & & $.58^{*}$ & .17 & -.08 \\
5. PHS3 & 5.41 & 1.38 & & & & & & $.69^{*}$ & -.08 \\
6. PHS4 & 5.96 & 1.64 & & & & & & & -.01 \\
7. PHS5 & 7.48 & 1.03 & & & & & & & \\
\hline
\end{tabular}

Note. ${ }^{*} p<.05$. 
Table 15

Regression Analysis Summary Results for SSMs' Intent to Coach and Predictive Variables

\begin{tabular}{llll}
\hline & $\underline{B}$ & $\underline{S E B}$ & $\underline{\beta}$ \\
\hline SS & .56 & .05 & $.43^{*}$ \\
CSES & .63 & .15 & $.44^{*}$ \\
PHS1 & -.01 & .09 & -.00 \\
PHS2 & -.04 & .08 & -.03 \\
PHS3 & .00 & .09 & .00 \\
PHS4 & -.00 & .07 & -.00 \\
PHS5 & -.23 & .13 & -.18 \\
\hline
\end{tabular}

Note. $R^{2}=.35(n=467, p=.000)$ $*_{p}<.05$. 
Table 16

Regression Analysis Summary Results for CAs' Intent to Coach and Predictive Variables

\begin{tabular}{lccc}
\hline & $\underline{B}$ & $\underline{S E B}$ & $\underline{\beta}$ \\
\hline SS & .26 & .08 & $.30^{*}$ \\
CSES & -.15 & .24 & -.12 \\
PHS1 & -.14 & .17 & -.16 \\
PHS2 & .16 & .15 & .20 \\
PHS3 & -.06 & .15 & -.06 \\
PHS4 & -.13 & .13 & -.15 \\
PHS5 & .15 & .22 & .13 \\
\hline
\end{tabular}

Note. $R^{2=} .150(n=114, p=.014)$ $*_{p}<.05$. 
Table 17

Regression Analysis Summary Results for AMs' Intent to Coach and Predictive Variables

\begin{tabular}{llll}
\hline & $\underline{B}$ & $\underline{S E B}$ & $\underline{\beta}$ \\
\hline SS & .24 & .19 & .24 \\
CSES & .53 & .65 & .19 \\
PHS1 & .56 & .39 & .38 \\
PHS2 & -.05 & .38 & -.03 \\
PHS3 & -.22 & .39 & -.14 \\
PHS4 & -.10 & .26 & -.08 \\
PHS5 & .05 & .48 & .02 \\
\hline
\end{tabular}

Note. $R^{2}=.23(n=53, p=.088)$ $* p<.05$. 
Table 18

Content Analysis of Open Ended Responses to "If yes, what has influenced your decision to pursue collegiate coaching as a career?"

Major Theme $r(\%)$

Love of sports $64(34.0)$

Sport experiences $42(22.3)$

Influencing factors 35 (18.6)

Desire to make a difference 25 (14.1)

Suitability 22 (11.7)
Sub-theme $r(\%)$

Passion for sports 45 (70.3)

Stay involved in sports 12 (18.7)

Interest in sports 4 (6.2)

Love working with athletes 3 (4.6)

Playing experience 21 (50.0)

Coaching experience 10 (23.8)

Experience working with teams 5 (11.9)

Sport experience undefined 6 (14.2)

Previous coaches 19 (54.2)

Family 6 (17.1)

Schooling 3 (8.5)

Connections 2 (5.7)

Media 2 (5.7)

Salary 2 (5.7)

Opportunity 1 (2.8)

Improve athletes 12 (48.0)

Share knowledge 5 (20.0)

Share passion 3 (12.0)

To give back 3 (12.0)

Influence others 2 (8.0)

Coach at a high level 7 (31.8)

Atmosphere 4 (18.1)

Be a good coach 3 (13.6)

Competitive 3 (13.6)

Knowledge 3 (13.6)

Confidence 2 (9.0)

Note. $r=$ number of responses; $r=188 ; N=147$. 
Table 19

Content Analysis of Open Ended Responses to "If no, why have you decided not to pursue collegiate coaching as a career?"

\begin{tabular}{|c|c|}
\hline Major Theme $r(\%)$ & Sub-theme $r(\%)$ \\
\hline Influencing factors 308 (53.5) & $\begin{array}{l}\text { Pursuing a different profession } 111(73.1) \\
\text { No interest } 75(24.3) \\
\text { Not suited for me } 69(22.4) \\
\text { Other Interests } 29(9.4) \\
\text { Not my passion } 14(4.5) \\
\text { Better career options } 10(3.2)\end{array}$ \\
\hline Perceived professional barriers 133 (23.1) & $\begin{array}{l}\text { Low salary } 30(22.5) \\
\text { Long work hours } 26(19.5) \\
\text { High pressure and stress } 17(12.7) \\
\text { Lack of job stability } 16(12.0) \\
\text { Difficult entry } 12(9.0) \\
\text { Limited job availability } 15(11.2) \\
\text { Conflict with family time } 7(5.2) \\
\text { Too competitive } 6(4.5) \\
\text { Discrimination } 2(1.5) \\
\text { Politics } 2(1.5)\end{array}$ \\
\hline $\begin{array}{l}\text { Interested in coaching at a different level } 64 \\
\text { (11.1) }\end{array}$ & $\begin{array}{l}\text { High school } 27(42.1) \\
\text { Youth sport } 9(14.0) \\
\text { Recreationally } 8(12.5) \\
\text { Professional level } 4(6.2)\end{array}$ \\
\hline Job qualifications 62 (10.7) & $\begin{array}{l}\text { Lacking experience } 15(24.1) \\
\text { Not a good fit } 14(22.5) \\
\text { Not qualified } 11(17.7) \\
\text { Not good at it } 9(14.5) \\
\text { Lacking skills or training } 5(8.0) \\
\text { Lack of playing experience } 5(8.0) \\
\text { Lacking confidence } 3(4.7)\end{array}$ \\
\hline Negative experiences 8 (1.3) & $\begin{array}{l}\text { Burnout } 6(75.0) \\
\text { Negative experience with a coach } 2(25.0)\end{array}$ \\
\hline
\end{tabular}

Note. $r=$ number of responses; $r=575 ; N=543$. 
Table 20

Content Analysis of Open Ended Response for "Why did you choose your major?"

Major Theme $r(\%) \quad$ Sub-theme $r(\%)$

Personal interest 424 (57.2)

What I love $117(27.5)$

Interested $108(25.4)$

Improve lives 56 (13.2)

What I like 45 (10.6)

Enjoyment 44 (10.3)

Stay involved with sports 33 (7.7)

Passion 21 (4.9)

Future goals 172 (23.2)

Future profession 145 (84.3)

Grad school 23 (13.3)

Degree 4 (2.3)

Outside influence 69 (9.3)

In-state tuition 50 (72.4)

Exposure to the profession 6 (8.6)

Family 6 (8.6)

Advisor 2 (2.8)

Eligibility 2 (2.8)

Career test 1 (1.4)

Coach 1 (1.4)

Teacher 1 (1.4)

Perceived occupational opportunities 37 (4.9)

Job opportunities 22 (59.5)

Job security 7 (18.9)

Salary 6 (16.2)

Work hours 2 (5.4)

Perceived personal abilities 20 (2.6)

A good fit 7 (35.0)

Interpersonal skills 7 (35.0)

Content knowledge 6 (30.0)

Personal experience 19 (2.5)

Coaching experience 14 (73.6)

Playing experience 5 (26.3)

Note. $r=$ number of responses; $r=741 ; N=679$. 